
Volkswirtschaftliche und wirtschaftsgeschichtiche Abhandlungen

herausgegeben von

Wilhelm Stieda

o. ō. Professor der Nationalöhonomie in Leipzig

III. Folge Heft 13

\section{Die westfälische \\ Schieferindustrie}

Von

Dr. Theodor Plümpe

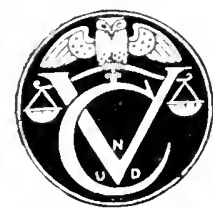

Leipzig

Verlag von Veit \& Comp.

1917 


\title{
Volkswirtschaftliche und wirtschaftsgeschichtliche Abhandlungen
}

\author{
herausgegeben ron \\ Wilhelm Stieda \\ o. ö. Professor der Nationalökonomie in Leipzig \\ Dritte Folge.
}

Heft 1. Die Landwirtschaft unter dem Einflusse von Bergbau und Industrie im Rheinischen Ruhrkohlengebiet. Von Dr. W. Avereck. $2 \mathscr{M} 40 . \%$

Heft 2. Das Aufkommeu der Grobindustrie in Leipzig. Von Dr. Karl Juckenburg. $5 \mathscr{M}$.

Heft 3. Die Entwickelung der Gätmerei. Mit besonderer Berücksichtigung der Verhältnisse in Dresden. Von Dr. phil. Kurt Hofmann. $3 \mathscr{M} 20 \mathscr{g}_{f}$.

Heft 4. Die Statistik der Einkommensverteilung mit besonderer Rücksicht auf das Königreich Sachsen. Von Dr. phil. Nicolae Tabacorici. $2 \mathcal{M}$.

Heft 5. Der Außenhandel Serbiens. Von Dr. Iran Z. Nestorović. $4 \mathcal{M}$.

Heft 6. Die Dentsche Möbelplüsch- und Ioquette-Industrie. Geschichtliche Entwicklung und gegenwärtige Lage. Von Dr. phil. Karl Germann. $2 \mathscr{A} 40 \mathscr{g}$.

Heft 7. Der Bauernbesitz in der Provinz Posen im 19. Jahrhundert. Von Dr. Th. v. Jackowski. $4 \mathscr{M} 50 \mathscr{P}$.

Heft 8. Das Volksvermögen und Volkseinkommen des König. reichs Sachsen. Von Dr. Erich Fuhrmann. $2 \mathscr{N} 50 \mathscr{g}$.

Heft 9. Eine Reichsdepositenbank. Von Dr. phil. Conrad Forstreuter. $5 \mathscr{M}$.

Heft 10. Fortschritte der Reichsversicherungsordnung. Von Dr. Alfred Erler. $5 \mathscr{M}$.

Heft 11. Landwirtschaftliche Besitzrerteilung und Besitzrerschichung in Albayern. Mit einem Anhang: Die Güterzertrümmerungsstatistik in Deutschland und Österreich. Von Dr. Burkhard Rabel. Mit einer farbigen Karte. $2 \mathscr{M} 50 \mathscr{7}$.

Heft 12. Die Framenabeit in der Spinnereiindustrie Sachsens. Von Dr. Johannes Queck. $3 \mathcal{M}$.

Heft 13. Die westfilische Schieferindustrie. Von Dr. Theodor Plümpe. $3 \boldsymbol{M}$. 


$$
\begin{aligned}
& \text { Ec.H } \\
& \text { P } 7336 \text { we }
\end{aligned}
$$

Volkswirtschaffliche und wirtschaftsgeschichtliche Abhandlungen herausgegeben von

\title{
Wilhelm Stieda
}

o. o. Professor der Nationalökonomie in Leipzig

III. Folge Heft 13

\section{Die westfälische Schieferindustrie}

\author{
Von \\ Dr. Theodor Plümpe
}

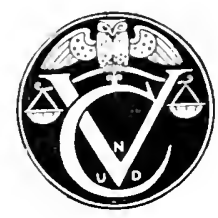

Leipzig

Verlag von Veit \& Comp.

1917 
Druck von Metzger \& Wittig in Leipzig. 
MEINEN LIEBEN ELTERN. 



\section{Vorwort.}

Die vorliegende Arbeit verdankt ihre Entstehung den Anregungen, welche ich von meinem Lehrer, dem Greh. Hofrat Prof. Dr. Wilh. Stieda-Leipzig, empfing. Es ist mir eine angenelome und liebe Pflicht, ihm an dieser Stelle meinen aufrichtigsten Dank für die wohlwollende Förderung meiner Studien auszusprechen.

Ferner möchte ich nicht unterlassen, auch jenen zu danken, welche cin mir sonst verschlossenes Yaterial zugänglich macht'm. Herr Dr. Ranchenberger, Syndikus der Handelskammer Arnsberg, überließ mir in liebenswürdiger Weise die Aliten der dortigen Handelskammer. Wertvolle Aufschlïsse erhielt ich ron Herm Schweder, Direktor der Schieferbau-Aktiengesellschaft Nuttlar zu Nuttlar. Das statistische Material stellte mir clas Königliche Oberbergamt Bonn zur Verfügung.

Durch das freundliche Entgegenkommen verschiedener S'chiefergrubenbesitzer wurde es mir erst möglich, von der hentigen Lage der Schieferindustrie Westfalens ein zimmlieh getrenes Bild zu entwerfen. Allen denen, die mich durch Überlassung ihres Materials oder durch Angaben in bereitwilligster. Weise unterstützten, spreche ich auch an dieser Stelle meinen verbindlichsten Dank aus. 


\section{Inhalt.}

Erster Teil: Geologische und Betriebsverhältnisse.

Seite

Zweiter Teil: Geschichtliche Entwicklung: Schicferbergbau in früheren Zeiten. Kurzor geschichtlicher Entwicklungsgang im 19. Jahrhmulert

Dritter Teil: Rechtsverhälnisse: Der Sehieferbergban vor 1865. Der Schieferbergbau nach 1865: Grundeigentümerbergban. Rechtsverhältnisse der verliehenen Gruben: Gewerkschaften, Aktiengesellschaft, Betrieb auf Grund von Pachtverträgen. Knaplsschaftswesen. Bergpolizei . . . . . . . . . . . . . . 16

Vierter Teil: Wirtschaftliche Verhältnisse . . . . . . . . 19

I. Produktion und Absatz von Dachschiefer und Schieferplatten . . . 19

1. Gewinnung und Verarbeitung des Materials zu

a) Dachschiefer . . . . . . . . . . . . . . . 21

b) Schieferplatten . . . . . . . . . . . . . . 23

c) Schiefertafeln . . . . . . . . . . . . . . . 25

2. Qualität des Materials. . . . . . . . . . . . . 25

3. Absatz . . . . . . . . . . . . . . 27

II. Unteruehmerverbände . . . . . . . . . . . . . . . . . . . . . . 28

III. Arbeiterverhältnisse . . . . . . . . . . . . . . . . . . . . 30

1. Arbeiterzahl und Arbeitszeit . . . . . . . . . . . . . . . . . . 30

2. Lohn- und Wirtschaftsverhältnisse . . . . . . . . . . . 33

3. Hygienische Verhältnisse. . . . . . . . . . . . . . . 37

4. Soziale Fürsorge . . . . . . . . . . . . . . . . . . . 41

IV. Die ungünstige Lage der Schieferindustrie Westfalens . . . . . . . 43

1. Konkurrenz des Auslandes . . . . . . . . . . . . . . . 43

2. Konkurrenz anderer Bedachungsmaterialien . . . . . . . . . . . 49

3. Interesselosigkeit der Behörden . . . . . . . . . . . . . . . 52

4. Hohe soziale Lasten . . . . . . . . . . . . . . . . . . . . 54

5. Uneinigkeit und Preisunterbietung in den heimischen S'chieferindustriekreisen . . . . . . . . . . . . . . . . . 55

V. Reformvorschläge . . . . . . . . . . . . . . . . . . 57

I. Regelung der Knappschaftskassenverhältnisse . . . . . . . . . 57

2. Höherer Sehutzzoll . . . . . . . . . . . . . . . . . . . . . 57

3. Bildung einer Verkaufsvereinigung . . . . . . . . . . 62

4. Anderung des Tarifsatzes für Schieferplatten bei Versendung als Stückgüter . . . . . . . . . . . . 65

Schlußwort . . . . . . . . . . . . . . 68

Anhang. . . . . . . . . . . . . . . . 69 



\section{Erster Teil.}

\section{Geologische und Betriebsverhältnisse.}

Dachschiefer wird in ausgedehntem Iaße in Westdentschland nur im Oberbergantsloczirk Bomn gewonnen. Seine der devonischen liormation des rheinischen Schiefergebirges zugchörigen Lagerstätten verteilen sich im wesentlichen auf dic Jergreviere Arnsberg, Nhüsen, Weilburg, West-Saarbrïcken, Koblenz-Wiesbaden und Kioblenz. Hiervon liegen in Westfalen die Bergrevicre Arnsberg und Müs'n, erstes in dem eigentlichen Sanerlande, letztes in dem siidlichen Teile des Regierungsbezirkes Amsberg, dem Kreise Wittgenstein-Berleburg.

Alljährlich suchen Tausende im Sauerlande Erhohng von dem Rauch und staul, der großen Städte und des Industriebezirlies. In den stillen Tälern rernimmt des Wanderers Ohr nur das Plïtschem des Baches und den Gesang der Vögel, nicht das betäubende Hämmem der Kesselschmiede und die schrillen Signale der Dampfpfrifen. Und democh wïre es falsch, zu glauben. daß das Sanerland ïberhaupt keine Industrie lıätte; im (iegenteil, sic ist stellenweise durchaus nicht mbedentend, nur tritt sie nicht so in die äupre Erscheinung, weil sie meistens mit Wasserkraft oder Elektrizität betrieben wird und nicht in mogheuren, kasemenartigen Gebäurlon untergebracht ist. Das Sanerland hat sogar verschiedene Industrien, die ihm eigentïnlich sind, und eine davon, die Schieferindustrie, die nicht zu den unbedentendsten gehört, hat seit Jahren schon die Aufnerlsamkejt woiterer Freise auf sich gezogen infolge der ungünstigen wirtschaftlichen Verhältnisse, unter denen sie ihr Dasein zu fristen hat.

Wie schon erwïhnt, gehört das Sanerland dem rheinisch-westfälischen Schiefergebirge an, doch stammen die einzelnen Teile nicht aus derselben geologischen Priode.

Auf dem nördlichen Zuge des Oberderon beginnt der Tachschiefer im oberen Ruhrtale bei Ifeschede und setzt sich über Eversbercr, Tolmede, Bestwig, Ostwig, Nuttlar, Antfeld bis gegen Altenbüren fort. Dachschicferbergban findet hier besonders bei Nuttlar und Antfeld statt, sowie in der Nühe von Eversberg und Bestwig.

W) ie Lagerung der Schieforbänke ist meist sedr flach, $15-20^{\circ}$ lialum übersteigend; dieselbe bekommt nur dort ein steileres bis zu $45-500$ steigendes Einfallen, wo infolge früherer Revolution des Gebirges große Falten zusammengeschoben wurden, wie dies speziell bei Grube Ostwig der Fall ist. Die Schieferung bleibt überall die- 
selbe. mögen die Bänke flach oder steil einfallen, nämlich im Winkel ron 450. Dic ron der Schichtung abweichemele Schieferung tritt also bei diesen Schieferlagern besonders dentlich hervor. Die Mächtiglieit des l)achschieferlagers ist verschieden, sie schwankt zwischen $3 \mathrm{mmd}$ 10 Metern. Die Schieferlager stehen in Wechselwirkmng mit Kalksteinbänken, die den lokalen, viclfach auf das untere Obordevon ansredehnten Samen Flinz tragen und gewöhnlich eine Mächtigkeit von (1.1-1.5 Jletern haben.

Der Lenneschiefer oder Orthocerasschiefer wird bei Silbach, sichlinghausen sowie in der Umgegend von Fredehurg abgebaut. Er ist rm viele Jahre älter als der Ruhrschiefer. Seine Mächtigkeit ist sehr verschieden und beträgt da, wo e. im Abbau gewonnen wird, geröhmlich 5-30 Meter. Seine Schieferung fällt hier mit der Lagerung der Gebirgsschichten zusammen. Die Lager sind thrch rauhe Tonschieferlager getremnt. Der Dachschiefer ist von vorzüglicher Beschaffenheit, leicht spaltbar, von dunlielgraner Farbe und wetterbeständig.

In der Standesherrschaft Wittgenstein-Berleburg befindet sich ein mächtiger Schichtenkomplex, in welchem Quarzitschichten mit Dachschieferschichten wechsellagem. Dieser Komplex hat das in den Glieklem der rheinischen Devonformation gewöhmliche Streichen von südwesten nach Nordosten und ist ungewöhnlich steil aufgerichtet, oft senkiecht und selten weniger als $60-70^{\circ}$ geneigt. Das Einfallen der schichten ist gewöhnlich sïdöstlich, seltener nordwestlich. Er begimnt in der Gegend von Leimstruth und setzt sich in nordöstlicher Richtmg bis in die Gegend von Hallenberg fort, hat also eine Länge von $25 \mathrm{~km}$, während seine Breite nur einige Kilometer und bei Berleburg und Rammland, wo er besonders gut entwickelt und durch den darin betriebenen Schieferhergbau am besten bekamnt geworden ist, ca. $5 \mathrm{~km}$ beträgt. Auf der geologischen Karte der Rheinprovinz und der Provinz Westfalen des Dr. H. von Dechen ist der Komplex als zum Oberkeron gehörig angesehen. Nenere Untersuchungen aber, gestützt atuf die in den schiefergrulen rom Rammland gefundenen Versteinermingen, machen es muweifelhaft, daß der Komplex zu der unteren Abteilung des Mitteldevons, dem Lemmesehiefer des Dr. H. von Dechen grehör, welcher in neuerer /eit mit dem Orthocrasschiefer identifiziert wird. In dem Schichtenkomplex wechseln dio Quarzite mit den schiefern derart, daf bald die ersten, bald die letzten vorwalten, ball reine Quarzite, bald reine Sehiefer in beträchtlicher, oft 30 Meter und mehr betragender Mächtigkeit auftreten.

Der Schiefer von Pammland und Silbach zeichnet sich vor demjenigen anderer Ciegenden des westlichen J)utschlands durch seine

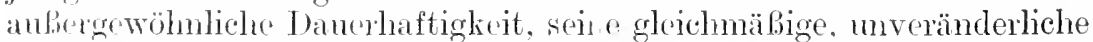
blangraue Farbe, seine leichte Spaltbarkeit, welche die Herstellung ron großem Schablonenschiefer gestattet, wie man sie noch vor 30 Jahren nur aus England beziehen zu kömnen glaubte, seine glatten Flächen und seine Widerstandsfähigkeit gegen Belastung vorteilhaft aus. Er wirl deshall, mit Vorliebe zum Decken öffentlicher Gebäude 
benutzt und selbst in sehrentfernt gelegenen Staidten verwendet. Sogar das herzogliche Sehloß in (imunden (Oberösterreich) ist damit gretecht.

Über den Betrieb der Sehiefergruben' ist im allgemeinen anzuführen, daß er unterirdiseh mit Firstenban und Bergversatz bei riner durchischnittichen Höhe des stoßes von 6 detern erfolgt. Die Abbanstrecken laben je nach der Festigkeit des Hangenden eine Höhe von 3-5 Metern. Der Aufschluß erfolgt durch stollen. In 'T'ageban hat sehiefergewimnung nur in früheren Zeiten stattgefunden. Lin Tagebau ist hente nirgends mehr zu finden, da der schiefer bei offenem Betriebe zu sohr den Einflüssen der Witterung ansgesetzt ist und die hohen Abramnliosten die Gewinnmg umrentabel gestalten. Die Beförderung des fichefers ans den Gruben zum spaltraume geschieht mittels Wagen, dio anf rechienen lanfen. Zum Fortsehaffen des Abfalles wird, soweit nicht in nächster Nähe der Spalträume Platz dafür geschaffen werden kann, ein elelitrisch angretriebener Haspel benutzt, der die tbfälle anf die Halden bringt. Über die Bearbeitung des Schiefer's zu Dachschiefer und Schieferplatten wird an anderer stelle noch eingehend gesprochen werden.

\section{Zweiter Teil.}

\section{Geschichtliche Entwicklung.}

\section{Schieferbergbau in früheren Zeiten. Kurzer geschichtlicher Entwicklungsgang} im 19. Jahrhundert.

Schon im frühen Vittelalter liamte man die Eigenschaft des Schiefers, in dümnen Platten zu spalten, die man als Belegsteine für Fluren und als Deckmaterial der Dächer zum Schutze gegen die Witterungseinfliisse verwentlete. Mleistens wird es wohl der Zufall gewesen sein, der zur Entdeckung dieses Gesteins gefïhrt hat. Zufälle verschiedenster Art sind es ja wohl immer gewesen, die zur Auffindung mancher Gesteinsarten beigetragen haben, weshalb man auch annehmen kamn, daß der Schiefer dem Zufall seine Auffindung und Verwendungsart verdankt. Wann allerdings ein Schieferbergbau begonnen hat, läßt sich nicht sagen. Auch über die Art des Betricbes sind Nachrichten nicht vorhanden. Er wird naturgenüß sehr primitiv gewesen sein. Ursprïnglich wird wohl jeder nur seinen eigenen Bedarf aus den "Schieferkaulen" gedeckt und erst allmählich bei größerer Förderung, verbesserten Absatzbedingungen und Verbreitung des Schiefers als Deckmaterial für den Absatz der Produlite Sorge getragen haben.

Zu den ältesten Gruben sind die Hörre-Raumländer zu rechnen, die schon seit Jahrhunterten im Betrieb gewesen sint. Möglich ist es, daß bereits zu des Bonifacius Zeiten, also im 7. Jahrhundert, die Kirche von Raumland bei Berleburg, die älteste Kirche des Kreises Wittgen- 
stein, die von obengenanntem Bischofe erhaut worden ist, mit Ranmländer Schiefer gedeckt wurde. Urkmollich werten die Schieferbrïche bei Raumland zum ersten Nale im Jahre 1563 erwähnt. In Akten des startsarchirs zu Marburg aus dem genamten Jahr beschweren sich die ,.Schieferkïutner" zu Gladenbach, daß sie gegen die „Hörre“ nicht aufkommen könnten. Dic ,Hörre" scheint demnach die erste und bis zur Nenzeit vielleicht die cinzige Schiefergrube bei Ranmland rewesen zu sein, der größere Bedeutung beizumessen gewesen ist. Thr Betrieb muB sich aber auf die Förderung des geringen Schieferbedarfes der näheren Ungebung beschränkt und periodisch, namentlich zu Kriegszeiten, ganz geruht haben, demn der in ihrem Grubenfulde abgebante 'Teil des Schieferlagers ist außerordentlich klein, wemn man die Höhe der Förderung in späteren Jahren damit vergleicht.

In der zweiten Hälfte des 17. Jahrhunderts war ihr Betrieb vollständig eingestellt worden. Aus welchem Grunde läBt sich nicht sagen, da in dem Bittgesuch eines Bancrn und eines Leyendeckers aus Raumland rom Jahre 1717 an den Fürsten von Wittgenstein nur die Rede ist ron der ,num bey die 50 Jahre wïstgelegenen alten Schieferkaule bey Raumland". In ihm wird um die Erlaubnis gebeten, die Grube aufräumen und darin von nenem arbeiten zu dürfen. Das Gesuch lautet:

\section{Hochgebohrner Graf, gnädigster Graf undt Herr!}

Ew. Hochgräfl. Exellenz haben wir hierdurch untertänigst fürstellen wollen, welchermaßen wir Endesbenannte die nun bey die 50 Jahre wüstgelegene alte Schieferkaule bey Raumland hinwieder aufzuräumen und darin ferner nach tüchtigen Steinen aufzuarbeiten Lusttragen. Wie nun dieses ein Mittel zu besserer Nahrung zu gelangen sein kamn, aber ohne dero gnädigen Consens nicht geschehen mag, So gelanget an Ew. Hochgräfliche Exellenz unser unterthänigstes Bitten, Sie geruhen gnädigst zu verstatten, daß wir in berïhrter Schieferkanle die Arbeit baldigst unternehmen mögen, immaBen den daron zu geben habenden üblichen Zehnten richtig abtragen wollen. In Erwägnng dero hierunter versierenden interesse, uns einer gefälligen Resolution unterthänigst getröstend

Hochgebohrner Graf gnädigster Graf und Herr

Ew. Hochgräflichen Exellenz Unterthänigste Unterthanen

......... Baner zu Raumland

........ Leyendecker. ${ }^{1}$

Die Antwort des Grafen lief nicht lange anf sich warten. Bereits am 30. Jannar 1717 erlaubte er ihnen die Wiederaufnahme der Arbeit in dem schieferbruch bei Raumland und ließ den Bewerbern eine Konzesionsurkunde zugehen:

${ }^{1}$ Die Urkunde befindet sich im Besitz der Firma Ohl Treude \& Metz, Paumlanrl. Die Namen des Bauern sowie des Leyendeckers sind nicht zu entziffern. 
,Dem nach der simplicanten begehr wollen wir demahlen erkennen unsem Gräfl. Häusem vortoilhaftig, des haben Wir ilnom vergënnet die alte sehieferkanle aufzurämmen mol darans Sohiefer-

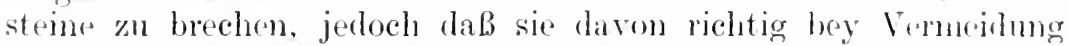
willibilicher Strafe unseren Leyendeckern den Kohnten abstatten; uhrimulich unseres Handschrobens

Berloburg, den 30. Januar 1717.

Casimir liraf zu Sayn mol Wittrenstein

Herr in Homburg, Vallemelar und Nimmagen.

Auch die Gruben des batrons von Papen-Anteslel laben nachweislich schon in Jahre 1590 in Betrieb gestanden. Ans diesem Jahre befindet sich in den Alten des von Schade-Antfeldschen Arehivs eine Schuld- mol Pfandrerschreibung, worin Schöneber von Br. ringhausen mol Tiburg Firstonberg, Ehelente zn Antfeld, hekemnen, von Heruam Rumpf 400 harte Rejehstaler erhalten zu haben und dieselben jährlich mit 15 livichstalern zu vorzinsen. Hicrfïr stellen sie als Selbstschuldner den Philipp (iaugreve und Dietrich Overlaker und verschreiben diesen Bürgen ihren Anteil an dem Schieferberge zu Antfeld.

„........ so sollen Philipp Gaugreve und Dietrich Overlaker unsorn Eigenthümblichen anteil und gerechtigkeit der schiefersteinkulen vor Antfold gelegen zn Ihrem Solbstnutzen .... besitzen und gebrauchen ......, so lange bis wir jene summe samt allem Interesse wieder erbracht und bezahlt haben."

Im Jahre 1615 wurden von Philipp Ga ugreve und Dietrich Orerlaker dem Rumpf zu Wahren die 400 Reichstaler nebst Kosten und Zinsen bezahlt und die diesen verschriebenen Schieferberge den Erben Beringhausen rom Gericht zu Brilon wieder übergeben.

Im Jahre 1690 gingen diese Brüche in den Besity ron Reinhard Caspar von śchade zu Antfeld durch Kauf über. Hieraus geht klar hervor, daß die Schiefergruben bei Antfeld schon im 16. Jahrhundert im Betrieb gewesen sind. Sic scheinen allerdings im gemeinsamen Besitze mehrerer gewesen zu sein, demn in dem Aktenstück aus dem Jahre $\mathbf{1 5 9 0}$ ist die Rede von dem Anteil der Schirfergruben; sie müssen im Betrieb gewesen sein, dem es heißt, sir sollten die ,Schiefersteinkulen“ zu ihrem Selbstnutzen besitzen und gebrauchen. Wann aber zuerst der Betrieb in den Gruben aufgenommon ist, läßt sich nicht sagen, da Alten hierüber nicht vorhanden sind. Wahrscheinlich ist jedenfalls, da anfangs nur Tagebau betrieben wurde, da $B$ auch hier der Zufall zur Entdeckung des Schiefers gefüht hat. Seit undenklichen Zeiten hat sich Antfeld in dem ruhigen Besitz der Zehntfreiheit seiner Schieferbriiche befunden und, soweit die Nachrichten zurückreichen, nie eine Abgabe, am allerwonigsten einen Zehnten entrichtet.

Über die Art des Betriebes, ob die Brüche rom Besitzer selbst betrieben oder an die Bergleute verpachtet wurden, fehlen aus früheren Jahrhunderten die Nachrichten. Wie die Pachtverhältnisse in späteren 
Tahren geregelt waren, läßt sich aus den Bergwerksregistern der Jahre 1706 bis 1720 erkonnen. In dieser Zeit muß schon ein regeImäßiger, grëßerer Betrieb stattgefunden haben. Dic Register sind sehr übersichtlich geführt, und über die Betriebsrerhältnisse lassen sich infolgelessen einige Schlïsse ziehen.

Die Brïche wurden von den Besitzern an die „Berglinaben“ rerpachtet und zwar nach Anteilen. Das ganze Grubenfeld war in 5 Anteile eingeteilt. Zn jedem Bergwerksanteil gehörten 4 Bergknaben. Der Ort, wo diese 4 Bergknaben arbeiteten, wurde nach dem Namen des Torabeiters oder Führers dieser Cruppe benannt. Es gab einen „Brunen-Berg", ,Fritzen-Berg“, ,Andreas-Berg“, „Micheh-Berg“ und „Taspar Sprink-Berg“. Jeder Vorarbeiter hatte also noch 3 Bergknaben unter sich, die mit ihm arbeiteten. Jeder dieser Bergknaben zahlte an Pacht 3 Reichstaler und an Gewinngeld 9 Silbergroschen, so daß der Besitzer den ganzen Schieferberg zu 60 Reichstalem verpachtet hatte und an Gewinngeld noch 6 Taler erhielt. Leider sind die Register ohne Datum, demzufolge es sich nicht sagen läßt, ob der Betrieb das ganze Jahr hindurch angedauert oder nur im Sommer stattgefunden hat.

Gefördert wurden z. B. im Jahre 1706

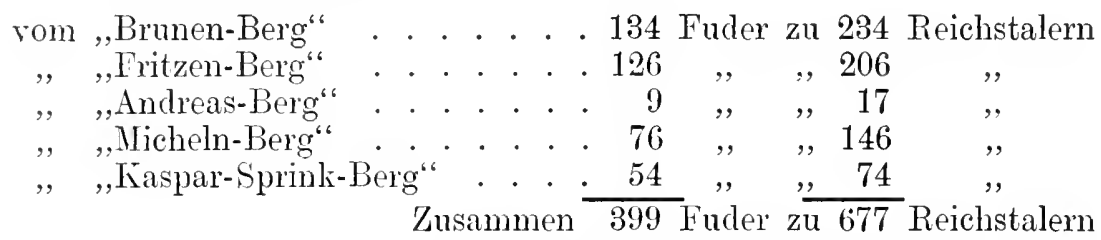

Verkauft wurde das Fuder Dachschiefer für 2 Reichstaler. Tatsächlich betrug jedoch der Durchschnittserlös nur 1,70 Reichstaler, weil nicht alle ausstehenden Gelder richtig eingingen.

Der Absatz war ziemlich geregelt, da sich ein bestimmter $\mathrm{Ab}$ nehmerkreis, wie die Register erkennen lassen, gebildet hatte. Die Schiefer wurden in der näheren und weiteren Umgegend von Antfeld gern genommen, und man lieferte sogar nach Paderborn, Soest, Lippstadt, Beckum usw.

Die Verwaltung selbst wurde von der Gutsherrschaft übernommen, die anch für den Absatz des Schiefers Sorge trug und die Einziehung des dafür geforderten Betrages ïbernahm.

Sie zahlte den Bergknaben für das Fuder Dachschiefer nur 1 Reichstaler, erzielte also noch aus dem Verkauf einen ganz angemessenen Gewinn.

Über die wirtschaftlichen Verhältnisse der Bergknaben läßt sich nicht riel sagen. Für das Aufräumen des Lagers und das Abbanen der Flinzbänke erhielten sie keine Entschädigung. Die Höhe ihres jährlichen Einkommens hing somit ab von der Abbaufähigkeit der einzelnen Lager. Hatten sie ein gutes Lager aufgeschlossen, so konnten sie natürlich verhältnismäßig viel Schiefersteine fördern, im andern Falle mußten sie sich mit einem geringen Jahresertrage zufriedengeben. Gut scheinen demnach die Arbeiterverhältnisse nicht gewesen zu sein. Aus den 


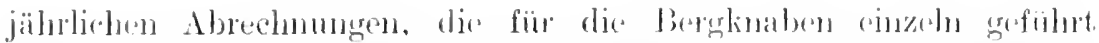

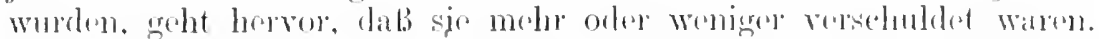

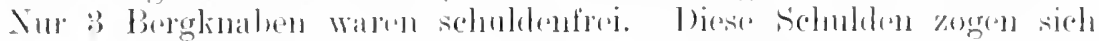

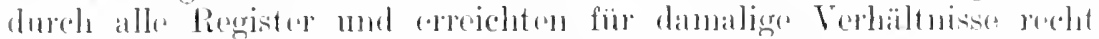

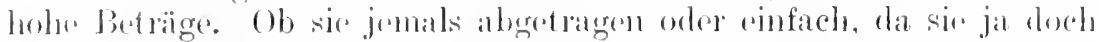

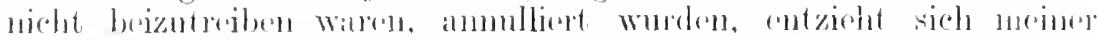

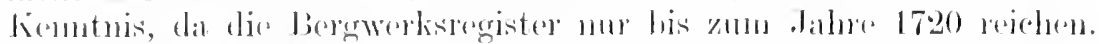

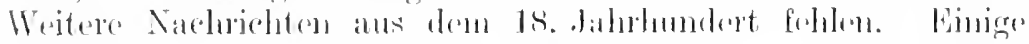

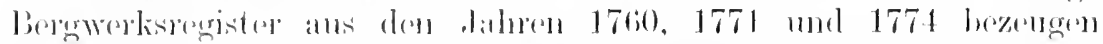

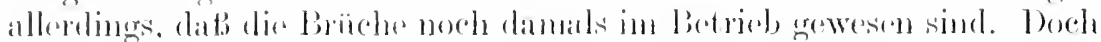
sind die Register so schloreht gefiihrt, dal., wern man ans ihmen anf

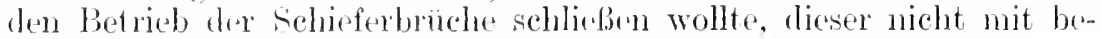
sonderer Sorgfalt vor sich gergangen zu sein scheint.

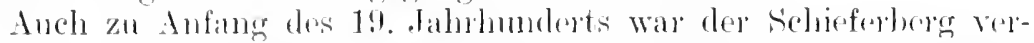

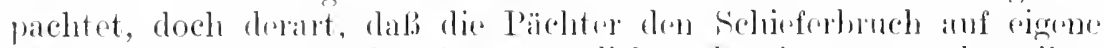

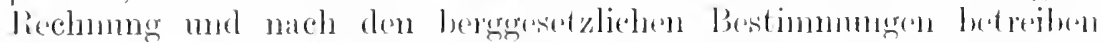
mubten. Nach Ablanf dines jeden Quartals hatten sie oime bestimmte Pachtsumme zu entrichten. Im Jahre 1833 pro Bergfuder 15 silbergroschen, das Jahr darauf 23 Silbergroschen 1 Pfennig. Weitere Abgaben und Lasten wurden von den Pächtem nicht entrichtet. Diese mußte der Terpäclster sellsst tragen. Wurden Bolegsteine groürlert.

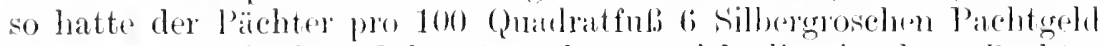

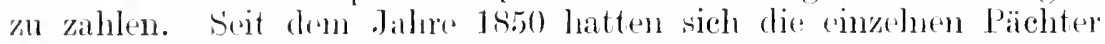
zu zwei größeren Gesellschaften zusammengeschlossen. Sie liomnten infolgedessen natürlich den ganzen Betrieb rentabler gestalten und größere Ertrïge erzielen, allerdings ohne Riicksichtnahme auf spätere Zeiten. Es worle mell orler weniger Raubbau betrieben.

Auch im Revier siogen hat schon in frïherer teit bachschiofer-

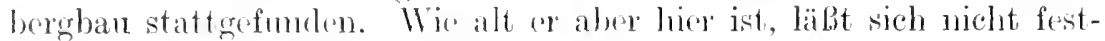
stellen, da alitemmäbige Nachweismmeren ïbor ihn nicht vorhanden sind. Nach riner älteren licvierbeschreibmes soll schon im 14. lalirlmundert Dachschiefer geförelert soin. ,Im Revier siegen bestanden die ältesten Dachschieferbrijche schon im 14. Jahrhmolert, wo am (rebirge Kiloff muterlall) Eisorfold trils anf den Hölen des Berges, teils am Fubo desselben lanobano botreben wurden." Wie weit man jedoch diesen Nachrichten (ikuben schenken darf, lälbt sich nicht angeben.

Wie alt die anteren in den Kreisen Siegen, Burbach und Itüsen gelegenen Dachschieferlagre sind, die schon seit vielen Jahren wegen Erschöpfung oder Minderwertigkeit des Materials anBer Betrieb gesetat wurden, ist nicht beliamni. Im Revier Siegon II standen Nitte des 18. Jahnhunderts die Fimben Ticolai und Hein in Betriels. Sio

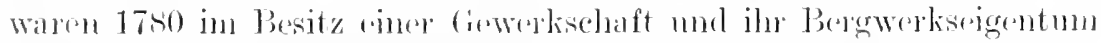

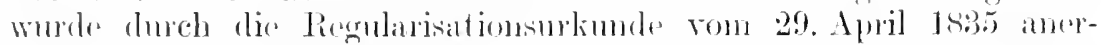
kimnt. Ans diesinn Ferhälnis schied die Grube durch Luterlassung der Zahlmng der Pezeßgelder für 1552 aus; an 14. Juni 1853 wurde ihre Frejerlibirmng ausgesprochen.

Die Gruben bei Antfeld und Berleburg sind somit die einzigen, 
die nachwo islich anf eine längere Fergangenlıeit zurückblicken liönnen. Nicht ana so alt scheint die Grube Ostwig bei Nuttlar zu sein, die frither in einem offenen Tageban betrieben worle. In cinem Aktenstiock des Antfoldex Archivs ans dent Jahre 1709 ist nämlich die Rede ron Nuther sicheferbrechern, mit denen Freifran von Wydenbrück zu Antfuld dinch Prozeb führte. Der Gegenstand des Prozesses ist kider mbekamnt.

Erst dio Nitte des rorigen Jahrhunderts gibt einige Klarheit

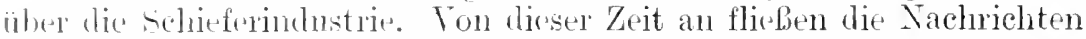
ïber diesen Industriezweig so reichlich, dafs man sich ein ziemlich klares bild äber den stand dieses Gewerbezweiges nachen kann.

Ton den mugefähn 175 Gruben waren ca. 15 im Betrieb, deren Produlition allerdings wegen Mangels an Kommunikationswegen nur in the nächste [ungeloung abgesetzt werden konnte. Dieser Umstand kinn besonders für die Gruben des Kreises Oppe in Betracht, die zu dieser Zeit noch cine erhebliche Menge an Schliefer förderten.

Dem inner'n Terbrauch stand zudem noch die früher allgemein äbliche Dechungsart mit Strol oder Holzschindeln entgegen. Nur in den städten benutzte man den wegen seiner Haltbarkeit und Güte und seines schönen Aussehens berühmiten westfälichen Schiefer. Doch blieb der Absatz immer nur auf die nächste Umgebung beschränkt, la das Fehlen winer Eisenbahn den Tersand nach benachbarten Provinzen wegen der hohen Transportiosten bis zur nächsten Bahnstation. die oft ein Drittel des Erlöses rerschluckten, unrentabel erscheinen lief. Erst als sich der wohltätige Einfluß der westfälischen Eisenbahn geltend machte und die Produlition im Kreise Meschede zunahm, lohnte es sich, die hohen Transportliosten bis zur nächsten station daran zu wenden, um einen größeren Absatz zu erzielen. Ühigens fand der westfälische schiefer wegen seiner guten Eigenschaften Absatz nach Holland, Baden, Posen und Schlesien. Im Jahre 1854 war die Nachfrage nach Schiefer ans dem Kreise Meschede so stark, daf sie nicht ganz befriedigt werden konnte.

Der vermehrte Absatz veranlaßte dic Grubenbesitzer, die Gruben zu erweitern und eine größere Rïhrigkeit zu entfalten. Die damals in Anwendung kommende Methorle, den schiefer nach Schablonen herzustellen. War für die Entwicklung besonders günstig. Die Schah) lonenfabrikation wurde eingeführt, wn den Wünschen und Gewohnheiton anderer Gegenden Pechnung zu tragen und den Alsatz zu erweitern. In sachsen waren z. B. nur sechseckige Formen unterzubringen, in Norddentschland wurde nur die rechteckige - englische Form rerlangt. Bei rer anch hrute noch in len Gebirgsgegenden iahlichen altdentschen überdopuntun Deckung ist das Gewicht des Daches naturgemäb schwerer als bei cinfacher Schablonendeckung. schablonen liomnen aber obenfalls iibedoppelt sedeckt werden; in diesem Fall ist der Materialverbrauch fast gleich. Die Dächer mit altdeutscher überdoppelter Deckung haben sich noch immer am besten bewährt. Es existieren leider nur noch wenige Dachdecker, die die alte kunstrolle Deckungsart ausführen können. Sodann beseitigte der 
Schablonenschiofer fast ganz dir zeitraubende Zubereitumer jerler einzehen Deckplatte auf der baustelle dureh don schirferdecker. Auberdem gestattote der Schablonensehiefer statt der bisher erforderlichen Beschalung der Dachfläche durch Brettre eine weniger hostspielige lattenbeschatung. mal zulem worde dem batche eine gröbere Dichtigkeit and Daterhaftigkeit relliehen. Abgreshen indessen von den vielen Vorteilen, die dar Sichablonenschiefer sowohl bei der Anfertigming als anch beim Verhameh bieter, wurde man dureh dessen Verwendung namentlich in den stand geseotzt, den Alsatz auf be-

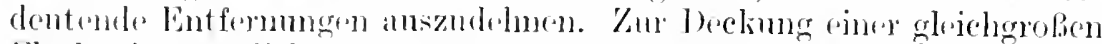
Eläche ist nämlich bei Anwrolung von sichablonenschicfer nu das halbe liewichtsquantum der früheren Jenge erforderlich, mithin verringert sich die racht a uf die Hälfte. Torteilhaft ist ferner, daß durch die gleichnäBige Form und Größe der Schablonen, sofern sie von einer Nimmer simb. die Verpackmng sich bequem bewerkstelligen läßst, mithin der beim Transport entstehende Bruch gegen frïher sich arheblich verringert und kaum den vierten T'eil beträgt. Diese Cmstände waren so günstig, daß die Kommanditgesellschaft Gessner \& Co., dic, im .Juli 1856 gegründet, zuerst den Schablonenschiefer herstellte, schon nach einjührigem Bestehen Aufträge nach Gotha, Erfurt, Merseburg, Berlin, Leipzig, Nagdeburg, Frankfurt, Nümberg ausführte, wïhrend früher sich der Versand nur bis Minden, Münster, Dortmund und Kassel erstreckite. Diese Firma wurde anf diese Theise die bedentendsto des ginzen Schieferbezirkes. Nachdem in den Jahren 1850-54 der Versuch gescheitert war, die im oberen Puhrtale seit umachweisbaren Zeiten betriebenen kleinen Schiefergruben zu einem größeren Unternehmen zu vereinigen, gelang es verschiedenen Unternehmern, in Jahre 1856 eine Kommanditgesellschaft unter dem Namen „Geßner \& Co." mit dem Sitz in Meschede zu gründen, die sich den Erwerb aufgeschlossener sowie das Aufsuchen nener Schiefergruben zor Aufgabe machte. Das Unternehmen war mit einem Kapital von 125000 Talern fundiert. Die Anteilscheine wurden zum größten Teile untergebracht, darauf wurde mit dem Ankauf von 16 Grubenfeldern im Werte von 80000 Talem begomnen und ein einheitlicher Betrieb eröfnet. Zunächst wurden die bedeutendsten Gruben bei Nuttlar angekanft und zu einem Grubenfelde ,Ostwig" vereinigt, sodann wurden erworben die ,Fuchtengrube“, die Grube ,stuckenland“, verliehen am 10. Februar 1825, die Gruben ,Franz" und ,Loh", beide hervorgegangen aus der Vereinigung je 3 kleinerer Gruben.

Außerdem wurden angekauft oder neu erschlossen die Gruben „Sonnenschein", „Libanon“, „Sonntag", „Katze", „Pankratius", ,Via“, „Friedrich", „Florentine“, „Königsgrube" und „Langertag".

Das auch heute noch ergiebigste (imbenfeld ,Ostwig" bildete die Grundlage des Geschäfts und lieferte außer dem gewöhnlichen Schiefer Material zur Anfertigung ron Platten. Diese wurden durch Handarbeit hergestellt und fanden hauptsächlich Verwendung als Bodenbelag, Fliesen, Treppenstufen und Tischplatten. Ton der Firma wurde zuerst die Herstellung ron schabloniertem Schiefer aufgenommen, 
dagegen die Anfertigung von Tafeln für Schulzwecke aufgegeben. Infangs fand nur eine geringe Plattenfabrikation statt. Es gelang aber bald, pralitische Waschinen zur Bearbeitung des Plattemmaterials zu beschaffen, und so entstand im Jahre 1867, in dem auch die Lmwandlung in cine Alitiengesellschaft erfolgte. die erste Maschinenanlage in ulten Tageban der Grube „Ostwig“. Die Arbeitsmasehinen. Freissigen und Hobel wurden aus England bezogen. Die Plattenfabrikation natm einen wesentlichen Aufschwmg. konnte sich jedoch bei den sethr ungïnstigen Verkehrsverhältnissen nur wenig entwickeln. Am 26. Juni 1867 wurden die obengenamiten Gruben unter dem Namen ,Schieferban-Alitien-Gesellschaft Nuttlar“" zu Nuttlar rereinigt. Die nächsten Eisenbahnstationen waren Bonenburg. Güterslol. Jippstadt mo Soest. Das Geschäft war also mehr a uf den lokalen Absatz angewiesen. In den Jahren 1865-70 wurden ansgedehnte Tersuchsarbeiten in den Grubenfeldern in Waldeck, „Pankratius“, „Friedrich", „Langertag" nsw. vorgenommen, die zum Teil das Torhandensein banwürdiger Lager feststellten. Ein dauernder Betrieb scheiterte indes an der sehr ungünstigen Lage der Gruben. Die Wiederaufnahme der Förderung blieb einer späteren Zeit vorbehalten.

Die bis zum Jahre $1870 \mathrm{im}$ Verhältnis zu dem kleinen Geschäftsumfange zur Terteilung gelangte hohe Dividende, die nach den rorliegenden Bilanzen unter dem hentigen Gesichtspunkte kaum zu rechtfertigen wäre, zeitigte für das Geschäft beim Ausbruche des Krieges üble Folgen. Nach dem Kriege war die finanzielle Lage des Geschäfts derart prekär, daß eine Krisis unvermeidlich gewesen wäre, wenn nicht einige Herren in Tertranen auf die gesunde Basis des Geschäfts und auf die Tüchtigkeit des Geschäftsführers dem Geschäft neue Yittel in Form von Darlehen zugeführt hätten. Hierdurch gelang es, nicht allein eine normale Dividende zur Verteihung zu bringen, sondern auch die erhaltenen Darlehen bis zum Jahre 1885 wieder abzustoßen.

Die Eröffnung der Ruhrtalbahn im Jahre 1873 war für das Geschäft sowie auch für die andern im Ruhrtale gelegenen Gruben von wesentlicher Bedeutung. Das Absatzgebiet gewamn an Ausclehnung, und namentlich Schieferplatten fanden ein immer größeres Arbeitsfeld. Eine zweite Maschinenanlage entstand im Jahre 1873, deren Tergröberung ron Jahr zu Jahr notwendiger wurde.

Bis zum Jahre 1882 lieferte der Tagebau der Grube „Ostwig“ fast allein das Rohmaterial für die Plattenfabrikation wie auch den Bedarf an Dachschiefer. Die hohen Abraumkosten sowie einige Störungen im Lager machten den Betrieb, mrentalsel und gaben Verankissung, die einfallenten Bänke durch den Fiaiser-Wilhelm-Stollen aufzuschliefsen. Diese im Jahre 1sis in Angriff genommene Arbeit war Ende 1880 soweit gediehen, daf die Förderung im nördlichen Flügel zunächst im kleinen Umfange aufgenommen werden konnte.

Nachdem das obere Lager im sürllichen Flügel ebenfalls durchfahren und die Bauwürdigkeit der Bänke nachgewiesen war, wurde 


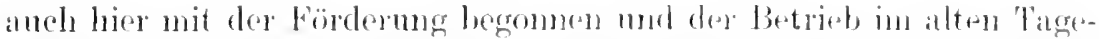
bitl nach und natch oingestollt. l)iese Noncinrichtomg dos Botriobes

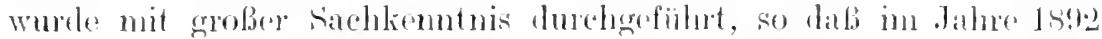

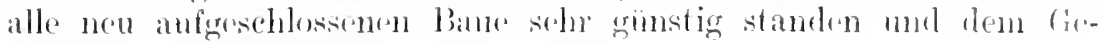
schäft rine lamge Lobernselaner sieherten.

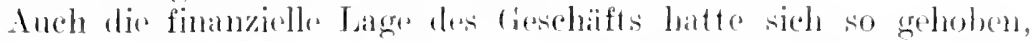

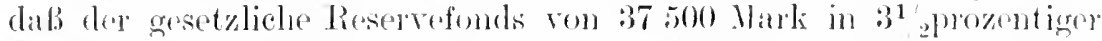

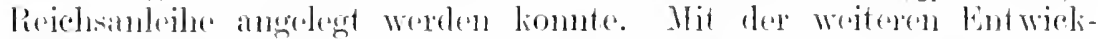

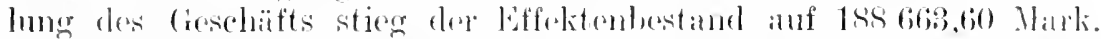

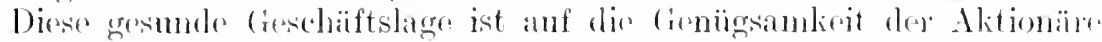

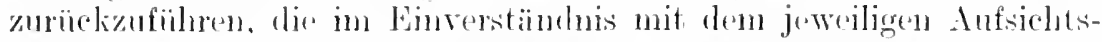
rate auf hohe Dividenelen rerzichteten, um dem lieschäft eine solide Grundlage zu sichem. Wem die im ersten statut der Gesellichaft vorgesehene Jebensdauer des Unternehmens mit 50 Jahren soinon Abschluf grefumlen hätte, so hätten aus ten vorlandencon flïssigen Mitteh olne Rïeksicht anf den Wert des (iebäude, Maschinen. Gruben usw. in Jahre 1907, in welehem die schicferban-Aktiengosellschaft in Nuttlar ihr 50jähriges Geschäftsjubiläum feiern konnte, rund 84 Prozent des Aktienkapitals gedeckt werden können.

Durch den in den letzten Jahren erfolgten Aufschluß der Lager unter der seitherigen Abbausohle im Kaiser-Wilhelm-Stollen ist dem Geschäft ene reichliche Förlerung für viele Jahre gesichert. Die schwierige Gewinnmog wirel tureh praktische technische Hilfsmittel aufgehoben. In den 50 Jahren ihres Bestehens wurlen von der Schieferbau-Alitiengesellschaft Nuttlar für 4162226,90 Nark Dachschiefer, für 4520924,85 Mark Platten, zusammen für 8683 151,75 Marli abgesetzt. Der Bruttogewinn betrug 2212 228,48 Mark. Hiervon dienten zu Abschreibungen 719 125,78 Mark. Dom Reservofoncls wurden zugefïhrt 37500 Nark. An Dividenden wuden rerteilt 1318131 Mark oder im Durchsehnitt pro Jahr 6,53 Prozent. Ist diescr Prozentsatz für einen Bergwerksbetrieb auch als mäBig zu bezcichnen, so dürften anderseits die Aktionäre in der gesunden Grundlage des Geschäfts ihre Befriedigung finden.

Zu gleicher Zeit ungefähr wie die Schieferbau-Alitiengesellschaft bildete sich eine neue Gewerkschaft, ,Sauerland". Auch ein englischer Oberstleutnant a. D. Mr. Money begann den Betrieb ron Schiefergruben. Er ließ ebenfalls Schablonenschiefer anfertigen, aber nach englischem Muster, wofür er englische Arbeiter in seinen (iruben beschäftigte. Während die Firma Gessner \& Co. ihren für einen großartigen Betrieb berechneten Anlagen fortwährend mehr Ausclehnung gab und bedeutende Mengen Schiefer gewam, der nach allen Teilen Deutschlands großen Absatz fand, muBte die Gewerlischaft ,Sauerland" im Jahre 1858 ihre Arbeiten einstellen, woil sie ihre Förtorung nicht so hillig vorzurichten vermochte, $u$ bei den bohen Frachtsätzen leistungsfähig zu bleiben. Dagegen setzte der Engländer Mon r seincu Betrieb in den Gruben bei Antfeld fort.

Im Laufe des Jahres entstanden noch andere Gesellschaften. von denen besonders die Gesellschaften ,Westfalia" und ,Neuengland" 
Erwähnung rerdienen. Ferner trat bei Hirschberg in Kreise Amsberg eine neue Dachschiefergrube unter dem Namen ,Marsfeld" in Förderung. Eine lange Lebensdaner war ihnen jedoch nicht beschieden. .. Tenenglind" und ,Marsfeld" mußten im Jahre 1859 ihren Betrieb einstellen, umel die dem Engländer Money gehörenden Gruben konnten nur in sehr geringem Umfange ihre Arbeiten fortsetzen. Aber auch die Firma Gessner \& Co. schränkte ilren Betrieb ein, da der Absatz getriiclit war.

Dic Dachschiefergruben bei Antfeld waren den Besitzern in den Jahren 1809, 1810, 1813 verliehen worden. Am 17. November 1850 wurden sie unter dem Namen ,Egonsgrube" und ,Antfelderbruch" rereinigt. Im Jahre 1853 waren durch Zufall bei Fredeburg Dachschieferlager entdeckt worden. Beim Ausbrechen eines Bierkellers fanden sich Spuren von Dachschiefersteinen, und das Grubenfeld wurde am 1. September 1853 verliehen. In den fünfziger Jahren wurde woiter verlichen die Grube , Magog" bei Fredeburg, zu welcher die Grubenfelder „Cham“, „Dido“, ,Javan“, „Martin“, „Sem“, ,.Mathusael", „Lamech", „Asecuez", ,Dido II", „Elisa“, ,Tharsis", ,Musoch“, ,Thiras“, ,Thubal“, ,Madai“, „Chus", ,Stella“, ,Riphal“, „Rostrum“, „Celthin“" gehören. Von diesen Grubenfeldern ist jedoch lieine in Betrieb genommen worden.

Am 13. Januar 1860 wurde die Grube ,Gomer" bei Fredeburg verhiren. In demselben Jahre wurden die Gruben, Skävola“ bei siedlinghausen und ,Eva“" bei Bestwig in Betrieb genommen. In den sechziger Jahren entstanden die Gruben ,Elberfeld“ bei Eversberg, „Felicitas" bei Heiminghausen, „Brandholz" bei Oberkirchen sowie die Grube ,Winterseite" bei Lengenbeck. Da diese Gruben aber in entlegenen Gegenden des Sauerlandes lagen, durch keine Eisenbahmen mit größeren Absatzstätten verbunden, so komnten sie naturgenı̈̈ß keinen größeren Aufschwung nehmen.

Der vorliegende Grund der Jähmung in der Schieferindustrie lag in dem sehon lange beklagten Mangel an Eisenbahnverbindungen. Überhaupt war der Mangel einer Ruhrtalbahn das Klagelied, das im Sanerländer Industriegebiet täglich lauter ertönte. Schon drängte sich manchen bestehenden Werken immer schärfer die Frage auf, ob nicht AnschluP an eine Eisenbahn eine Lebensfrage sei. Der Schicferindustrie würde bei der lebhaften Teinahme, die ihr infolge der großen Brauchbarkeit ihrer Produkte mit Recht fortgesetzt geschenkt wurde, eine der wichtigsten Rollen im Wirtschaftsleben des Sauerlandes zufallen, wenn die Rentabilität der Unternehmungen durch die langersehnte Ruhrtalbahn gesichert wiirde. Das baldige Zustandeliommen dieser Bahn mubte daher anch besonders für diesen Intustriezweig als das dringendste bedürfnis bezeichnet werden.

Anferd $\rightarrow m$ waren die Eisenbahnfrachten im T'erhältnis zu anderen Produkten $z$ hoch angesetzt. Eben deshalb konnte es auch nur den größten Anstrengungen gelingen, dem neuerdings ron England eingeführten Schiefer, dessen Vertrieb auf dem Wasserwege bis in das Herz Deutschlands sehr erleichtert wurde, Konkurrenz zu bieten. 
Doeh war im allgemeinen der Betrieb der Schioforgruben wïlremel der

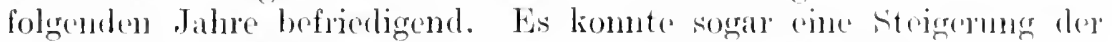
Produlition nachurewiosen werden, obschon sie keineswours dex Ausdehnungsfähgkeit bej billigen Torkehrsmittoh entsprach.

In den Jahren 1870-71 litt der Bergban in allomeinen dadureh. dab seit dem Ausbruch des Dentseh-französischen Krieges viele Arbeitskräte ihm entzogen wurden. Tn unserem Bezirlio wirlite brsonders der Cmstand lähmend, daß der Eisenbahnban ans gleicher Ursache riner Menge Arbeiter bedurfte, die aus allen fowerben zu hohen Jöhmen herangezogen wurden. Auch das Sehwinden allor Bantätigkeit während des Kriegres war Ursache, daß ein Aufsehwung des Geschäfts, wie er der guten Qualität und vervolliommneten Bearbeitung entsprechend gewesen wäre, nicht stattfand.

Doch glaubte nan, daß die für 1872 in Aussicht gestchlte Vollcndung der Ruhrbahn nicht verfehlen wïrde, den Schiefergruben dieses Toiles groben Vorschub zu leisten, wïhrend manche andere, nicht mbedeutende Ablagerungen, wie bei Fredeburg und Berleburgr, zu erhoblichem Abban gelangen wïrden. Als nach dem Kriego eine rege Bantiatigkeit einsetzte, wurde der Absatz von Schiefer wesentlich erleichtert und die Produktion gesteigert. Die Werko aler NuttarGesellschaft gingen dazu ïber, Schneidebänke und Hobelmaschinon mit Dampfbetrieb zur Herstellung von Platten aller Art cinzustellen. Die endlich in Betrieb gekommone Ruhrtalbahn erleichterte ebenfalls den Absatz bedeutend.

So besa B die schieferindnstrie in sich alle Bedingungen cince kräftigen Entwicklung. Allein, zu den mancherlej bisher hestehenden drückenden Auflagen wio Bergwerksstener, (iewerbestener, hohe Kommunalumlagen usw. kam bald cine Erhöhung des Tarifs der Fisenbahn, wodureh der Absatz berengt und namentlich nach Nordin, wo England seinen schiefer mit nedrigen Frachten zollfrei einführte. ganz abgeschinitten wurde. Der Bergworksstener unterlagen zwar die in den letzten Jahren entstandenon Produlitionsstätten nicht mehr. Auch gehören dic Schiefergruben nur teilweise zmm Bergrergal und zahlen daher nur teilweise Bergwerkstener, weshalb man ihre beseitigung mit aller Kraft anstrebte.

Hierzu kam der Umstand, daß Frankreich und Belgien, die selber auf Schiefer einen so hohen Einfuhrzoll gelegt hatten, dads ex cinem Einfuhrverbot gleichkam, in Deutschland zollfrei ('infülnter). Damit drückten sie die Preise außerordentlich und beherschten cinen wosentlichen Teil des deutschen Marktes. England war unter gleichen Verhältnissen in unseren Küstenländern nebst den durch die Wassorstrabun angeschlossenen Rayons malogebend. Der in der Zollvorlage zum Zolltarif von 1879 in Vorschlag gebrachte Zoll von 0,20 Mlark pro $100 \mathrm{~kg}$ war viel zu niedrig bemessen. Ein Zoll von 2-3 Mark pro $100 \mathrm{~kg}$ wäre nicht zu hoch gewesen. Diese ausländische Konkurrenz ließ die heimische Industrie nicht recht zum Aufblïhen kommen, und nur ein hoher Eingangszoll hätte helfen können. Eine Zollerhöhung wurde jedoch abgelehnt. Veranlaßt durch die Annahme, daß 
die buabsichtigte wohlbegrïndete Zollerhöhung auf ausländischen Schicfer nicht ausbleiben wïrle, hatten auBerordentlich starke Einfuhren stattgefunden, die nach crfolgter Ablehnung las Geschäft fast zun Erliegen brachten. Das 'Jaln 1895 brachte rine geringe Zollrhöhnng. die, da sie sich anf den seewärts eingehenden Schiefer nicht bezog, nur den sïddeutschen mal rheinischen Prodnzenten zugrute kam.

Im Jihre 1887 legte Österreich einen Eingangszoll anf Schiefer, so daß die bis dahin bedentende Ausfuhr nach den Donauländern fast gan\% schwand. Die malogesetzte Menge wurde jetzt ebenfalls auf den inländischen Markt gredrängt, der anBerdem die fast erdrückende Konkurrenz des Auslandes anszuhalten hatte, kein Wunder, dab die Preise (rheblich zuruickgingen. Zndem äuberte sich das zu fest eingewurzelte Torurteil der Banbeanten zugumsten dos ausländischen Schiefers recht lälmend für die Schieferintustrie.

Unter all diesen mißlichen Verhältnissen hatte die Schieferindustrie in den folgenden Jahren zu leiden. Wenn anch die Produlition eine steigerung erfuhr, so komte ein angemessener Gewinn deshalb nicht erzielt werden, weil oft die Lagerbestände sich so gewaltig anhäuften, daß die Ware mit nur ganz geringem Gewinn verkauft werden mußte. Trotz mehrfach wiederholter Tersuche kam e Zusammenschlup nicht zustande. Die Rhein- und Moselschiefergruben, die seit Jahren eine sich gut bewährende Verkaufsvereinigung bildeten, erzielten lather gegenüber den hiesigen Gruben 15-20 Prozent höhere Preise.

Don niedrigen Preisen, die für das Produkt bezahlt wurden, standen seit den neunziger Jahren steigende Löhne gegenïber; trotzdem machte sich infolge der Agitation des Christlich-sozialen Gewerkvereins Unzufriedenheit unter den Arbeitrm bemerkbar. Die jungen Lente von 18. 19 mol 20 Jahren, die frïher in den Bergwerken ihr lohnendes Auskommen hatten, gingen lieber auf den Hausierhandel; da nach den gesetzlichen Bestimmungen Minderjährigen Gewerbescheine nicht ansgrestellt wurlen, gingen sie nit älteren Lenten. Auch ein häufiges Weehseln der Arbeiter gegen frither machte sich bemerkbar.

In Jahre 1898 traten zu den bisher betriebenen Guben drei nene hinzu, dexen Schiefer. ron großer Haltbarkeit und g'eichmäßig baner Färbmog, lehbaft begehrt wurde. Sie beeinfluBten die Preise dw übrigen Gruben nachteilig. Doch kamen sie schon m nächsten Julne zun Erliegen, teils wegen ungïnstiger Aufschlïsse, teils wegen zu hoher Landfracht, und wurden seither auch nicht wieder in Betrieb gesetzt.

In Jahre 1900 muBte dex Preis für Schieferplatten noch weiter nm 15 Prozent herabgesetzt werden, nur um die Produktion abzusotzen. Dagegen war es erfrenlich, daßs die in den letzten Jahren vorgrenommenten Tersuche. Fußleisten, die sich im Laufe der Zeit als Massenartikel herausgebildet haben, aus I'on oder anderen Rohmaterialien herzustellen, zu keinem befriedigenden Ergebnis führten. Weder vermochton diese Erzeugnisse die Schieferfabrikate zu verdrängen, noch den anfänglich befürchteten Preisdruck auszuüben. 
Die Herstellung der Fußleisten ermöglichte nantentlich rine lessere Ausnutzung des gewonnenen Rolmmaterials.

In grecehter Wïrdigun der unsicheren wirtschafulichen Lage der Dachsehieferindustrie sowie der erdräckenden Konkurenz des Auslandes mol der Kunststeinfabrikate sind ron dor Eisenbahnrerwaltung

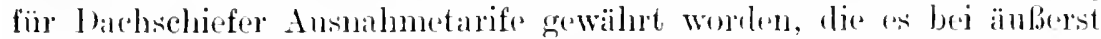
mäbigne l'reisstellumer inmerhin amöglichen, westfäliselen Dachschirofer bis nach Ostprenßen zu liefern. I)ie Sichieforplattenerzengnisie harren jedoch noch dieses Torzuges. Ein Fernabsatz fïr diese liann nur durch giinstige Bahntarife rrocicht weden.

In den wirt sehaftlichen Verhältuissen trat in den folgenden .Jahnen keine Verändromg ein. Nur im .Jahere 1906 versehlimmerte sich die

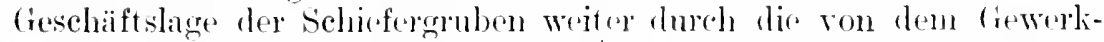
verein christlicher Bergarbeiter ins leben grerufene Arbeiterbewegmer. lie eine Lolnerhöhung bezweclite und zu Ausständen und Aussperrungen fïhrte. Auf diese Bewegung ist der Ausfall der Dachsehieferförderung zurïckzuführen. Doch beschränkte sich die Arbeiterbewegung auf 6 in und bei Fredeburg und Nordenan gelegene Schiefergruben. In den Ausstand traten 58 Mam, wähend 18 ansgesperrt wurden. Tachdem sich die Werkbesitzer bis auf rinen zu einer angemessenen Lohnerhöhung verstanden hatten, sind die meisten der Ausständigen zur Arbeit zuräckgekchrt und von den Ausgesperiten 9 wieder angenommen worden. Dis Arbeiterbewogung komnte Anfang Olitober als beendet angesehen werden.

Auch die letzten Jahre waren der Entwicklung wenig gïnstig. Die Erträgnisse waren einmal durch die Arbeiterverhältnisse, stejerende Löhne bei verkiirzter Schichthlaner, damn abes durch llen Emstand

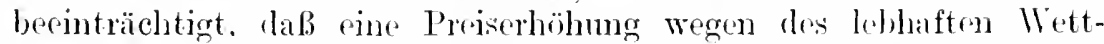
bewerbes des Anslandes nicht durchgefïhnt wercon komite. 1)ie bestehende lose Vereinigung dor westolontschen J)achschieformalustriellen, die bei antsprechendem Torgehen vielleicht Abhilfe hätte sehaffen kömmen, bewährte sich nicht, da nur bei änBeren Fragen, \%ollangelegenheiten usw. eine Einigung zu arzielen war. Schon in nächsten Jahre trat ein solcher Rückschlagr oin. daß sich sorar die bedentendste Unternehmung genötigt sah, mit beschränktem betrieb zu arbriten. Lagerbestände wurden angehäuft, die zu Schleuderpreisen abgogeben wurlen. Moselgruben gaben 80 l'rozent Rabatt. Fubleisten z. B. wurden im heimischen Crobiete pro laufondes Meter zu 0.s0 Mark verzeichnet, in rheinisch-westfälischen Industricbezirk mit 0,5.2 Nark und 0,56 Mark angeboten. Nur im Interesse der Arbeiter nahm man ron einer noch größeren Einschränkung und Herabsetzung der Löhne Abstand. Die letzten Jahre wieder standen unter dem Zorichen flotten Absatzes bei sehr gedrïckton Preisen, die durch gegenseitige Preisunterbictungen rerursacht wurden.

Die im Jahre 1911 rersuchte Gründung einer Preislionvention scheiterte leider. Auch auf die Eingabe der Handelskammer zu Arnsberg im Jahre 1911, fiur den Versand der Schieferplatten die Vergünstigung des spezialtarifes für bestimmte Stückgüter zu gewähren, 
wurde von der Kgl. Eisenbahndirektion unter der Begründung, daß der Versand in den letzten Jahren sich stets gehoben habe und taher von einem Niedergang in der Schieferindustrie nicht gesprochen werden könne, ein ablehnender Bescheid erteilt. Ein Nittel zur durchgreifenden Besserung wäre allerdings auch darin für die westfälischen Gruben nicht zu sehen gewesen. Da eine solche unbedingt erstrebt werden muß, hat sich die Handelskammer zu Amsberg veranlaßt sesehen, durch ihre Vertreter in den Eisenbahmräten Frankfurt und Kö̈n den Torschlag zu machen, daß genannter Antrag als Notstandstarif speziell für die sanerländischen Schieferplattenwerke zur Einführung gelange.

\section{Dritter Teil. \\ Rechtsverhältnisse.}

Bis zur Einführung des Allgemeinen Preußisehen Berggesetzes vom 24. Juni 1865 galt in dem Revier Olpe und in den das Revier Westfalen bildenden Revieren Arnsberg, Brilon und Meschede die kurköhnische Bergordnung vom 6. Januar 1669. Nach ihr gehörten die Dachschiefergruben zu den von dem Verfügungsrechte des Grundeigentiimers ansgeschlossenen Vineralien und konnten daher von dem Grundeigentïmer olne vorherige Verleihung nicht ausgebeutet werden. Ther also glaubte, daß auf seinem Grund und Boden oder irgendwo auf fremdem Boden Dachschiefer vorhanden sei, mußte um Erteilung eines Schürfscheines beim Bergamte nachsuchen und, nachdem er geschürft hatte. Mutung auf das entdeckte Schieferlager einlegen. Wurde bei der Besichtigung des Fundpunktes das Dachschieferlager für mutfähig erkannt, so wurde die Intung erteilt. Sobald die nötigen Aufschluß- and Versuchsarbeiten vollendet waren, beantragte der Juter die Verleihung des Bergwerkseigentums. War cliese erteilt, so erfolgte die Eintragung in das Berghypothekenbuch.

Als Regel galt den alten Bergordnungen das Iuängenfeld, bei dess'n Terleihung der Beliehene nur die grefundene Lagerstätte nach ihrem Streichen und ihrem Einfallen mit einer Vierung von meistens nur 7 Lachtern ins Hangende oder Liegende oder teilweise in das eine und andere, also (inen sehr beschränkten, in seiner Erstreckung erst. nach geschehenem Abbau genau bekannten Körperraum, erhält. In der Praxis wurde die gevierte Termessmng angewandt, wobei die Fundgrube 42 Lachter ins Grvierte und 2 Mabe, jede, nach dem Gesetz vom 1. Juli 1821, 14 Lachter ins Gevierte erhält. Unter Geviertfeld versteht man einen auf der Erdoberfläche zu vermessenden Flïchenraum. unter dem zwischen senkrechten Ebenen his zum Mittelpunkte der Erde die Mineralien dem Konzessionär gehören. 
Die alte Burorinung verlangte den zolnten von der Bruttoeinnahme. Der Zehnte wurte in barem Gelde bezalilt mol nach den Verkitufspreisen des gewonnenen Dachschiefers berechnet. Anfangs war ditse Abgabe nicht ibbermäbig. Alhmählich enpfand nath sie in

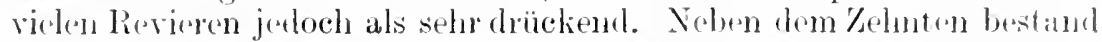
noch eine llenge anderer Gofaille: so Rezefo- mol Quatrubergeddere Ein fresctz rom 12. Mai 1851 setzte für die ostrheinischn (iruben den Kehnten auf den Zwanzigsten herab und ermäligte die Rezebgelder auf einen Taler jälndich von jeder Grube. Die Berowerke, die nicht im besitze von Alleinejgentiimern waren, hatten durchwerg die Form von Gewerkschaften, mit der Eierenschaft tex juristisehen Person; sie wurden in das Berghypothekenbnch mit 128 Kuxen emgetragen.

In dem das ehenalige fürstentum siegen bildenden Teile des jetzigen siegrolandes, der die Reviere siegen I, II und Müsen nmfaBt, galt bis zur Einführung des Allgemeinen Preubischen Berggesetzes die Nassau-Katzenelnbogische Bergordnung vom 1. Mai 1559. Sie zählte den Dachschiefor nicht zu den Gegenständ'n des Bergregals. Die Beaufsichtigung der Betriebe lag der Ortspolizeibehörde ob.

Die Gruben ron Raumland standen unter der Landeshoheit des Fürsten von Sayn-Wittgenstein-Berleburg. Die älteste Konzessionsurkunde datiert vom 30. Januar 1717. AnBer dem Zehnten scheinen keine Abgaben geleistet worden zu sein.

Seit dem Inkrafttreten des Allgemeinen Preubischen Berggesetzes vom 1. Oktober 1865 gehören Dachschiefer und Schieferplatten nicht mehr zu den vom Verfügungsrechte drs firundeigentimers ausgeschlossenen Vineralien und können also ron dem Cirundeigentümer ausgebeutet werden. Doch bestehen die Verleihungen nach den alten Bergordnungen für die ror dem Inkrafttreten des Allgemeinen Berggesetzes verliehenen (truben, die sogenaunten alten liechts, noch zu Pecht. Die Gruben, die nach dem 1. Oktober 1865 anfgeschlossen worden sind, also dem Regal nicht melw unterworfen waren, unterstehen der Beaufsichtigung der Gewrbeinspektionen und Ortspolizribehörden, denen die erforderliche technische Hilfe auf ihr Ansuchen von der Bergbehörde gewährt wirl. Die von der Berghehörde verlichenen Schiefergruben stehen dagegen unter der brorgpolizeilichen Aufsicht. Eine Gewimnung des Schiefers hat jedoch bisher fast nur in den Feldem älterer verliehener Bergwerke stattgefunden. Diejenigen Gruben, die vor 1865 verliehen worden sind, strhen auch heut noch unter der Aufsicht der Bergbehörde. Hierin liegt insofern ein Vorteil, als der Grundeigentümer, im Fall der Wer der Giite fehlgeschlagen ist, gezwungen werden liann, das zum Dachschieferbergbau nötige Land gegen eine in Wege der Expropriation festzusetzende Entschädigung dem Bergwerlisbesitzer abzntreten. In Händen von Grundeigentümern befindet sich der Schieferbergbau nur in Raumland und bei Meschede. Der Besitzer der Hörre-Raumländer-Gruben hat das Schieferbergwerk von dem Fürsten von Wittgenstein-Berleburg käuflich erworben. Die ,Schieferindustrie zu Meschede" ist ein Unternehmen neueren

\footnotetext{
Plüm pe, Schieferindustrie.
} 
l)atums. An beilen Orten findet der Betrieb im großen und mit Hilfe fremder Arbeiter statt. Grundeigentiumerbergbau als Eigenlohnerbetrieb ist nirgends zu finden. Die ubrigen Gruben Westfalens, d. h. diejenigen, die der Bergbehörde muterstellt sind, haben durchweg die Form der Gewerkschaften mit der Eigenschaft der juristischen Person. Sie werden nach der Zeit der Verleihung als Gewerkschaften alten oder nenen Rechts mit 128 bzw. 100 Kuxen unterschieden. Nur sanz selton ist durch Zusammenlegung der Anteile infolge Kaufs oder Erbschaft cin schieferbergwerk in den Besitz eines einzelnen ereliommen.

Auch die Anteile der in Gewerkschaftsbesitz befindlichen Bergwrike werlen nach der rechtlichen Natur der Gewerkschaften als alte und neue Kinxe bezeichnet. Erstere wurden frïher selbst wie die Bergwerke in die Berghypothekenbücher der Bergämter eingetragen; an deren stelle sind jetzt die Grundbücher der Kgl. Amtsgerichte getreten. Über die Gewerke mit Kuxen neuen Rechts wird nach Eintragung der Bergwerke im Grundbuche nur noch ein Verzeichnis in den Gewerkenbüchem von den rechtlichen Vertretem der Gewerkschaften (Repräsentanten) geführt; jene alten Kuxe werden als immobile (unbewegliche), die neuen Rechts als mobile Kuxe bezeichnet. Die Gewerkschaften betreiben ihre Bergwerke in größerem Maßstabe mit Hilfe fremder Arbeiter. Die Form der Aktiengesellschaft ist bis jetzt nur einmal gewählt worden.

Auf Grund von Pachtverträgen werden noch zwei Gruben betrieben: Grube Fürst Richard bei Dotzlar im Kreise Wittgenstein, im Besitze des Fürsten von Wittgenstein-Berleburg, und die Schiefergruben ron Antfeld. Erste ist gegen Zahlung eines Prozentsatzes vom Bruttoertrag, die letzten sind an die Schieferban-Aktiengesellschaft zu Nuttlar durch besonderen Vertrag verpachtet. Nach diesem Vertrag übernimmt die Schieferbau-Alitiengesellschaft den auf den Gruben les Besitzers zur Förderung gelangenden Schiefer in gespaltener Form zu den in der alljährlichen Preisliste genannter Gesellschaft festgesetzten Preisen für Rohschiefer nach Abzug eines Prozentsatzes. Falls Platten zur Förderung gelangen, so bleibt hierfür die Vereinbarung eines Preises rorbehalten. Die rerantwortliche Leitung des Betriebes der Gruben übernimmt der Pächter. Alle technischen Betriebsarbeiten werden anf Kosten und mit Einwilligung des Besitzers nach den Angaben rles Pächters ausgeführt. Die Abnahme des Schiefers für eigene Banten und Peparaturen steht dem Besitzer zu und wird nicht berechnet.

Das Instandhalten der Abfuhrwege von den Gruben, desgleichen die Anlage ron spalt- und Zechenhäusern, Geleisen sowie Lieferung des Betriebsmaterials übernimmt der Besitzer nach eigenem Ermessen. Die Daner der Giiltigkeit des Vertrages ist unbestimmt und wird nach Ablauf einer bestimmten Zeit jeweilig von den Kontrahenten neu festcresetzt, gewöhnlich auf die Dauer von 15 Jahren. Während der Dauer des Vertrages hat der Besitzer die Gesamtproduktion nur an den Pächter abzugeben, mit Ausnahme des vorher genannten Quantums. 
Uber das Knappschaftswesen hestimmtr die kurköhischt Bergordnung, daß die einzehnen Gruben Kassen einrichten sollten,

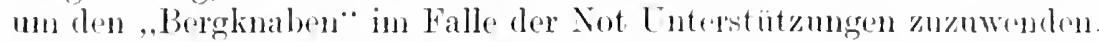
Hierzu mußten die Berglente wöchentlich ,t schwäre l'fennige onled

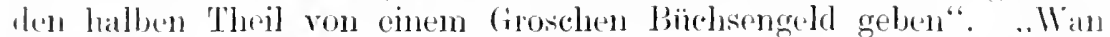
nun arme, krancke oder sonstige gebrechlische bergleuthe mol dero Wittiben und Waisen in das Bergambt suppliciren, und daranff ihmen cin Ciewisses an finadengelt verordnet, oder was sonsten armen Lentluen! aus der Knappschafft gestenert wird, sollen die ältesten der Knappschafft von diesen Biichsonpennigen dic Kahlung thun." Auch für den Fall der Invalidität erhielt der Bergmamn eine , wöche'ntliche Steur aus dor Knappschafft". Anch das Ciesotz rom 12. August 1894 bestimmte, daß, für den Fall, wenn die Krankheit länger als S Woehen (lanerte, die Verpflegung des kranken Bergmanns der Knappschaftskasse zur Latst fiel. Seit den fünfziger Jahren grehören die voliehenen schirefergruben den in diesen Jahren gegriundeten Kuappschaftsverrinen von Brilon und Arnsbereg an. Die dex Bergbehörde nicht unterstellten Giruben haben sich den Ortskrankenkassen angeschlossen. Gegen Unfall sind diese Gruben bei der Steinbruchs-Berufsgenossenschaft versichert.

Die polizeiliche Aufsicht äber die verliehenen Schiefergruben steht der Bergbelı̈rrle zu. Die dem Regal nicht unterworfenen Schiefurgruben sind der Beaufsichtigung der Gewerbeinspelition und der Ortspolizeibehörden unterstellt.

Vierter Teil.

Wirtschaftliche Verhältnisse.

\section{Produktion und Absatz von Dachschiefer und Schieferplatten.}

Über die Zahl der Gruben (Tafel 1) sowie deren Belegscluaft (Tafel S) und die Höhe der Produlition und des Cieldwertes (Tafel 1) belehren die statistischen Übersichten im Anhange. Auch sind der Gesamtstatistik Einzelstatistiken (Tafel 4-7) ibber die Produktion, den Geldwrot, die Bulegschaft (Tafel 9) der (inzehnen Kreise sowi rine Statistik hinzugefügt, welche die Beteiligung der Kreise, in Prozenten (Tafel 2 und 3) ausgerlrickt, wiedergibt.

Den Höhepunkt erreichte die Produktion an Dachschiefer in den Jahren 1891 und 1892, in diesen beiden Jahren wurden je rund 170000 Meter Dachschiefer in Werte von rund 500000 Mark gremumen. Dicse Höhe wurde jedoch später niemals wieder erreicht. Vielmwhr gelangte sie nit größeren oder geringeren Schwankungen im Jahre 1912 auf den Tiefstand von 80000 Metern. Der Wert des Dachschiefers 
scluwalite noeh stärker, ging aber jectenfalls über die Höhe von 1891 und 1892 nicht hinins. Er stieg pro 1 Meter im Laufe der Zeit stetig.

Dic Produktion ron Schicforplatten erreichte ihren höchsten sitand in den Talnen 1902-1906 und war fast keineu Schwankungen unterworfen. während iln Geldwert 1906 seinen Höhepunkt erreichte und in den folgenden Jahren grobe sehwankmugen zeigte. Der Wert pre 1 Quadratmeter Schieferplatten war am höchsten im . Tahre 1908 and fiel nachler wieder etwas.

Mit drm Fallen und Steigen der Produktion steht natiurlich die Kahl der in den Betrioben beschäftigten Arbeiter in Zusammenhang, lerten es in Jahre 1891 beinahe 800 waren, welche 2000 Angehörige zu nuterhalten hatten. Bis zum Jahre 1900 hielt sich mit einigen Schwankmongen die Zahl der Arbeiter auf derselben Höhe, fiel dann aber ständig bis auf 478 im Jahro 1912. Natürlich ging die Zahl der Angehörigen ebenfalls zurück. Im Jahre 1912 betrug sie 1339.

Unter den einzehen Kreisen stand in den Jahren 1891 und 1892 ter Kreis Wittgenstein an erster Stelle, rer mit rund 124000 Metern Dachschiefer oder 72 Prozent an ter Produktion teilnahm, während die Beteiligung des Kreises Meschede in dieser Zeit infolge Stillegung einiger Werke nur 7 Prozent und die des Kreises Brilon 17 Prozent betrug. Der Kreis Siegen, dossen Produktion friiher nicht mbedentend war, - im Jahre 1880 betrug er 20,58 Prozent der Gesamtproduktion -, produzierte damals nur 5 Prozent.

In Lanfe dor Jahre verschob sich das Verhältnis der einzelnen Kreise derart, daß Wittgenstein, infolge sehr großer Einschränkung seiner Betriebe, immer mehr zuriickging, während der Kreis Meschede den Haupteil der Produktion für sich in Anspruch nahm. Im Kreise Brilon verminderte sich die Produlition ebenfalls, während der Kreis sieg('n für die Dachschieferproulution überhaupt nicht mehr in Betracht komme. - Fïr rlie Schieferplattemproduktion kommen nur noch die Kreise Meschede und Brilon in Frage. In dem Kreise siegen, der frühr allerdings auch nicht viel Schieferplatten lieferte, hat die Förlerung vollständig aufgehört, während Wittgenstein seit einiger Zeit die Plattrufabrikation viedrer anfgenommen hat. Hente stellt der Kreis Meschede den größten Prozentsatz an Platten, 91,29 Prozent, wäln'nd Brilon sich nur mit 8,71 Prozent beteiligt.

Die Preise pro 1 Moter Dachschiefer und 1 Quadratmeter Schieferplatten in den cinzelnen Kreisen sind ebenfalls selnr verschieden und richten sich nach der (riite des Materials. Auch hier steht der Kreis Mescherle an erster stolle.

DaB die Produlition von Dachschiefer und Schieferplatten in Westfalen zurücligegangen ist, lat seinen Grund in der immer mehr um sich greifender Abwanderung der Arbeiter zur Eisenbahn, wo sie als Streckenarberiter, Rangicrer usw. leicht Anstellung finden, sodann in der Konkurrenz des Auslandes und namentlich in den hohen sozialen Lasten. Durch the engen Beziehmgen, die den Schieferbergban mit den Bangewerber rerbinckn, erklär'n sich anch die Schwankungen. 


\section{Gewinnung und Verarbeitung des Materials zu}

a) I) achschiefere.

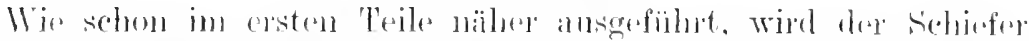

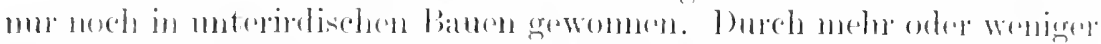

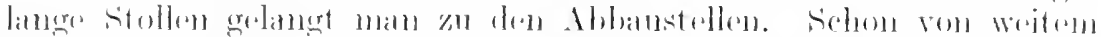

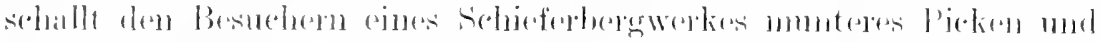

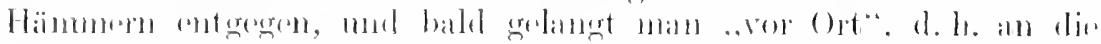

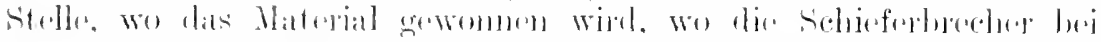

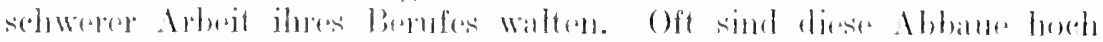

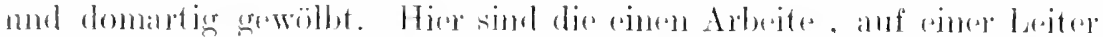

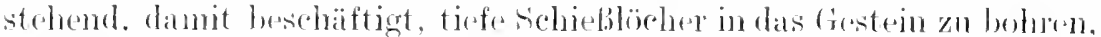

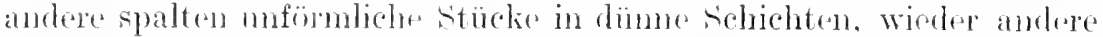

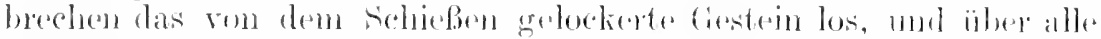

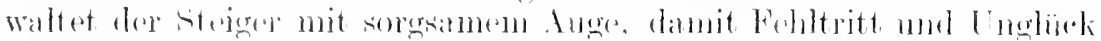

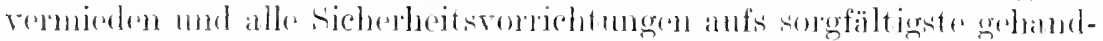
habt worders.

In den meisten Gruben werken zum Bohren der Schieplöchno Bohrmaschinen benutzt, die durch PreBluft betrieben werden. Dnrch diess Bohrmaschinen wird denjenigen Arlestern, die mit der Tor-

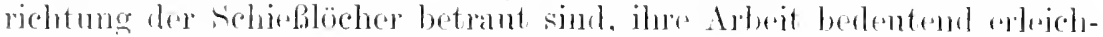

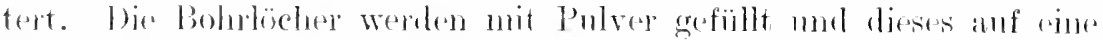

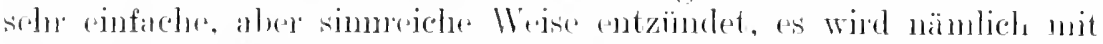
uncr starken Messingnadel, der sogenannten Raumnadei, ein Loch in die Pulverfüllung oder den Besatz gestoBen und in das Bohrloch ein mit feinkörnigen Pulver gefüllter Strohhalm cingeführt, in dessen äuBores Fnde cin Stiockchen Fenerschwamm geklemmt wird. ]) Schwamm. der angebrannt wird. entzïndet das Pulver in stroh-

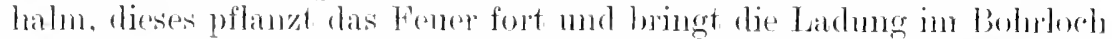

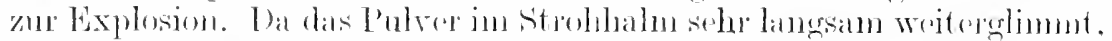

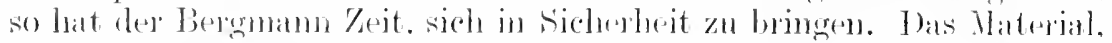
das anf liese Whise gewommen wirel, sind rohe Platten, die im Douchsclmitt 5 Zentimeter dick sind und bis zu 4-5 Quadratmeter ()herfläche baben; doch kommen anch viele kleinere, dagegen anch gröbere Stüclie bis zu 8 oder 9 Quadratmeter vor.

Nur die kleineren werden zom spalten bestimmt. In den Brïchen selbst findet eine Weiterverarbeitung nicht statt. Dio Bearlestmug iiber 'T'age geht mit der Gewimmung Hand in Hand, da sich das Belatuen und spalten des Schiefers riel schwioriger gestaltet, wenn er seme natüliche Feuchtigkeit durch Austrocknen an der Luft rerloren hat. Nanche Schiefer lassen sich an besten spalten, wenn sie durel die Luft ast ansgetrocknot sint. Nan mub die Eigne-

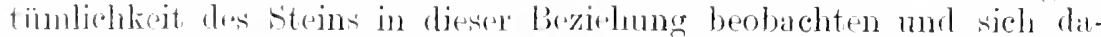

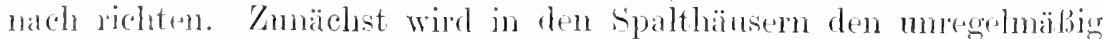
gefornten und ungleich dicken schieferblöcken eine handliche form gegeben, indem die aufrecht gestellten, durch Einhauen mit dem Spalteisen orler durch Sägen mit oinem Einschnitt versehenen Platten durch einige Schläge mit dem Holzhammer auf den Kopf der Blöcke 
zum sprengen gebracht wrelen. Das spaltwerkeng ist ein schlanker dïmncr Keil ron Stahl, eine Art MeiBel, der durch seine Gestalt etwas Biogsamkeit und berlontencle lederkraft erhält. Er besteht aus einer otwa 6 Kentimeter breiten und 20 Zentimeter langen, dümmen und dastischen Klinge und them Handgriff. Zum S'palten sehr großer Platten werten größere, zmm Spalten klemerer Platten kïrzere Eisen verwendet. L'm das Spalten zu rerrichten, wirl die ticke Platte oder der Klotz so anfgestellt und gehalten, daß die blätterlagen fast senkrecht stehen und die größrere Dimension der spaltungsfläch von oben nach unten sich erstreckt. Der Arbeiter setzt das Spalteisen mit der an den Ecken ahgermuleten Schneide in gehörigen Abstand von der Endliante, mit seiner Breite parallel zu dieser Ebene, an und treibt es durch Schlagen auf den Stiel mit einem hölzernen Hammer ein. Die Stellung cler Arbeiter beim Spalten ist sehr verschieden. In den Schiefergruben im Ruhrtale sitzen die Arbeiter auf einem mit einer Rückenlehne versehenen Spaltbrett auf der Erde, während die Arbeiter in den Schiefergruben bei Fredeburg 10 Lentimeter über dem Erdboden befindliche Brettersitze benutzen. Ganz abweichend von den sonst beobachteten Methoden stehen die Arbeiter von Raumland vor der etwa 1,20 Meter hohen Spaltplatte aufrecht, indem sie den zu spaltenden Schiefer senkrecht zwischen Bank und Oberkörper festklemmen. Zum Schutze des letzten tragen sie einen um den Hals hängenden, gefütterten Lederschurz.

Durch vorsichtiges Hin- und Herbewegen des dümnen, elastischen spalteisens erfolgt darauf die Trennung der Platten, welche in der geschilderten Weise so lange bearbeitet werden, bis die gewünschte Dicke des Dachschiefer's erreicht ist. Bei Platten von geringerer Breite und Länge ist nur ein eimmaliges Aufsetzen in der Nitte der Breite rforderlich, indem das Weiterdringen, welches entweder allein durch den Druck der Hand oder durch schwache Schläge anf das schlanke Instrument bewirkt wird, unter ler gehörigen Vorsicht sehr leicht von statten geht und die völlige Ablösung der dümnen Platten zur Folge hat. Dagegen muß bei größeren Platten das Spalteisen nach und nach auf mehreren stellen von oben her eingebracht werden, und es ist für diesen Fall zweckmäBiger, beim Aufstellen des Steines die Länge statt der Breite in horizontale Richtung zu legen. Bei den allergrößten Tafeh kann man nicht umhin, das Werkzeug ron allen vier Seiten, d. h. sowoht in der Länge als anch in der Breite der Spaltungsflächen, nach und nach zu gebrauchen. Je dümner die Platten durch das Ab. spalten von Tafeln werden, desto schwieriger zeigt sich die Fortsetzung der Arbeit.

Durch das sualten erlangt man gröBtenteils Tafeln, die weder das richtige Maß in Länge und Breite noch die zweckdienlichste Gestalt haben; chemn selbst wenn die zum Spalten gebrauchten Blöcke schon vorläufig mit der säge zurechtgeschnitten sind, ist doch das Zerbrechen und Ausspringen vieler Platten oder Tafeh unvermeidlich. Nan ist daher genötigt, sowohl die Dimensionen als auch die Gestalt zu berichtigen. Dies geschieht bei diünnen Platten, die zu 
Dachdrekung bestimnt sind, mittels Alscherens. Futwoler kommt

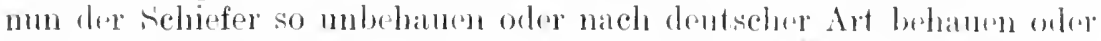

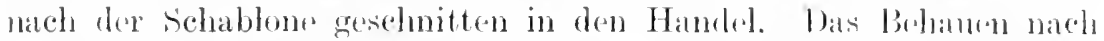

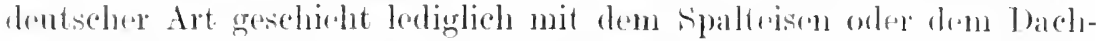

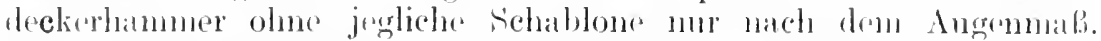

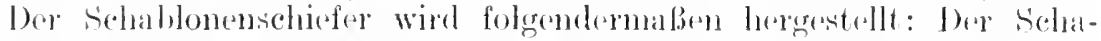
hlomenschneider oder dessen jugendlicher Gohilfo bedeckt die unhere

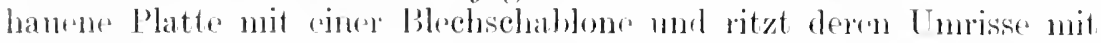

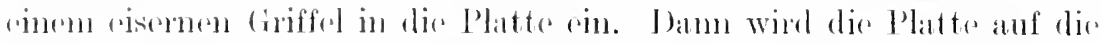

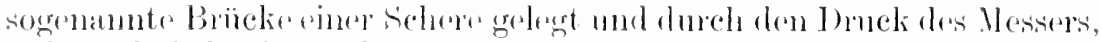

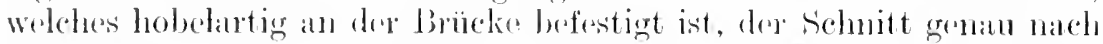
den Unrissen der Blechschablone hergestedlt. Briacke omel Sichere bestehen aus gutem Stahl. Von der Schärfo dieses Workzouges hängt es ab, ob der schirfer mehr als nötig unterbricht und ausspringt. Der obere Rand des Schnittes hlejht scharflantig. Auf anigen Cirmbern

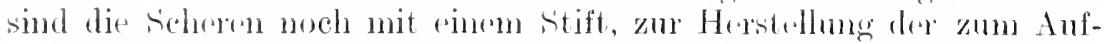

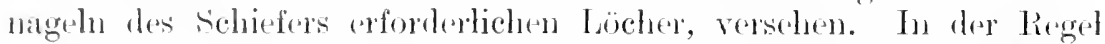
besorgt der bachdeckr das Jochen sellust. Die so hergestrollten Schiefersorten werden auf den Halden oder in Lagerräumen auf die hohe Kante gesetzt, «.h. die einzelnen Tafehn worden senkrecht dicht derartig nebeneinander gestellt, dab sio allmählich lange Rorihen bilden. Dabei hat jede Gugend ihne rigenen Gewohnherten. Finn Fasson, die in märlischen sauerland ganglar ist, ist in Kähischen oder im Bergischon morerkäuflich. Die vieken Fassoms sind ein Krenz für die Schreferindustrie, demn es ist natürlich schwer, von diesen mannigfaltigen Sorten cin Lager zu halten.

Auf den westfälischen Gruben werten an Dachschiefer horgestellt: sechseckige, fünfrekige. rechteckige sogenamite fuglische Schablonen bis zu den gröbten Dimonsionen. AnPerdem Qmadratschiefer, Oetogones, Pentagones, C'oppettes. Anber dieson Formen worden alle andern bimmsionen mol sichablonen angefertigt: so fiir Kirchtürme. Kuppehn, fermer nach framzösischer und Wostlorm, sechseckige schablonen mit rechten Winlieln an Kopf und FuB.

\section{b) Schicereriatten.}

llas aber unsere Schiofergruben vor allen andern bekannten Cimber Deutschlands anszeichnet, ist das grobartige Plattenvorhommen, das cinzig in seiner Art dasteht. Besonders den Gruben um Nuttlar und Frodeburg ist gememsam, daß weniger Wert auf die Förlerung ron Dachschiefer gelegt wird, als vielmehr die geologische Art des Torkommens wichtig ist, das, von Ablösungen und Störungen nur in gröBeren Abständen durchsetzt, die Herstellumg von mächtigen Platten in umfangreichen Maße gestattet. Seit zwoi 'Talnen wird anch oin Teil des Materials der Grube Hablar bei Rammland zur Plattenfabriliation benutzt.

Die Platten, die im Durchschnitt 5 Zentimeter dick sind und rine Oberfläche von $4-5$, oft aber bis zu 8 oder 9 Quadratmeter haben, werden zunächst mittels Kreissägen rechtwinklig geschnitten. Tuben 
diesen Kreissägen sind mächtige Hobchmaschinen anfgestellt, welche die Platten gliitten. Fü manche /wecke ist noch ein Schliff mit Sand olter Bimsstein erforderlich. wodurch den Platten jede Unebenheit genenmen wird. Ianche Platten, die zu Zwecken der Elektrotechnik bestimmt sind. werden auberdem noch poliert. Diejenigen Gruben, die nur ein sohr hartes, schwer spaltbares Material fördern, benutzen (iatfer. Wolche die sichieferblöcke in Platten zerschmeiden, die dann roman in derstben Weise rerarbeitet werden.

Die tiefdumkelblane bis schwarze Farbe des Schiefers, der dem Ange angenehme Glanz, die leichte Ammahme der Politur, wobei der schirefer in schwarzen Narmor an schönheit ubbertrifft, die Fähigkeit, jeden Anstrich in Öl leicht mnd danerhaft anzunehmen. die große Danerhaftigkeit - so bei Fluren in vielbetretenen öffentlichen Gebäuden die Eigenschaft, wenn die dunkle Farbe durch anhaltenden Einfluf starken somnenlichts etwas gebleicht sein sollte, dieselbe durch Trockenreiben mit wenig Öl sofort wieder anfzunehmen, die Zartheit les Gefüges, die das Gehen auf Schieferfluren und, verbunden mit dem warmen Ton des Gesteins, das Baden in den Badewannen aus Schiefer so angenehm macht, das feine Korn, das die schärfste Bearbeitung und die reinsten Konturen ermöglicht, die Unangreifbarkeit gegen ätzende und beizende Flüssigkeiten, die bequeme Reinigung Anrch Wasser - alle diese und viele andere Eigensehaften zeichnen den Schiefer Westfalens vor jeder anderen Steinart aus. Er empfiehlt sich für monumentale und Prachtbauten, für ländliche und bürgerliche Wohnungen und gibt dem weniger Wohlhabenden ein Mittel an die Hand, sich mit Eleganz und Komfort zu umgeben.

tus Schieferplatten werden hergestellt zu Bauzwecken Fliesen zu Flurungen und Parketts für Entrées, Korridors, Pavillons, Veranden, Gartenzimmer usw., Belegsteine zum Belegen von Fluren, Küchen, Werkstätten, Fabriklokalen, ställen, Höfen, Gartenwegen, Speichem, Tennen, zum Auskleilen und Decken ron Kanälen, Gruben usw., Platten für Wandbekleidung und Vertäfelung, Abdeckungsplatten für Gesimse, Pfeiler, Nauern, Gewölbe, Kamindeckel, Schornsteinplatten, Fensterbänke, Fußleisten, First-, Grat- und Bordleisten, Treppen, Treppensockel, Galerien an Treppen. Balkons, Konsolen. Altäre. Der schiefer empfiehlt sich für Frai- wie für innere Treppen, sowohl wegen seiner Schönheit, als Leichtigkeit, Daner und Fenersicherheit. Als leitungsfreies Isoliermaterial für elektrotechnische Zwecke sind Schieferplatten sehr in Aufnahme gekommen.

Auch fïr öffentliche Anstalten und zum Hausgebrauch eignen sich die Schieferplatten vorzüglich z. B. zu Tischplatten. Dieser Artikel hat grobe Vorbreitung und ibberall ausgezeichmete Anerkennung gefunden, so für Zimmer-, Garten- und Tüchentische. Anrichten, Nipp- mad spiegeltische usw. Auch sehr schöne Waschtischaufsätze, fein geschliffen, ansgetieft und geschweift werden hergestellt, sowie Badewannen für Privat- und öffentliche Bäder und Badeanstalten zum Einmauern. Sie übertreffen jedes andere Naterial, da sie nicht angegriffen werden und auch nicht kälten wie Marmor. Durch das 


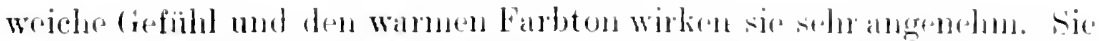
weden verwandt in Burlin, Pymont, Göttingen, Jenal, lenptir nsw.

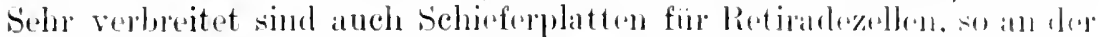

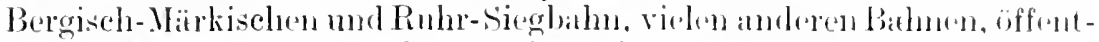
lichen Lokalen und Anstalten. Ein Artikel, der nenedelings wieder viel

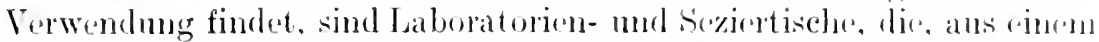
stiick hergestellt, nicht faulen und nicht angrgriffen wordon.

Besondere Erwälnumg verdienen die ron der Schiofortan-Alitim-

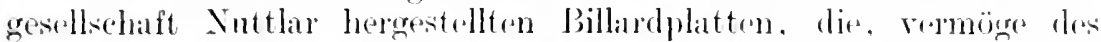

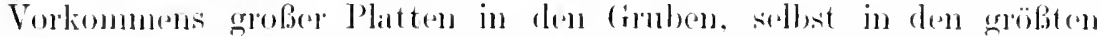

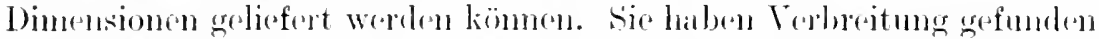
in ginnz Dentschland, Holland, Rubland, und von vielen Billardfibriken werden nur Platten benutzt, die aus den Nuttarer Gruben stammen.

c) Schiefortafeln.

Die Verarbeitung des Schiefers zu schiefortafeln ist rin Industriezweig für sich. In Westfalen besteht nur cine Schirfertafelfabrik, und "zwar in Nuttlar, die Schiefermaterial ron dre Schieferbau-Alitiongavellschaft Nuttlar bezieht. Der aus der Grube gobrachte Schieferblock wird gespalten. Für Tafelzwecke muB die Spaltung dïnner scin als für Dachschiefer. Ferner liann nur ausgesuchtes Material, frei ron Mratlen mul sonstigen Lneinlichkeiten, für Tafeln Verwendnug finden. Den gesimnten Bedarf an Schiefer, der von der Tafelfalrik zur Herstellung von sclnefertafeh benutzt wird, decken dic Gruben der Nuttlarer Alitiengesellschaft. Die Schieferblöcke, die aus diesen Gruben kommen, werden dort gespalten und in rohem Zustand der Tafelfabrik geliefert. Diese besorgt die weitere Bearbeitung, das Schleifen, Linieren und Einrahmen. Alles geschieht mit razu bestimmten Maschinen, die durch elektrische Kraft angetrieben werden. Einig. Arbeiter bringen mittels Maschinen die feinen Rillen auf den Strin, andere tragen die Farbe anf und wieder andere reingen damn die 'Tafo] ron dem überflüssigen Farbstoff.

Neben der Fertigstellung des Schiefers läuft noch die Herstellung der Rahmen aus Holz. Zu diesen Holzrahmen wird meistens Buchen-, weniger Tamnenholz benutzt. Zur rollständigen Herstellung, rom einfachen Buchenbrett bis zum fertigen Rahmen, gohören eine Mongr Holzbearbeitungsmaschinen. Bis zur Fertigstellung der Rahmen sind allein 15 Arbeiter nötig. Die ganze Fertigstellung der Tafel läuft durch ric Hände von ungefähr 30 Arbeitern. Nachdem Rahmen und Schiefer fertiggestellt sind, wird der Stein in den Rahmen eingefügt, sorlann diescr geschliffen und abgerundet. Die fertigen schiefortafeln werden darauf $z u$ je 25 stïck zusammengepackt, aufgestapelt und harren damn des Versandes.

\section{Qualität des Materials.}

Brauchbare Schiefer müssen möglichst frei von Schwefelkies sein, weil dieser leicht verwittert, sein Tolumen vergrößert und den Dachschiefer sprengt. Der Tachweis des Schwefelkicses lïßt sich an der 
Bildung ron schwefliger säure mit ihrem charakteristischen Geruch beim Rösten oder Glühen anf Kohle erkemen. Beträchtlicher Gehalt an Mangan und Fisenoxydul sind der Verwendung ebenfalls hinderlich. Auch eine Bemischmor ron vieler kohliger Substanz ist ein Nachteil. Thre Nenge wird durch den (iewichtsverhst boim Glühen des Schiefers bestimmit. Die Menge des kohlensamren Kalkes dauf einen gewissen Botrag. 15 Prozent, nicht überschreiten. Schwefelkies und Kalkspathrimengung sprengen den schiefer beim Bremnen und Glühen. Die Porositit num minimal sein; im Vittel soll sie 0,12 Prozent des Volumens betragen. Die Masseraufnahme beträgt in gesätigtem Zustande etwa 0.5 Prozent les Eigengewichtes. Risse und feine Spalten müssen fehlen; das in Risse, Spalten und Poren eindringendè Wasser würde den Stein sprengen beim Gefrieren. Der Stein soll beim Anschlagen hell klingen. Das Vorhandensein von größeren Quarzkömern im Schiefer rerbictet dic technische Verwendung und hemmt besonders die Bohrung der Löcher, anch das Feilen. Hobeh und Sägen der Platten. Die Wetterbeständigkeit des guten Dachschiefers ist sehr groß. Dächer ron 300-400jährigem Alter weisen kaum nennenswerte Veränder'ungen auf.

Diesen an einen guten Dachschiefer gestellten Anforderungen genügen sämtliche westfälischen Schiefer, wie viele Anerkennungsschreiben, Zengnisse und Analysen beweisen. Der beste Dachschiefer ist unstreitig der bei Fredeburg, Silbach und Rammland gewonnene. Der Schiefer ron Fredeburg und Silbach ist ron vorzüglicher Beschaffenheit, leicht spaltbar, von dunkelblauer Farbe und sehr wetterbeständig. Der Rammländer Schiefer besitzt eine außergewöhnliche Danerhaftiglieit, eine schöne, gleichmäßig blangraue Farbe, die nicht nur nicht bleicht, sondern sogar im Laufe der Jahre noch dunkler wird, und ebenfalls leichte Spaltbarkeit. Es gibt Kirchen, auf denen Raumländer Schiefer seit mehr als 150 Jahren liegt, ohme dab gröbere Reparaturen notwendig waren. Seit mehreren Jahren ist der' Tagehaubetrieb vollständig eingestellt worden und nur unterirdischer Betrieb findet noch statt. Die Qualität des Schiefers hat sich dadurch noch verbessert, da nummehr der in größerer Täufe anstehende Grundschiefer gewommen wird und eine Vermischung mit dem Tagesschiefer unmöglich ist. Versuche und Untersuchmngen der Kigl. Prïfungsstation, die auf besondere Veranlassung des Garde In Corps zu Berlin stattgefunden haben, ergaben das beste Resultat. Bei diesen Untersuchungen konkurierten 8 verschiedene Schiefersorten deutschen Ursprungs; Rammländer Schiefer nahm in bezug auf Festigkeit, Wetterbeständigkeit und Haltbarkeit in natürlichem und gefrorenem Zustande die erste Stelle ein,.

Die ausgezeichnete spaltbarkeit in großen. glatten Flächen, die exakte Burbeitung, die Eigenschaft, kein Moos anzunehmen, sich leicht lochen und nach jeder Richtung hin behauen zu lassen, ohne auszusplittern, und nicht wie der langfaserige, englische Schiefer auf dem Dache zu reißen, die schöne gleichmäßig blaue Farbe, die Elastizität und Dauerhaftigkeit, die vollständige Reinheit von fremden Bestand- 


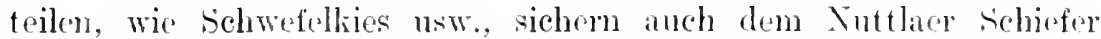
einen der ersten Plïzo unter den beliannten Vorkommen des Inund des Auslandes.

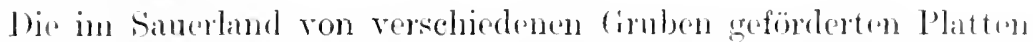
egnen sich ehenfalls rorzüglich zur bearbeitung. Sis besitzen grofor 1)anerhaftigkeit mel praktisehe Anwendharkeit fïr die velschiedensten biulichen und gewerblichen \%wecke. Worgen soiner vorzïglichen Eiren-

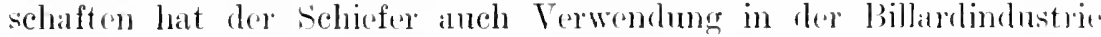
acfunden. Die Schioforban-Aktiengesollschaft Nutlar gilt als die bodentendste mol beste der Schieforplatten liofernden Werke Deutsehlands.

\section{Absatz.}

In der ersten Zeit der Schieferindustrie konnte der reichlich vorhandene Schiefor nur in der nächsten Lingebung Absitz finden, und anch dort nur in seln buschränlitem Maßse, da der lienutzung von sicliefer die früler äbliche lockmngwart mit stroh oder Holzschindeln entgegenstand. Eine nene Epoche trat für die schieferindustrie cin, als das Herzogtum Westfalen infolge des Reichsdeputationshauptschlusses im Jahre 1803 in Großherzoglich Hessischen Besitz überging. Das nele Gouvernement erwarb sich besondere Verdienste um die Industrie durch Einführung des segensreich wirkenden westfälischen Provinzial- Wegebaufonds, der es den vier Kreisen möglich machte, olne besonderen Druck der steuerpflichtigen Verbindungswege nach allen Richtungen hin zu beschaffen. Infolgedessen dehnte sich der Tersand des Schiefers auch auf weitere Strecken aus. Doch war der westfälischen Sichieferindustrie mangels einer Eisenbahn die Gelegenheit entzogen, die umliegenden Provinzen mit Schiefer, der dort von England bezogen wurle, zu versorgen. Aber schon im Jahre 1857 konnte die bedeutendste Gesellschaft Aufträge nach Erfurt, Gotha, Merseburg, Leipzig, Hannover, Braunschweig, Magdeburg, Berlin, Frankfurt, Nümberg usw. effelituieren. Die nächsten Eisenbahnstationen waren Lippstadt und Soest. Es würde noch weiter Schiefer versandt worden sein, wemn nicht die hohen Landfrachten, die bis zur nächsten Eisenbahnstation ein Drittel des Wertes der Produktion verschluckten, sowi die hohen Eisenbahnfrachten dies unmöglich gemacht hätten.

In den siebziger Jahren nahm infolge der Eröffnung der Ruhrtalbahn der Absatz bedeutend zu und ging sogar über die Grenzen Deutschlands hinaus. Nach PuBland wurden namentlich Billardgarnituren in nicht umbedeutenden Mengen exportiert. So konnte der Absatz, soweit die Gruben im Ruhrtale lagen, befriedigend genannt werden, während die abseits von der Ruhrtalbahn liegenden Gruben nur wenig ron ihren Produkten absetzen lionnten und auf den lokalen Absat\% beschränkt blieben.

Erst in den neunziger Jahren, als das Sauerland dem Terkehr mehr und mehr erschlossen wurde, als durch Eisenbahnen und gut angelegte Wege sich die Verkehrsrerhältnisse mehr und mehr besserten, konnte 
dir schieferindustrie, die bisher abseits ron den großen Verbrauchsstätton gelegen hatte, an den Absatz ihrer Produlite auch anf weitere Entfermungen denlien.

Heute findet der 1)achschiefer Westfalens wegen seiner bekannten (iiite und Danerhaftigheit Absatz in allen Teilen bentschlands. Ein besonteres thsitzgel,iet biklen für die wostfälischen Gruben die Provinz Westalen sowie der rheinisch-westfälische Industrieburirk. Aber anch nach Ansterdam, Rotterdam. Hamburg. Berlin, Breslan, Wien kïmnen dank des Ausnahmetarifs für Dachschiefer hei niedrig gehalfenen Preisen Diachschiefer gediefert werten. Nach Österreich ist die Ausfuln seit der Wiedereinführung der Ansmannetarifsätzo für österreichische stationen wieder reger geworden. Die Ausfuhr nach Rußland und den Niederlanden ging zuriek, nach schweden und Norwegen hat sie rollständig aufgehört.

Hente sind die westfälischen Gruben fast nur noch auf den inländischen Terbrauch angewiesen. Da die Gruben meistens in abgelegenen Tälem des sauerlandes liegen, haben sie mehr oder weniger lange Anfuhrwege bis zu den Eisenbahnstationen. Am günstigsten sind in dieser Beziehung die Nuttlarer. Werke gestellt, die direkt an der Bahnstation liegen. Die meisten Gruben haben Anfubrwege von 20-60 Winuten bis zur Station, wohin der Schiefer mit Wagen gefahren wirt. Die Fiosten dafür stellen sich je nach der Länge der Anfuhrwege auf 6-10 Pfennige für den Zentner Schiefer.

Die Schieferplatten finden ebenfalls Absatz in ganz Deutschland. Auf weite Entfernungen Stücliguiter zu versenden, verbietet der hohe Frachtsatz. Der Export nach dem Ausland beträgt nur einige Tausend Mark. Die Schieferbau-Alitiengesellschaft Nuttlar versandte im Jahre 1904 nach Rußland für 2667 Nark, nach Lngarn für 1347 Mark, nach Belgien für 2288 Mark, nach Holland für 158 Nark. Angaben über den Export anderer Werke waren nicht zn erlangen, doch wird er nicht die Höhe des Nuttlarer Trerkes rreicht haben.

Ein grobes Absatzgebiet fü Schiefertafeh ist Deutschland selbst, sind ferner Österreich-Ungarn, die Balkanlänler, PuBland sowie Frankreich. Auch der Bedarf für Übersee ist sehr groß. Der größte Teil der Schiefertafeln geht aus dem Lande.

\section{Unternehmerverbände.}

In fast allen Industrien geht das Bestreben clahin, sich zu Verbänden zusammenzuschließen, um auf diese TTeise den Absatz der Produkte zu regeln und für sie angemessene Preise zu erzielen. In der westfälischen Sichieferindustrie gibt es solche Lnternehmerverbände nicht. Der Grund hierfür ist in der Uneinglieit der Schieferintustriellen zu suchen. Ferner ist die Qualität der Schiefer so verschieden, daß die einzelnen Grubenbesitzer bei ihren auseinandergehenden Interessen an die Durchführbarkeit einer Vereinigung nicht glauben.

Dem scit längerer Zeit bestehrnden Terband Deutscher Schiefer- 
inclustrieller in Köhn gehoren nur die Nuttarer Sichieferban-Aktiongesellschaft und die von Papensehe Verwaltmeg von Antfuld an. Dir. ibbrigen Ginben Mistfalens halten sich in unverständlichere mul

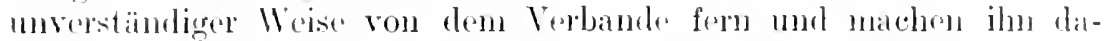

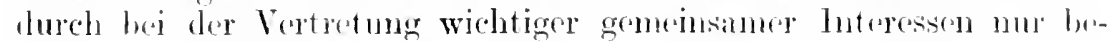
dingt loistmugsfïhig. J)er Verband ist hisher in allen wichtigen dir.

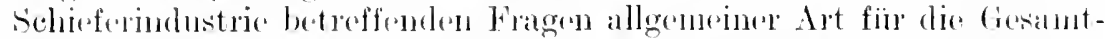
heit cingetreten. Dahin gehören die Fassmug der verschiedenen Posi-

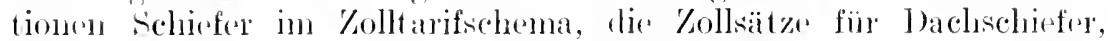
Rohblöcke, schieferplatten, Tarifangelegenheiten, ausländischer Whet1-

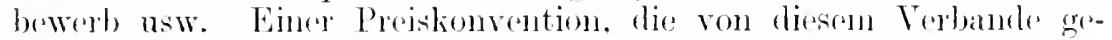
troffen worde, gehören die westfälischen Gruben abenfalls nicht an. Die Nittlarer Gesellschaft arklärte es bisher für ein aussichtsloses Lntermonnen, sich nit den anderen Guben zn verständigen. Verschiedene wohlgemeinte Versuche der Nuttaner (iesellschaft sind fehlogeschlagent.

Dagegen besteht seit langem zwischen den Produzenten und den

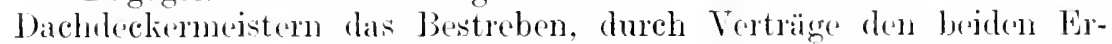
worbsgruppen wirtschaftliche Vorteile zu verschaffen. Zwoifellos ist der Gedanke, den Konsumenten zu stärken, gesmud, denm hierdurch erwächst den Produzenten wiederum ein zahlliäftiger Abnehmerkreis

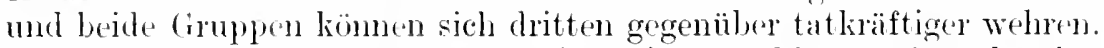
Aus diesem Grunde treten auch die meisten schiefergruben den bestehenden Dachdeckermeisterveremignugen bei. Als mäbter dieser Verbände, denen sich alle Cruben angeschlossen haben, ist die Dachdeckermeistervereinigung fïr Siegen und Umgegend anzusiden. Viele Grubenbesitzer gehören auch dem Rheinisch-west fälischen D)athdeckermeisterverbande und dem Bergischen Dachdeckermedisterverbande sowie dem sülwestdentschen bachdeckermeisterverbande an.

Die Terträge, die zwischen diesen Verbänden und den Gimbenbesitzern abgeschlossen wurden, sind im Prinzip einander gleich. Ich gebe sie der Vollständigkeit wegen mil an: Die Schiefergrubenbesitzer verp flichten sich, an Nichtmitglieder dor Dachdeckrmeistorrereinignngen und Private in den Tertragsgebieten keinerlei Bedachungsuaterialien zu liefern und auch zu rerhindegn, dafo diese Abmachnng aurch Ver-

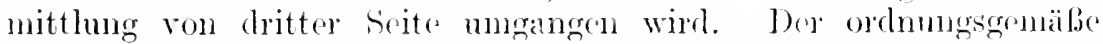
\%wischenhandel ist ohne Einschränkung zngedassen. jedoch vorpflichten sich die Schieferindustriellen, soweit von ihnen herrührende Jieforungen an Nichtmitglieder oder Private vorkommen sollten. zur Feststellumg der Zwischenhändler mitzuwirken. Lieferungen an industrielle Wroke und Behörden, die bisher ihr Berlachungsmaterial direlit von dem Wrerk. der Grube oder dem Händler bezogen haben. bleiben hirron unberüht. Die Mitglieder der Dachdeckermeisterveroing gungen sind dagegers rer'pflichtet, ihren Bedarf an sämtlichen Bedachungsmaterialion mur von solchon Giuben, Werken oder Händlern zu kauf('n, welche diesen Vereinigungen angehören. Zuwiderhandlungen werden bodderseitig mit 25 Prozent Tertragsstrafe vom Fakturenbetrag der vertragswidrig gelieferten oder bezogenen Materialien belegt, und diese Beträge fließen, 
soweit sie von Lieferanten eingezogen werden, in die Kassen der Dachdeckermeistervereinigungen. soweit sie von Dachdeckermeistern eingrezogen werden, in die Kasse des Verbandes Deutscher Schieferindustrieller e. V. in Köhn. Die Abmachung erlischt für diejenigen Kireise, in denen mehr als die Hälfte der ansïssigen selbständigen Dachdeckernneister ciner Vereinigung nicht angehören. Ebenso dehnt sich die Abmachung anf die weiteren Kreise aus, die sich nachträglich der Vereinignng mit mindestens der Hälfte der ansässigen selbständigen Dachdechermeister anschließen.

Eine Tereinigung der Platten herstellenden Werke besteht ebenfalls nicht. In Jahre 1904 wurde cine Anregung gegeben, die Platten herstellenden Gruben, wenigstens der beiden benachbarten Bergreviere Olpe-Arnsberg und Brilon, zu einer gemeinsamen gleichmäßigen Preisfestsetzung zu vereinigen. Eine derartige Vereinigung, wenn auch nur auf loser Grundlage, ist tatsächlich mit dem gewänschten Đrfolge zustandle grekommen. Im Jahre 1905 ist zwar eine ähnliche Vereinbarmng nicht wieder getroffen worden, doch hat immerhin die mäßige Preisalufbesserung ans dem Jahre 1904 noch angehalten, wenn sie auch stitdem wieder eine mehr und mehr nach unten gerichteten Bewegung angenommen hat. Alle Versuche, diejenigen Gruben, die Platten herstellen, zu einer Konvention zu vereinigen, sind bisher gescheitert.

\section{Arbeiterverhältnisse.}

\section{Arbeiterzahl und Arbeitszeit.}

Im Jahre 1912 betrug die Zahl der im westfälischen Schieferbergbau beschäftigten Arbeiter 478, dürfte jedoch für 1913 etwas höher anzunehmen sein. Amtliche statistische Angaben aus diesem Jahre waren mir noch nicht zugänglich. Es werden wohl angenblicklich ungefähr 500 Arbeiter beschäftigt werden, die gegen 1500 Angehörige zu ernähren haben, so daß die Zahl der aus der westfälischen Schieferinclustrie ihren Lebensunterhalt ziehenrlen Personen 2000 beträgt. Ihren höchsten Stand erreichte die Arbeiterzahl 1891, in diesem Jahre wurden 779 Arbeiter beschäftigt, die 2056 Angehörige zu unterhalten hatten. Seitdem ist die Zahl der Arbeiter ständig zurückgegangen, wie aus der Tabelle und der graphischen Darstellnng zu ersehen ist.

Die Verteilung der Arbeiterzahl anf die einzelnen Freise richtet sich naturgemäls nach der Zahl und Gröbe der Bergwerksbetriebe der einzehnen Kreise. Im Kreise Yeschede, der im Jahre 1912 mit 51,70 Prozent Dachschiefer. also mehr als der Hälfte, und mit 91,25 Prozent schieferplatten an der Gesantförderung beteiligt war, findet man die größte Anzahl ter Arbeiter. Ende der achtziger und Anfang der neunziger Jahre nahm der Kreis Wittgenstein eine herrschende Stellung in der Dachschiefergewinnmug ein und beschäftigte daher auch mehr als die Hälfte. 57,50 Prozent, aller Arbeiter, ging dam aber ständig zurück.

Die Ursache liegt vornehmlich darin, dafs infolge des Banes der Eisenbahnen Hilchenbach-Laasphe und Erndtebrïck-Raumland 
die Arbeitslöhne sehr verteuret wurden und es nicht möglich war, den Arbeiterstand vollständig zu erhalten oder gall nene Arbeiter heranzuzichen. Durch den Ban dieser Bahnen wurden die Abbaurenhialtnisse anf den bejelen miteren sohlen der Cirube Höree derart sehwierier. dals der Butrieb in diesen Stollen aufgegeben und cine gröbere Anzahl dol Arbeitur contlassen werden muliste,

Auch die Freise Brilon und Siegen stellten in den letzten Jalnem

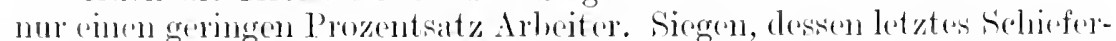
bergwerk an 1. Mai 1911 toils wegen Differenzen in der ciewerkischaft, teils worgen mangelneler Aufschlïsse stillgelengt werden mubte, boschäftigt scitdem ïbrhampt lioine Arbeiter molur.

Für die Abnahno an Arbeitern in den letzten 12 Jahren ist die Einführung tochnischer Hilfsmittel, besonders in des P'lattenfabrikation, verantwortlich zn machen, die violn monschliche Arbcitslirüftr. durch maschinelle ersotzt haben. Ein woiterer Ubelstanel in dex Arbeiterfrage ist das Abwandern der besten Kräftr zur Eisenbaln. Jeder junge Mamn, der seiner Militïpflicht geniigt hat, wird dureh die Aussicht, bei der Bahn Boantenqualifikation zu rroichen, zum Weggange veranlabt, wenn auch \%unächst weniger vordiont wird.

Die enormen Beiträge zur Knappschaftskasse bei minimalen Bezïgen verhindem ebenso den Nachwnchs. Findet sich für die jungen Arbeiter irgendwelche andore Arbeitsgelegenheit, so fält es kinem ein, Bergmamn zu werden. Die frühere Gewohnheit, daß Vater und Sohn im gleichen Betriebe Beschäftigung suchten, hat vollständig aufgehört. Die Belegschaft besteht vorwiegend aus jugendlichen und alten Arbeitern. Es tritt also eine wesentliche Vermindermo der Durchschnittsleistung ein. Ist nicht bald eine Änderung in dem kligglichon Zustand der Krnappschaftskassen zu erwarten, damn gehen schlieblich die Werke an Arbeitermangel zugrunde.

Die Arbeitszeit ist in den einzelnen Gruben verschieden. Im Kreise Wittgenstein beträgt sie in den Hörre-Rammländer-Gruben 12 Stunden einschließlich der 3 Pausen. Die Arbeitor in den Gruben bei Fredeburg arbeiten $91 / 2$ Stunde, während die Arbeitszeit dor Nuttlarer Arbeiter mur 8 stmolen beträgt. Eine amtliche Statistik ïber Arbeitszeit, Höhne usw. der Schieferindustrie ist nicht vorhandrn, nur das Borgrevieramt Arnsberg hatte zufällig noch rinige Jahrog̈inge nicht vernichtet. Diese statistik entlült säntliche (imben, mit Ausnahme der im Kreise Wittgenstein gelegenen. Ich gebe sie der Vollständiglieit wegen mit an (s. Tabelle auf S. 32).

1)anach betrug im Jahre 1908 die eigentliche Arbeitszeit der unterirdisch beschïftigten Arbeiter 8,5 Stumden in I)urchschnitt, wïhrend sie im . Jhre 19138,8 Stunden betrug. Dic über T'agr beschäftirten Arbeiter hatten in Jahre 1908 eine reine Arbritszeit rom 9,\$ mil im Jahne 1913 eine solche von 9,4 Stunden. Die jugendlichen Arbeiter, die num mit Zeichnen der Dachschiefer und mit leichteren Arbeiten beschëftigt sind, haben gleiche Arbeitszeit und -rlaurer wie die über Tago beschäftigten. Nachtschichten werden nicht gofahren. 
Nur die Schieferbau-Aktiengesellschaft Nuttlar läßt auch nachts in der Plattenfabrik ihre Maschinen laufen.

\begin{tabular}{|c|c|c|c|c|c|c|c|c|c|c|}
\hline \multirow[b]{2}{*}{$\stackrel{\Xi}{=}$} & \multicolumn{2}{|c|}{$\begin{array}{l}\text { Cinter Tage } \\
\text { laseh. Arbeit. }\end{array}$} & \multicolumn{3}{|c|}{$\begin{array}{c}\text { Über Tage beschäft. } \\
\text { Arbeiter }\end{array}$} & \multicolumn{2}{|c|}{$\begin{array}{l}\text { Jugendl. Arb. } \\
\text { mit. } 16 \text { Jahren }\end{array}$} & \multicolumn{3}{|c|}{$\begin{array}{l}\text { Summa im Durch. } \\
\text { sehnitt }\end{array}$} \\
\hline & 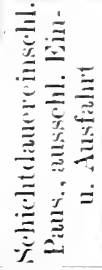 & 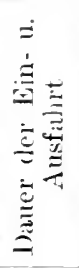 & 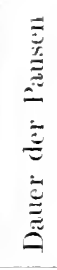 & 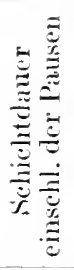 & 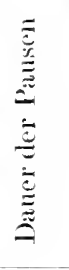 & 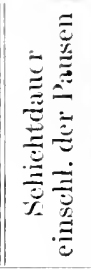 & 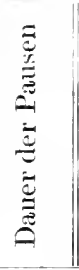 & 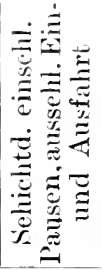 & 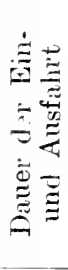 & 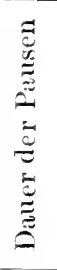 \\
\hline 1908 & 9,6 & 0,5 & 1,1 & 11,8 & 2 & 11,5 & 2 & 10,6 & 0,5 & 1,5 \\
\hline 190 & 9,5 & 0,5 & 1,2 & 11 & 2 & 11 & 2 & 10,6 & 0 , & 16 \\
\hline 1910 & 9,8 & 0,5 & 1,1 & 11 & 2 & 11 & 2 & 10,8 & 0 & 1 \\
\hline 1911 & 9,7 & 0,5 & 1,1 & 11 & 2 & 11 & 2 & 10,8 & 0,5 & 1,5 \\
\hline $1 ! 1$ & 9,9 & 0,5 & 1,1 & 11 & 2 & & 2 & 10,8 & 0 , & 1,5 \\
\hline 1913 & 10,1 & 0,5 & 1,3 & 11,4 & 2 & 11,5 & 2 & 10,8 & 0,5 & 1,5 \\
\hline
\end{tabular}

Im Interesse der Arbeiter ist die allgemeine Verkürzung der Arbeitszeit, wie sie in Jahre 1908 in Nuttlar eingeführt wurde, nur wïnschenswert.

In allgemeinen ist mit der Verkürzung der Arbeitszeit bei gleichbleibenden Löhnen nicht unberingt ein Pückgang der Produktion, also eine Terkleinerung des Gewinnes des Arbeitgebors verbunden. so konnte in England, nachdem der Achtstunden-Arbeitstag in den staatlichen Werkstätten im Jahre 1894 für 4300 Arbeiter eingeführt worden war, nach den Ergebnissen von 10 Jahren mit größter Bestimmtheit festgestellt werden, daß aus der Herabsetzung der Arbeitszeit weder für den Arbeiter, noch den Staat ein Lohn- oder Einnahmeausfall zu verzeichnen war. ${ }^{1}$ Dasselbe Resultat lat Professor Abbe nach der Einführung des Achtstunden-Arbeitstages in dem von ihm geleituten Betriebe der optischen Werkstätte Carl Zeiss in Jena erreicht.

Anders liegren die Verhältnisse im Bergbau. Der Bergbau unterscheidet sich von den anderen Gewerben im wesentlichen dadurch, dab die Lejstung des Bergmanns so äuBerst schwer zu kontrollieren ist. ${ }^{2}$ Seine Leistung hängt nicht nur ron seiner körperlichen Geschicklichlieit und Ausdauer, seiner Intelligenz und Arbeitslust ab, sondern ebensosfhr ron den natürlichen Terhältnissen der Lagerstätten. Diese können sich mit jedem Augmblick ändern. In einem Dachschieferlager kömun z. B. an die Stclle orllor Partien taube Jager treten und ungekehrt, die Härte- und Kohäsionsverhältnisse des Gesteins, ebenso die Masserzuflüsse können wechseln und die Ablösungen die Gewinnbarkrit bald vorteilhaft, bald nngünstig beeinflussen.

${ }_{2}^{2}$ Herbig, Sehwierigkeiten des Lohnwesens im Bergbau. Glückauf 1907. 


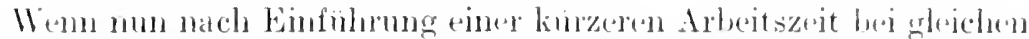
bohnen die Gesantlestumer der Haner die frobhere Höhe nicht ere-

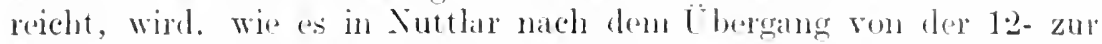
S stimdigen sicheht geschehen ist, die schulel an der geringeren Ledistung ron dem Arbejter den ungunstiger gewordenen Gesteinsterhälnissen

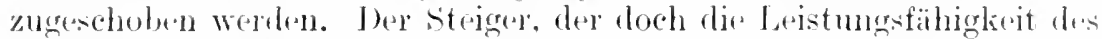
betreffenden Arbeiters zu beurteilen versteht, wird, dat "r mur einoder zweinal in der schicht die Arbeitsstelle betährt, also nicht lüchenlos die Anderung der natülichen trbeitsbedingmengen rerfolgen lamm. dem Arbeiter unnöglich beweisen liömen, dab seine Ansisage den Tatsachen nicht entspricht; er wird nur die Termutung hegren, dab die seringere Leistung auf die persönlichen Eigenschaften eles Hauces zurickzufühen sei. Bei jeder Virküzung der Arbeitizeit im Dachschieferborghan wind dise dem Hauer zu Terfiggung stehende Ansredre ein Grund dafior sein. dab die cintretende Erhöhnng der Leistungen pro stunde nicht so hoch ist, daß sie die Verringermug der stunden ansgleichen könnte.

Jje Erahrungen, die man vor viex Jahren mit dem Übergang ron dem 12- zu dem sistürligen Arbejtstage bei Nuttlar gemacht hat, rechtfertigen olige Ausfibrungen. Bei Vorringerung der eigentlichen Arbeitszeit un 16,66 ; Prozent trat zwal cine steigerung der Leistung pro stunde ein, der Ertrag der schicht blieb jedoch inmer noch um 9,3 Prozent hinter dem fruberen zurück.

Also obige theoreticche Betrachtung wie auch die in Nittlar gemachte Erfahrung lassen erkennen, dab die Verliurzmng der Arbeitszeit im Bergban - zum Cnterschiede ron anderen (iewerben - eine Steigerung der Leistungsfähigkeit des Arbeiters nicht in dem Mabe herbeiführt, dals ein Gewinnausall des Arbeitgebers nicht eintritt.

\section{Lohn- und Wirtschaftsverhältnisse.}

Sach der antlichen Statistili des Oberbergantes Bomn ïber die letzten Jahr betrug der Lohn dre einzelnen Arbeiterklassen in dem Bergrevier Arnsberg, also in allen Kreisen mit Ausnahme Wittgenstein:

\begin{tabular}{|c|c|c|c|c|c|c|c|c|}
\hline \multirow{3}{*}{ Jahr } & \multicolumn{2}{|c|}{$\begin{array}{c}\text { Arbeiter } \\
\text { unter Tage }\end{array}$} & \multicolumn{2}{|c|}{$\begin{array}{l}\text { Arbeiter } \\
\text { über 'Tage }\end{array}$} & \multicolumn{2}{|c|}{$\begin{array}{l}\text { Jugendliche } \\
\text { Arbeiter }\end{array}$} & \multicolumn{2}{|c|}{$\begin{array}{l}\text { Lohn im } \\
\text { Durchschnitt }\end{array}$} \\
\hline & Lohn & pro & Loh & pro & Lohr & pro & Lohr & pro \\
\hline & $\begin{array}{l}\text { Schicht } \\
\text { II. }\end{array}$ & $\begin{array}{c}\text { Jahr } \\
\text { II. }\end{array}$ & $\begin{array}{l}\text { Sichicht } \\
\text { II. }\end{array}$ & $\begin{array}{c}\text { Jahr } \\
\text { M. }\end{array}$ & $\begin{array}{l}\text { Schicht } \\
\text { MI. }\end{array}$ & $\begin{array}{l}\text { Jahr } \\
\text { II. }\end{array}$ & $\begin{array}{l}\text { Schicht } \\
\text { MI. }\end{array}$ & $\begin{array}{l}\text { Jahr } \\
\text { II. }\end{array}$ \\
\hline 1908 & 2,99 & 810 & 2,88 & 797 & 1,67 & 471 & 2,87 & 788 \\
\hline 1909 & 3,00 & 797 & 2,89 & 70 & 1,55 & 416 & $2,8,5$ & 773 \\
\hline 1910 & 2,95 & 799 & 2,89 & 782 & 1,47 & 409 & 2,85 & 768 \\
\hline 1911 & 3,05 & 792 & 2,99 & 821 & 1,53 & 417 & 2,94 & 782 \\
\hline 1912 & 3,16 & 888 & 3,03 & 883 & 1,53 & 445 & 3,02 & 861 \\
\hline 1913 & 3,24 & 913 & 3,22 & 918 & 1,44 & 404 & 3,12 & 886 \\
\hline
\end{tabular}

Als Arbeitslohn gilt der reine, rerdiente Lohn. nach Abzug aller Jebenkosten, die sich aus den persönlichen Beträgen für die VerPlü mpe, Schieierindust rie. 
sicherung gegen die Folgen ron Krankheit, Alter und Tod und aus den sachlichen Kosten für Arbeitsgezähe, Sprengmaterialien und Geleuchte zusammensetzen. Die Höhe der Bezüge ist für jede Arbeiterklasse im Durchschnitt angegeben.

Die Abzuge pro Schicht und Arbeiter betrugen im:

\begin{tabular}{ccc|c}
\hline Jahr & $\begin{array}{c}\text { (iezähebeschaffung } \\
\text { und dergleichen } \\
\text { Pfg. }\end{array}$ & $\begin{array}{c}\text { Knappschaftskassen- } \\
\text { beiträge, Kranken- und } \\
\text { Invalidenversicherung } \\
\text { Pfg. }\end{array}$ & $\begin{array}{c}\text { Lampenöl für die } \\
\text { unterirdisch beschäf- } \\
\text { tigten Arbeiter } \\
\text { Pfg. }\end{array}$ \\
\hline & 11,7 & 18,7 & 8,9 \\
1908 & 11,5 & 20,5 & 6,9 \\
1909 & 12,1 & 21,5 & 5,2 \\
1911 & 17,3 & 20,5 & 6,7 \\
1912 & 15,6 & 21,6 & 4,6 \\
1913 & 19,6 & 23,5 & 6,1
\end{tabular}

In den Gruben bei Raumland im Freise Wittgenstein arbeiten die Hauer nach Gedingsätzen, das Spalten und Schneiden erfolgt dagegen in Tagelohn. Fin Versuch der Grubenverwaltung, Hauer und spalter in eine Lohngemeinschaft zu bringen, scheiterte am Widerstande der Hauer, die eine Herabsetzung ihrer Löhne befürchteten.

Auf lem Schieferbergwerk, Fürst Richard", ebenfalls im Kreise Wittgenstein, haben die Arbeiter 12-Stundenschicht und arbeiten nach Gedingsätzen. Der Durchschnittslohn beträgt auf dieser Grube für die spalter 3.40 bis 3,60 Mark, während die Hauer ungefähr 4,20 bis 4,40 Mark rerdienen.

In den Gruben bei Fredeburg erhalten die Hauer 3,50 bis 4,20 Mark. Auf gleiche Höhe stellt sich der Lohn der Arbeiter bei Nuttlar, während auf den andern Gruben ein etwas geringerer Lohn bezahlt wird.

Tergleicht man die heute bestehenden Löhne mit denen in den nemziger Jahren - die Hauer verdienten damals 2,20 bis 2,40 Mark, die über Tage beschäftigten Arbeiter 2,70 bis 2,80 Mark -, so ist eine Steigerung der Löhne wohl zu erkennen und in der wirtschaftichen Lage der Arbeiter eine Besserung eingetreten.

Für die Zeit, in der Schieferförderung nicht stattfindet, sondern AufschluBarbeiten ausgeführt werden, tritt in den meisten Fällen Schichtlohn oder ein von der Bergwerksverwaltung festgesetzter Lohn ein.

Die Arbeiter eines Schieferbergbaubetriebes, die im Akkordlohn stehen, haben sich zu sogenannten ,Kameradschaften" zusammengeschlossen, die in der Regel aus 10 Arbeitern bestehen. Der eine Teil einer solchen Kameradschaft ist Hauer, der andere Spalter. Für den Fall, daß infolge größerer Aufschlußarbeiten geringere Schieferförderung stattfindet und die Spalter ohne Schiefer zum Spalten sind, gehen diese mit ins Bergwerk und helfen ihren ,Kameraden" so lange. bis für längere Zeit wieder genügend Schiefer zum Abban vorgerichtet ist. 
Die Arbeiter des engeren sauerlatgdes sind fast alle am Ort ihrer Tätigkeit ansässig. während der Anfahrwerg zur cirube für virle Arboiter des Kreises Wittgenstrin 4 Kiloneter, fuir einige anch 6-7 Kilometer beträgt.

AuBerhalb ihrer Tätgkeit in Borgwerk oder spalthaus widnen sich die Arbeiter, da die neisten Iändereien und (rärten besitzen, der Landwirtschaft, oder sio gehen, falls sie ohne Grundbesitz sind. eincr anderen Beschäftigmng nach, so dab sich ihr täglicher Verdienst noch un ungefähr 1 Mark erhöht. Wie mir von der Girubenverwaltung mitgeteilt wurke, gibt es viele Arbeiter. die auf diese Weise einen täglichen Arbeitshohn von 5 Mark bis 6 Mark haben. Für die Arbeiter. des Kreises Wittgenstein, deren Schicht 12 Stunden boträgt, fällt eine solche landwirtschaftliche Täigkeit natiurlich fort.

Die wirtschaftlichen Terhältnisse der Arbeiter sind demnach nicht als schlecht zu bezeichmen. Der Lohn ist auf den meisten Gruben ausreichend. Die Besitzer der Schiefergruben erklären allerdings, sie wïrten ihren eigenen wirtschaftlichen Ruin herbeiführen, wemn sie höhere Löhne bewilligten, sie könnten dies nur dann tun, wenn ihnen ron staatlicher Seite durch wirksamen Schutz gegen die ausländische Konkurrenz und bei der Schieferplattenindustrje durch Herabsetzung der Eisenbahntarife geholfen würde.

Fast jeder Arbeiter besitzt neben seinem Hause so viel an Grund und Boden, dab er eine Ziege oder mehrere Ziegen orler gar eine Kuh halten kann, außerdem werden ron jeder Familie jührlich mindestens zwei schweine geschlachtet. Ton der Nuttlaer Belegschaft besitzen insgesamt

$\begin{array}{lcl}59 & \text { Arbeiter } & 62 \text { Häuser, } \\ 44 & . . & 140 \text { Iorgen Land. } \\ 25 & . . & 29 \text { Kühe, } \\ 78 & . . & 120 \text { Ziegen, } \\ 80 & . . & 183 \text { Schweine. }\end{array}$

Der Besitz an Waldgrundstücken konnte nicht genau festgestellt werden, beträgt aber mindestens 100 Morgen.

Änhliche Terhältnisse konnten bei den Arbeitern auf den Gruben bei Antfeld und bei Fredeburg festgestellt werden. Im Kreise Wittgenstein sind die wirtschaftlichen Verhältnisse nicht ungünstig. Da die schichtdauer aber 12 Stunden beträgt, so sind die Arbeiterfrauen gezwungen, die Ländereien zu bestellen. Nur scheint die Ernährung nicht zureichend zu sein, während bei den Arbeitem in Nuttlar, Fredeburg und Antfeld die Ernährungs- und Trinkwasserverhältnisse gut sind. Für den billigen Bezug guter Waren sorgt in Nuttlar ein Konsumverein, der bei den Arbeitern sehr beliebt ist und es verdient, in einem Abschnitt näher behandelt zu werden.

\section{Konsumverein.}

Seit mehr als 40 Jahren haben die Arbeiter der SchieferbauAktiengesellschaft Nuttlar zur Beschaffung billiger Lebensmittel 
mater sich einen Konsmmerein einfachster Art. Tor dieser Zeit lieferte die Terkverwaltung die Hanptnahrungsmittel zum Selbstkostenpreis. Da sich aber dabei infolge mangehder Warenkenntnisse seitens der betreffenden Beamten Unzuträglichkeiten und schäden heransstellten, so ïherließ man den Einkauf und die Terteilung der Waren ausschließlich den lionsumierenden Arbeitem und ging ihnen nur mit Barrorsehüssen zur Regulierung ilner Bezüge zur Hand.

Die Geschäftsführung und generelle Behandlung ist sehr einfach. Zu Anfang eines jeden Monats hat jeder Arbeiter dem mit der Verteilung der Waren beanftragten Steiger seine Angaben darüber zu machen. was und welche Quantitäten er für den lanfenden Monat rebrancht. Diese Angaben werden notiert und damit der Gesamtbedarf festgestellt. Aus der Reihe der Arbeiter wird ron diesen selber rine Kommission von drei Mann gewählt, welche die eingehenden Warenproben und Preise zn prüfen und in dem am 10. eines jeden Honats stattfindenden Submissionstermin, zu dem die Lieferanten meist persönlich erscheinen, den Bedarf selbst und direkt zur Liefermng zu vergeben hat. Diese Konmission wird jeden Monat nen gewählt, so daß bei jeder Submission andere Mitglieder funktionieren und Cnzuträglichkeiten ausgeschlossen sind.

Das Terfahren bei der Submission ist folgendes. Die Reflektanten liefern den betreffenden Steigern die Taremmuster, die nur mit Preisangabe, aber nicht mit Namen rersehen sein diurfen. Der Steiger versieht diese Waremmuster mit Nmmmem und notiert auf separatem Bogen zn den Nummern die Namen der Lieferanten. Hierauf werden die Proben den Fommissionsmitgliedern zur Ansicht und Wahl vorgelegt. Ist letzte getroffen, so wird aus der Notiz des Steigers der Tame des Reflelitanten festgestellt und diesen die Lieferung der Waren übertragen. Die ganze Angelegenheit wird also vollständig unparteisch behandelt. Die Proben werden ron der Fommission aufhewaht und später mit der Lieferung rerglichen. Ist diese nicht nach Muster ausgefallen, so wird sie den Lieferanten wieder zur Verfügung gestellt, was zuweilen rorkommt. Die Waren werden in Gegenwart les betreffenden Steigers und der Kommission an die Arbeiter gemäß ihrer Bedarfsangaben ausgewogen und verteilt. Alles geschieht ganz sachgemäß. so daß niemals Flagen oder Mißstimmungen der Verwaltung zu Ohren gekommen sind.

Wer es unterläBt, zu Anfang des Nonats seine Bedarfsangabe zn machen. hat keinen Anspruch auf Zuteilung ron Waren, denn es werden monatlich stets nur die Mengen bezogen, die wirklich bestellt waren, so daß also ein Lager nie existiert. Die Zahlung der Waren erfolgt nach der Monatslölmung an den Steiger direkt durch die Arbeiter. Der Steiger reguliert die Rechnungen der Lieferanten oder die ihm rom Geschäft aus geleisteten Torschiisse. Für die Mühe und Arbeit, die dem steiger durch den Konsumverem erwächst, haben clie Lieferanten ihm eine kleine Provision zu zahlen, die anf 100 Kilogramm ungefähr 25 Pfennige beträgt.

Die Arbeiter haben auf diese Teise inre Hauptbedarfsartikel 


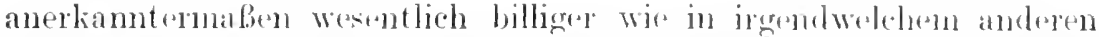
Konsumverein. AnBerdem werden den Arbejtern in Fillen der Sot

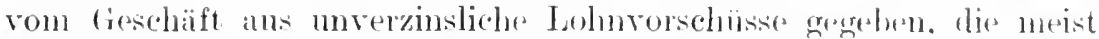

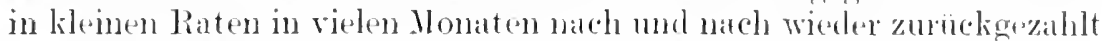
werelen diurfen.

Die Bedarfartilin sind meistens und hanptsächlich Roggen, Mehl. Cierste, Erbsen. Bohnen unel Kohlen. Fïr kleinere bedarfsartikel, wie /ucker und Kaffee usw.. sind die Preise am Ort infolge recht besdeutender Konkurrenz mäßigr. Die Lohlen werken den Arbeitern rom Geschäf aus zum sielbstliostempreis waggonweise geliefort und ron ilmo selbst rerteilt; deren Bezalılung erfolgt in der liegrel auch wieder in Raten.

\section{Hygienische Verhältnisse.}

Der Gesmolheitszustand der auf den westälinchen Schiefergruben beschäftigten Arbeiter kam als durchweg gut bexeichnet werden. Unglücksfälle, die Menschenleben gefordert hätten. sind bei den hohen Anforderungen in bezug auf sicherheitsrorrchtungen ganz minimal. Unbedeutende Quetschungen oder sonstige geringfügige Verletzungen bleiben auber Betracht.

Das Durchschnittsaltex der Nuttlarex Belegschaft stellt sich auf ungefähr 381/2 Jahre, im Alter von über 50 Jahren stehen 29 Arbeiter.

Gelegentlich der Generalrersammlung in .Tahe 1907, dem 50 jährigen Jubiläum der Finma, konnten

Auszeichnumgen erhalten.

$\begin{array}{rcccc}7 & \text { Arbeiter mit } & 25-30 & \text { Dienstjahren } \\ 12 & . . & . . & 30-35 & . . \\ 5 & . . & . . & 35-40 & . . \\ 3 & . . & . . & 40-45 & . . \\ 1 & . . & . . & \text { iber } 50 & . .\end{array}$

Besondere Krankheiten. die auf die Beschäftigung in den Schiefergruben oder in der Plattenfabrikation zurückzuführen wären, kommen nicht vor. Was besonders in den Räumen der Plattenfabrikation angenehm auffällt. ist tas Fehlen ron Staub in der Luft, denn der S'chieferstaub, der sich beim Sägen und Hobeln bildet, ist so schwer. daß er ruhig auf cler Platte liegen hleibt, und deshalb sind auch Erkrankungen der Atmungsorgane in der westfälischen schieferindustrie sehr selten.

Der Gesundheitszustand der Angehörigen der Belegschaft ist als normal zu bezeichnen. Die Gemeinde Nuttlar, aus welcher der größte Teil der Nuttlarer Bergarbeiter hervorgeht, hatte vor nicht langer Zeit in $1^{1 / 2}$ Jahre keinen Todesfall zu verzeichnen.

Die Feuchtigkeit in den Gruben ist sehr gering. Sie sind durch breite Stollen aufgeschlossen und besitzen eine gute natürliche Bewetterung. Zur Verbesserung des Wetterzuges sind an einigen von Wettern weniger bespülten stellen die in Kohlengruben iublichen Wettertüren eingebaut. Die Durchschnittstemperatur beträgt 10 bis 
$12^{0}$ C'elsius. Auch über die Bewetterung in den Hörre-Raumländer ciruben kann nicht geklagt werden, da an mehreren Stellen Verbindungen zwischen Stollen und den Tagebanen bestehen. Eher wird über Xässe geklagt, ror allem in den Wintermonaten, eine Tatsache, die sogar ron den (irubenbesitzern zugegeben wird. Die Durchschnittstemperatur in den Gruben beträgt $\gamma^{0}$ ('elsius.

Der Anfahrweg zur Grube beträgt für die meisten Bergarbeiter im Liveise Wittgenstein, wie bereits erwähnt, 4 Kilometer, für einige auch 6-7 Kilometer. Berüclisichtigt man diese langen Anfahrwege, die die Arbeiter zu den Gruben haben, so ist nicht von der Hand zu weisen, daß sie, durch den langen Marsch erhitzt, leicht Erkältungen ausgesetzt sind, wenn sie in die Gruben einfahren.

Jan wird deshalb gerade nicht auf günstige SterblichleitsverIlältnisse in diesem Kreise gefaßt sein. Die meisten Schieferbrecher sind in den zu dem Standesamtsbezirk Raumland gehörigen drei Gemeinden Raumland, Dotzlar und Berghausen schon seit langem ansässig. Das Durchschnittsalter der in den letzten 20 Jahren verstorbenen 37 Schieferbrecher beträgt 46,2 Jahre, während die übrigen 148 männlichen Personen 60 Jahre alt wurden. Hierbei muß jedoch bemerkt werden, daß die 12 durch Unfall zu Tode gekommenen nicht mitgerechnet worden sind. Ein so großer Unterschied konnte kaum erwartet werden, $u m$ so weniger, als die andern in denselben Gemeinden wohnhaften Arbeiter zum Teil zwar Waldarbeiter und Bauern, zum Teil aber auch in Holz- und Papierfabriken in Berleburg beschäftigt sind, teilweise also in Gewerben, die sich ebenfalls durch Entwicklung gesundheitsschädlichen Staubes auszeichnen. Auch die persönliche Mitteilung des die Schieferbrecher behandehnden Arztes, daß über große Sterblichkeit unter ihnen nicht zu klagen wäre, ist nit dem Ergebnis der Statistik nicht gut in Einklang zu bringen. Lungenkrankheiten kämen ja wohl vor, aber keine Lungenschwindsucht. Rheumatismus dagegen trete häufig auf, beinahe so häufig wie bei den Waldarbeitem, meines Erachtens eine Erscheinung, die sich auf die Nässe in den Gruben zurückführen läßt.

Die Spalthäuser sind sehr geräumig und hell. Die Leute auf Grube Hörre und Haßlar spalten ganz abweichend von den sonst beobachteten Yethoden vor der etwa 1,20 Meter hohen Spaltplatte aufrecht stehend, indem sie den zu spaltenden Schiefer senkrecht zwischen Bank und Oberkörper festklemmen. Zum Schutze dieses tragen sie einen um den Hals hängenden Lederschurz. Der entstehende Abfall wird unter die Spaltbank geworfen in große Behälter, deren -chiefe Böden unter starker Neigung ins Freie auf die Halde führen. Ton Zeit zu Zeit wird der sich dort ansammelnde Schutt draußen abgezogen.

Die schuttbeseitigung geht also sehr zweckmäßig vor sich, denn der durch das Hinabwerfen aufgewirbelte Staub wird durch die Spaltbank gewissermaßen gegen den Spaltraum abgeschlossen. Sollte er trotzdem über die Spaltbank hinaus sich erheben, so ist es noch zweifelhaft, ob er so hoch kommen würde, daß er die Atmungsorgane der 
aufrechtstehenden sipalter in Mlithidenschaft zu ziehen imstande wäre. In dem anderen Spalthaus dageggen wirft jeder sipalter den Abfall in einen blechernen, ror ihm auf der Spaltbank stehenden Fülltrog, der, wenn er gefüllt ist, in einen zur Scite stehenden, auf Schienen laufenden Schuttwagen goleert wird. Diese Methode der Selnuttbeseitigung ist natürlich nicht so vorteilhaft. Es bleibt der Nachteil bestehen, daß der Abfall innerhalb des Spaltraumes eine zweimalige Staubaufwirblung verusacht, eimmal, wenn er unmittelbar nach dem spalten in den Fülltrog geworfen, sodann, wemn er in den Abfallwagen befördert wird.

Auf Grube ..Fürst Richard" arbeiten die Spalter in großen, luftigen, heizbaren liäumen. Hier sitzen sie rittlings auf 20-30 \%entimeter hohen, länglichen Spaltböcken. Der Schutt, der sich in likinen Haufen neben den Spaltern ansammelt, wird, bei vorhergehendem Besprengen mit Wasser, in den Pausen oder nach der Schicht in Förderwagen fortgeschafft. Auf den in den andern Kreisen gelegenen Gruben haben die Spalter ebenfalls große, luftige Räume zur Verfügung, in denen die Arbeiter auf einem mit einer Räckenlehne versehenen Spaltbrett, das, wie in Nuttlar, ohne stützen direkt auf dem Boden liegt oder, wie bei Fredeburg, sich etwa 10 Zentimeter über dem Boden befindet, sitzen.

Die Entfernung des Schuttes geschieht häufig und meist erst, nachdem er genügend mit Wasser besprengt worden ist. Da die rollständige Terhinderung der Entstehung des Staubes und die vollkommene Beseitigung des entstandenen Staubes ausgeschlossen ist, sind vielfach Respiratoren angewendet, Schutzmittel, die den Staub am Eingang zu den Atmungsorganen, also an Nase und Mund, zurückhalten. Sie haben sich aber nicht bewährt, da, wie die Arbeiter erklären, diese Apparate die Atmung erschwerten. Ia der Respirator außerdem, wenn er seinen Zweek erfüllen soll, fest an das Gesicht gepreßt werden muß, so soll er im heißen sommer infolge der durch die Pressung hervorgerufenen Schweibbildung geradezu unerträglich sein. Die Abneigung der Arbeiter wird sich vielleicht äberwinden lassen, wenn die Respiratoren leicht und bequem genug gebaut sind und die Leute von Anfang an schon als Schnitter- und Spalterlehrlinge angehalten werden, sie zu tragen.

Über die Stellung der Spalter im Spaltranm ist noch folgendes zu sagen. Bei Raumland ist die mit der Tätigkeit des Spaltens verbundene Aufrechthaltung des Körpers, durch welche Erkältungen, Hemmung des Blutkreislaufs und Erkrankung des Magens kaum entstehen können, vorteilhafter als bei Nuttlar, wo die Leute durch ihre Sitzweise zwar gegen die Feuchtigkeit und Kälte des Bodens geschützt sind, die Lage der Beine aber unbequem und unnatürlich ist. Auch das Sitzen rittlings auf einem Spaltbock ist sehr empfehlenswert, da Erkrankungen des Magens nach der Äußerung des Arztes nicht rorkommen.

Die Arbeiter haben sich aber an die auf den einzelnen Gruben übliche Sitzweise so sehr gewöhnt, daß es schwer sein würde, eine 
andere als die gewohnte Sitzweise einzuführen. Daß Schädigungen der (resundheit durch die Sitzweise der Spalter erwachsen sind, ist nicht bekannt geworden. Von nicht zu unterschätzender Bedeutung wäre es. wemn die spalter, wie bei Raumland, in der warmen Jahreszeit im Freion arbeiteten. Satülich müßten damn bewegliche Schutzdïchery zur Verfügung stehen.

Früher wurde ron den Arbeitern viel Krlage geführt über das schlechte Licht und den üblen Geruch der Öllampen. Seit einigen Tahren sind diese aber abgeschafft. Jetzt werden in allen Gruben Karbidlampen gebraucht, die unstreitig ein besseres Licht erzeugen. als die Öllampen. Sie waren aber anfangs für die Arbeiter ebenso gestundheitsschädlich wie Öllampen. Die Behauptung der Verteidiger der Karbidlampen, diese setzten kieinen RuP ab, beruhte auf einem Irrtum. Der Ruß setzte sich bedentend fester an und war viel schwerer zu entfernen als Ölruß. Diese Eigenschaft mußte daher sehr ungünstig auf die Atmungsorgane einwirken. Der üble, den Atem benehmende Geruch, der sich überall in den Gruben bemerkbar machte, konnte ebenfalls nicht anders als gesundheitsschädlich wirken. Solche Übelstände traten allerdings nur damn auf. wem Gase in nnverbranntem Zustande aus der Lampe entweichen konnten. Neuerdings sind die Karbidlampen aber sehr verbessert. Die Arbeiter haben sich an diese Lampen gewöhnt, da gesundheitsschädliche Einwirkungen nicht mehr zu beobachten sind.

Im allgemeinen kamn über allzu großen Alkoholgenuß nicht geklagt werden. In alle Arbeitsordnungen sind Strafbestimmungen aufgenommen, wonach der, welcher anf dem Werk betrunken vorgefunden wird, oder wer Branntwein und Bier bei sich hat oder bei dem Herbeischaffen dieser Getränke behilflich ist. mit einer Geldstrafe bis zur Höhe des durchschnittlichen Tagesarbeitsverdienstes seiner: Arbeiterklasse belegt wird. Infolgedessen ist der Alkoholgenuß bei den Arbeitern erheblich zurückgegangen. Bei einzelnen Arbeitern allerdings ist der ïbermäBige Genuß von Branntwein als gesundheitsschädlicher EinfluB zu bezeichnen.

Unter all diesen Umständen ist mit ziemlicher Wahrscheinlichlieit zu erwarten, daß Klagen über große Sterblichkeit unter den Dachschieferarbeitern der Kreise Brilon und Meschede nicht lant geworden sind. Diese Erwartungen treffen denn auch zu. Nach übereinstimmenden Anssagen der Ärzte, auch des Freisarztes, wirkt der Betrieb in den Dachschiefergruben und Spalthäusern, sowie in den Päumen der Plattenfabrikation nicht schädigend anf die Gesundheit der Arbeiter ein; wo eine solche Einwirkung zu bestehen scheint, ist der frühe Tod des betreffenden Bergmannes nicht auf den Dachschieferbergbau, sondern auf seine frühere Beschäftigung in den sehr gesundheitsgefährlichen Betríben der Erzbergwerke zu Pamsbeck und Meggen zurückzuführen. Der Dachschieferbergban Westfalens ist der einzige, ron dem mit ziemlicher Bestimmtheit gesagt werden kamn, daß er anf den Organismus der Arbeiter einen unheilvollen Einfluß nicht ausuibt. 
Angesichts diesere 'latsache dringt sich mwillkiulich dir Frage auf, woher es denn komme, dab bei der linkisheminchen sehiefereindustrie, wo doch dieselben schutzmaßregehn tuwrondung findent wie in Westfalen, die sterblichlieitserhälnisse der schioferbrecher so riel ungünstiger liegen. Der Untersehied der siterblichkeitsrerhältnisise ist wohl zum gröbten Teil anf lie gröbre oter geringere Gefährlichkeit des sehieferstaubes zuriekzuführen. J)ie (iefährlichkeit des staubes ist ron seinen physikalischen und chemischen Eigenschaften abhängig. Siom mereld schreibt: ,Am goführlichsten sind diejenigen stanbarten, deren feinste Partiliolchen unebene zackige Rändler besitzen oder spitz auslaufen. Relativ unscliadlich sind glatte, runde staubmolekïla." Ob die bei der bearbeitung cines Steines entstehenden likinsten l'eilehen mit scharfen zackigen oder rumden Rändern versehen sind, hängt lediglich von der Härte und Festigkeit des betreffenden steines ab, je härter und fester dieser ist, $11 \mathrm{~m}$ so schärfer und spitzer sind die staubpartikelchen ansgebildet. Ein sichiefor hat im allgemeinen in $11 \mathrm{~m}$ so höherem Maße diese beiden physikalischen Eigenschaften, je größ↔ der Gehalt an freier Kieselsäure ist, je mehr die Sesquioxyde iuler die Monoxyde vorherschen und je weniger Alkalien und alkatische Erden rorhanden sind. Der Schiefer ron Nuttlar enthält einerseits eine geringere Menge von Kieselsäure und Tonerde, anderseits verfügt er über einen größeren Gehalt an kohlensaurem Kalk. Diese Tatsachen sind die Ursachen fïr die geringere Härte und Festigkeit des Nuttlarer Schiefers. Ähnliche Zusammensetzungen liaben sämtliche westfälische Schiefer. Dasselbe ist natürlich auch von den Staubpartikelchen zu sagen. Sie werden infolge ihrer geringen Härte und Schärfe also nicht so seln die Luftröhre und Bronchien verletzen, sie werden sich in den Schleimhäuten weniger leicht festsetzen und werden durch die ausgelösten Hustenstöße und die Flimmerbewegungen der Schlcimhäute schneller herausgeschleudert werden können. So ist schon die physikalische Beschaffenheit des westfälischen Schiefers in viel geringerem Maße dazu angetan, Erkrankungen der Atmungsorgane hervorzurufen, insonderheit der Lungentuberkulose einen geeigneten Boden vorzubereiten.

\section{Soziale Fürsorge.}

Um den Arbeiter im Falle der Erwerbsunfähigkeit, durch Krankheit, Unfall in den Gruben usw. verursacht, oder im Falle seines Todes die hinterbliebenen Angehörigen vor Not zu schützen, gehören die Arbeiter der Knappschaftskasse an oder, wie die nicht der Bergbehörde unterstellten Bergwerke, der Steinbruchberufsgenossenschaft. Arbeiter, die im Betriebe eines Vereinswerkes oder des Knappschaftsvereins gegen Entgelt beschäftigt sind, gehören sowohl der Krankenkasse als auch der Invalidenkasse an, ohne daf es einel Beitrittserklärung bedarf. Die meisten in der westfälischen Schieferindustrie beschäftigten Arbeiter gehören den Briloner und Arnsberger Knapuschaftsvereinen an. 
Die Beitrïge zur Trankenkasse betragen zurzeit:

beim Briloner Knappschaftsrerein

$$
\begin{aligned}
& \text { Klasse I 0,70 Mark } \\
& . \quad \text { II } 0,80 \quad \text {,. } \\
& \text {.. III } 0,85 \text {,., } \\
& \text {.. TV } 0,90 \text {, } \\
& . \text { T } 1,20 \text {., } \\
& \text {.. TI } 1,40 \text {, } \\
& \text {.. VII } 1,70 \text {,, } \\
& \text {.. VIII 2,50 ,, }
\end{aligned}
$$

beim Arnsberger Kinappschaftsverein

$\begin{array}{crrr}\text { Klasse } & \text { I } & 0,65 & \text { IIark } \\ ., & \text { II } & 0,90 & , \\ , & \text { III } & 1,15 & , \\ , & \text { IV } & 1,45 & , \\ , & \text { V } & 1,75 & , \\ . & \text { VI } & 2,05 & , \\ ., & \text { VII } & 2,40 & , \\ , & \text { VIII } & 2,75 & ,\end{array}$

Die Mitglieder des Knappschaftsvereins Brilon werden in folgende Ǩlassen mit den beigesetzten Grundlöhnen eingeteilt:

Grundlohn

Klasse I Weibliche Mitglieder unter 16 Jahren . . . . 1, - Mark

.. II Nännliche Nitglieder unter 16 Jahren . . . . 1,20 ,,

., III Weibliche Mitglieder von 16-21 Jahren . . 1,30 ",

. IV Yännliche Mitglieder von 16-21 Jahren . . 2,20 ,,

.. T Teibliche Nitglieder über 21 Jahre . . . . . 1,50 ,

.. VI Nännliche Mitglieder über 21 Jahre: Arbeiter . 2,80 ,,

., VII Beamte und Aufseher mit einem Verdienst bis 120 Nark monatlich, sowie Arbeiter in gehobener Stellung . . . . . . . . 3,40 ,

"VIII Beamte mit einem festen Gehalt von mehr als 120 Nark monatlich . . . . . . . 5,- ,

Die Mitglieder der Arnsberger Krankenkasse werden nach der Höhe der duirchschnittlich erzielten Tagelöhne in folgende Klassen eingeteilt :

Kilasse I mit einem Grundgehalt von 1,20 Mark

$$
\begin{aligned}
& \text {.. II ., ., } \quad, \quad, \quad 1,60 \quad, \\
& \text {.. III ., ., } \quad, . \quad, \quad, \quad 2,40 \quad,
\end{aligned}
$$

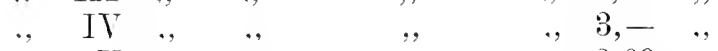

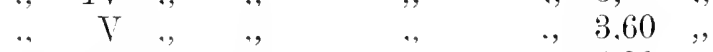

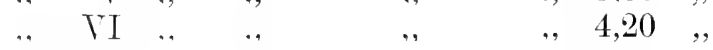

$$
\begin{aligned}
& \text {.. VII ., } \\
& \text {., VIII ", }
\end{aligned}
$$

Alle Beamten gehören zur höchsten Lohnklasse.

Die Höhe der Beiträge zur Pensionskasse ist clerart zu bemessen, daß sie unter Hinzuziehung der etwaigen weiteren Einnahmen der Kasse und unter Berücksichtigung aller sonstigen für die Leistungsfähigkeit des Tereins in Betracht kommenden Umstände die dauernde Erfüllbarkeit der Pensionskassenleistungen ermöglichen. Die Beiträge der Vitglieder werden jährlich durch den Vorstand festgesetzt.

Die Beiträge der Terkbesitzer zerfallen in Krankenkassen- und Pensionskassenbeiträge. $\mathrm{Zu}$ beiden Kassen haben die Terkbesitzer 
gleich hohe Beiträge zu zahlen wie die auf ihren Wirkin bescluäftigten beitragspflichtigen Mitglieder.

Die Leistungen der Frankenliasten bestehen in freder ärtlichn Buhandlung und Versorgung der Mitglieder nit Arznei, sowie in Krankenereld. An Stelle der Kirankenpflege und des lirankengeldes kamm die Kasse Kur und Terpflegmng in einem Frankenhause grewähren. AnBerdem zahlt die Trankenkisse beim l'ode eines Witgliedes ein sterbegeld.

Die Leistungen der Pensionsliasse bestehen in Invalidempension, Witwenpension, Erziehungsbeihilfe und Begräbnisbeihilfe. Die monatlichen Invalidenpensionen betragen fiir den Kuapschaftsverein bei einem Jienstalter von

$$
\begin{array}{lrrrrrrrrc} 
& 5 & 10 & 15 & 20 & 25 & 30 & 35 & 40 & \text { Jahren } \\
\text { Arrsberg } & 4.25 & 5,50 & 10,- & 11,50 & 13,- & 14,50 & 16,- & 17,50 & \text { Iark } \\
\text { Brilon } & 2,90 & 5,50 & 8,70 & 11,60 & 14,50 & 17,40 & 20,30 & 28,20 & ,,
\end{array}
$$

Die Witwenpension beträgt die Hälfte der Invalidenpension, welche der verstorbene Ehemann bezogen hat oder bezogen hätte. Dir Beihilfe zur Erziehung der Kinder verstorbener Hitglieder wird bis zur Vollendung des 14. Lebensjahres gewährt. Sie beträgt monatlich für jedes Kind: für raterlose Waisen 2 Mark, für vaterund mutterlose Waisen 2,50 Mark. In Krankheitsfällen erhalten die Invaliden freie Kur und Arznei. Ku den Begräbnisliosten eines Invaliden wird ein Beitrag von 50 Mark gewäht. Im Falle auBerordentlicher Bedürftigkeit eines Invaliden kam der Vorstand auBerordentliche Unterstützungen gewähren. In gewisser Weise ist also für die Arbeiter im Falle ron Krankheit und für die Witwen und Waisen gesorgt.

\section{Die ungünstige Lage der Schieferindustrie Westfalens.}

\section{Konkurrenz des Auslandes.}

Wenn wir vor einer Toukurrenz des ausländischen Schiefers sprechen, haben wir zu unterscheiden zwischen den Staaten, die Dachschiefer nach Dentschland einführen, die also nicht nur die Dachschieferindustrie Westfalens, sondem auch ganz Westdentschlands bedrohen, und den Staaten, die anf dem Grebiete der Schieferplattenindustrie besonders Westfalen den Absatz seiner Produkte erschweren. Zu den ersten Staaten werden besonders England, Frankreich, Belgien und Luxemburg zu rechnen sein, während die italienischen, österreichischen und amerikanischen Schiefer weniger gut sind und als Konkurrenz für Deutschland weniger in Betracht kommen. Als Hauptkonkurrenten für Schieferplatten kommen Italien in Frage, dann Belgien, die Schweiz, Portugal, sowie neuerdings Amerika.

Die besten englischen Bezugsquellen sind die sogenannten ,old veins": die Penrhyn- und Dinorvicbrüche in Nord-TTales und die 
Portmadoeschiefer in Portmadoc in Nord-Wales: und zwar aus den Palmerston- und Oakeleygruben, auch Palmerstonschiefer genannt, welcher ron blaner Farbe ist. Der rote, Penrhyn, ist der beste englische Schiefer.

Es gibt damn noch Schiefer minderer Qualität, wie Carnarvon und die sogenannten new reins, im Gegensatz zu obengenannten old reins.

Der Oakeleyschiefer hat eine schöne blaue Farbe und eine glatte Oberfläche; er ist gleichmäßig in der Stärke, aber nicht so hart wie der rote Penrhyn, liefert daher nicht so viel Bruch und rissige Steine wie dieser und wird deshalb besser verkanft. Diese'Eigenschaften besitzt der rote Penrhyn weniger, er ist dafür aber härter und der wetterbeständigste von allen Schiefern. Der englische Schiefer zeichnet sich ferner ror allen andern Schiefern durch leichteste Spaltbarkeit in große Platten, durch glatte ebene Oberfläche und feines Korn aus, was ihm aber nur für den einzigen Fall der Verwendung zur Bedeckung von ganz flachen Dächern vor anderen Deckungen den Vorzug gibt. Die Wetterbeständigkeit der besten englischen Schiefer ist der der besten dentschen Schiefer teilweise überlegen, teilweise gleich.

Die Struktur der Schiefer ist langfaserig, sie spalten dabei gleichmäBiger und können daher besser als dentsche zur Doppeldeckung benutzt werden. Für deutsche Deckart wäre der englische Schiefer zu dümn und bräche sofort. Der Struktur und der Sprödigkeit wegen kann aber der enghische Schiefer nicht in jeder Form, wie es bei dem mit verwachsener, knorriger Struktur versehenen deutschen Material der Fall ist, verwendet werden, sondern mur zu Rechtecken bei Doppeldeckung, the natürlich viel mehr Naterial beansprucht als deutsche Deckung, also teurer ist als diese.

Die Mächtigkeit und Leistungsfähigkeit der englischen Gruben sind gröper als die irgendwelcher anderen Gruben; besonders ist die stete Gleichmäßigkeit des Naterials als ein besonderer Vorzug zu bezeichnen, den kein anderer Bruch aufweisen kann. Kein westfähischer, überhaupt kein deutscher Bruch liann so schnell und in solchen Nassen die großen Rechtecke liefern, die für die früher üblichen flachen Dächer zur Doppeldeckung notwendig waren und hente oft noch bei steilen Dächern zu Unrecht bevorzugt werden. Der gesamte englische Schiefer geht zur See, also mit billiger Wasserfracht, in die Nord- und Ostseehäfen und die Flüsse hinauf und beherrscht besonders Nord- und Nordostdeutschland, weil hier das westfälische Material wegen der langen Bahnfracht zwar dem Werte nach, aber nicht im Preis konkurrieren und schon minderwertiger englischer Schiefer zur Besiegung der Konkurrenz ins Feld geführt werden kann. $\mathrm{Ob}$ man immer das IIaterial der allerbesten englischen Schiefer bekommt, ist zweifelhaft, da mit Frachtscheinnachweis usw. nicht wie bei deutschem Material operiert werden kann.

Die bedentendsten Gruben in Frankreich sind die bei Fumay und Rimogne in den Ardennen, bei Deville an der Maas und Anger's an der Loire. Die Schiefer sind wesentlich weicher, also weniger" wetter- 
beständier als die englichen. J)e beste französische schiefer ist der rote aus den Guben von Fumay, er besticht sehn loicht durch seine

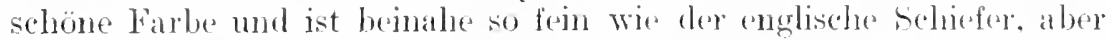
el bricht nicht so grob und fein wie diesere er eignet sich atuch mut fuir ] oppeldeckung. '/ur. Terwendung in Nordeleutschland mol als Konkmrent dex westfähischen Bräche komme nur der blane Angersschiefer, der chenfalls wie der englische mit billiger beofracht in die Häfen der Nord- und Ostsee eingeht, in Betracht.

Die belgischen s'chiefer, die sich nur zur Doppeldecliung eignem, sind noch ein wenior wodehex als die französischen. Die bedentendsten bezugsquellen sind $n$. a. Herbemont, wofü Bertrix, and Warmifontaine, wofür Nenfehatean Bahmstation ist. Die Schicfer liömen im allgemeinen nicht mit dem guten westfälischen Schiefer in bezug auf Haltbarlieit konkmrierm. Sie sind nicht so wetterbeständig, weil sie viel schädliche Bestandteile enthalten.

Eine empfindliche Konkurenz bereitet auch das luxemburger Naterial. Der šchiefer ist trihweise sehr weich, enthält riel schädliche Bestandteile, wie schwefolkies usw., und fault ziemlich schnell. Er wird gewounen in Martelange und Perlé.

Die Gründe für die gewaltige Konkurrenzfälnigkeit des Auslandes gegenüber den westfälischen Gruben sind so mamnigfacher Art, dab es wohl angebracht ist, näher darauf einzugehen.

Zunächst sind es die Gestehmgsliosten, die Lagerungsverhältnisse, die das Ausland gegenïber unseren heimischen Gruben so konkurrenzfähig machen. Frankreichs und Englands Schieferbergbau ist infolge seiner gïnstigen Lage an der See oder an Kanälen ungemein erstarkt und daher in der Lage, die westfälische Schicfermelustrie ganz rheblich zu schägligen, aber auch Belgien und Luxemburg liönnen trotz der nicht merheblichen Bahnfrachten, aber auch dank der sehr günstigen Lagerungsverhältnisse und Gestehungskosten, beispielsweise für Essen, Köln, Elberfeld usw. billiger liefern, als es der westfälischen Schieferindustrie bei nur mäßiger Gewimnberechnung möglich ist. Dabei hat das ausländische Material keinerlei hole Kosten, wie sie bei uns durch die sozialen Lasten erwachsen, die von der westfälischen Schieferindustrie ganz besonders empfunden werden.

Da ferner die ausländischen Schiefer sehr düm spaltbar sind, so diunn, daß die Haltbarkeit in Frage lommt, ist die Beladung und Ausmutzung des Waggons gegenüber dem westfälischen Material äußerst günstig. Das westfälische Material kamn nur stärker erzeugt werden, erfüllt damit aber die Ansprüche auf Haltbarkeit der Dächer hei wesentlich geringen Reparaturen. Besonders macht sich auf dem schablonenschiefermarkte in erster Linie der Wettbewerb von luxemhurger Schiefer bemerkbar. Seit mehr als 30 Jahren hat sich im Großherzogtum Luxemburg aus kleinsten Anfängen herans eine Schieferindustrie entwickelt, die, gestützt anf ein ungewölnnlich mächtiges Torkommen und geringe Gestehungskosten, unsere Schieferinclustrie mm so schlimmer bedrängt, als sie sich rorzugsweise auf die Anfertigung der sogenannten deutschen schieferformen verlegt. Dadurch 
wird unseren heimischen Betrieben, ron denen die meisten dex Struktur des Gesteins wegen auf die Anfertigung dieser deutschen Formen angewiesen sind, die empfindlichste Konkurrenz gemacht. Während die hemischen Gruben mit cinem Ausbringen von 30-40 Prozent zu rechnen haben, erzielt das Ausland ans dem Rohprodukte 60-90 Prozent verkaufsühige Ware.

Der billigere luxemburger Schiefer bedrängt den Absatz des heimischen Produlites selbst in ummittelbarer Nähe der Gruben und in Absatzgebieten, die ron altersher nur die Terwendung deutschen schiefermaterials kannten.

Die luxemburger Schieferguben können aus folgenden Gründen billiger liefern als die westfälischen Betriebe: vor allem ist das natürliche Torkommen, wie bereits erwähnt, erheblich mächtiger und in Torrichtung und Abbau leichter zu bearbeiten als dasjenige der weitaus meisten westfälischen Gruben. Die Gewinnung geht zwar in beiden Gebieten unterirdisch ror sich, aber das Gestein selbst ist in Luxemburg viel ergiebiger, der Abfall viel geringer, die Ausbeute deshalb bedeutend lohnender als im westfëlischen Revier. Die Schiefervorkommen sind in Luxemburg $1 \mathrm{~m}$ ein vielfaches mächtiger als in den Revieren der westdeutschen Schieferindustrie, in denen das flachere Einfallen die Gewimnung erschwert und rerteuert, und die Reinausbente an Dachschiefer aus dem gleichen Raummaß Rohschiefer steht im westfälischen Schiefergebiet hinter derjenigen im luxemburger Gebiet erheblich zurïck. Der luxemburgische Schiefer ist in sehr dümnen Platten spaltbar. Es kann somit auf die Waggonladung eine erheblich gröBere Stückzahl verfrachtet werden, wodurch sich wiederum der Transport wesentlich verbilligt. Die luxemburger Schieferindustrie macht sich durch Umkartierung dieser Ladungen auf Station Ruwer bei Trier die Torteile des den deutschen Gruben gewährten Ausnahmetarifs für Dachschiefer zunutze. Die Ladungen werden bis zu dieser Station gebracht, dort umkartiert, d. h. mit deutschen Frachtbriefen versehen und dam unter dem Genuß des Ausnahmetarifs bis in den Osten, Norden und Süden Deutschlands weiter verschickt. Durch Anfwendungen für soziale Zwecke ist die luxemburger Industrie nicht belastet, während im westfälischen Schieferbergbau für die Arbeiter vom Arbeitgeber pro Jahr und Arbeiter 172 Mark aufgebracht werden mïssen.

Der luxemburger Schiefer wird endlich unter dem Namen „,Obermoselschiefer" eingeführt, wodurch der Anschein erweckt wird, als handle es sich um eine bekannte inländische Qualität. Hierdurch werden Täuschungen in großen Maße hervorgerufen; diese werden noch dadurch gefördert, daß diese Bezeichnumg leider als Warenzeichnung ordnungsgemäß eingetragen ist. Diese Einfuhr in Verbindung mit der rlurch die bestehende Zollgesetzgebung besonders begünstigten Einfuhr aus dem übrigen Ausland verhindert die uralte westfälische Schieferindustrie in ihrer gesunden Entwicklung und bedroht sie geradezu in ihrer Existenz.

Noch ungünstiger liegen die Terhältnisse für die Schieferplatten- 
industrie. Fïr Platten ron größerer Ausdehnung, wie sit z. B. für Billardtafeh gebrancht werden, ist in den letzten Jahren der $1 \mathrm{Vett}$ bewerb Italiens vollstandig erdriickend geworden. IIan liann wohl behaupten, daß fast der ganze bedarf ron Italien gedeclit wird. sowohl italienische wie anch belgische und Schwoizer Worke schicken aus Zollersparnis die rohen Śchioferblüclie an ihre Verarbeitungsstätten in Deutschland, um sie hier zu allen möglichen Plattenartilieln verarbeiten zu lassen. Belgien schicht seine Rohschiefer nach Lnxemburg; dort werden sie in den labriken fertiggestellt und gelangen so in den GenuB der zollfreien Einfuhr nach Dentschland.

Ein außerordentlicher Mißstand ist auch die Umgebung der Zollvorschriften für gesägte Schieferplatten; diese werden liantig geschnitten, jedoch nachtrïglich mit spitzhammer fein gespitzt. Anf diese Weise ist die Tonne gesïgter Platten anstatt mit 30 Mark nur mit 10 Mark zu rerzollen. Wenn auch das italienische Material den westfälischen l'latten in der Qualität nachsteht, so ist der Preisunterschied doch so enorm, daß ein Wettbewerb vollständig ausgeschlossen ist.

Berliner Firmen beziehen itahenischen Schiefer in jeder Größe und Stärke zu 12 Nark frei Haus. Ton diesem Betrage entfüllt auf

Verpackung . . . . . . . . . . . 1,25 Mark

auf Fracht, pro 100 Kilogramm 4,45 Mark . . . 3,60 ,

fiir Anfuhr in Berlin . . . . . . . . . . .,- 30 ,

zusammen pro Quadratmeter 5,15 Mark.

Es bleiben also für Schiefer übrig . . . . . 6, 65, ,

Zu diesem Preise ist es für die westfälischen Gruben rollständig ausgeschlossen, solche Platten herzustellen und zu liefern. Zudem müssen die Platten nach der allgemeinen Stückgutklasse nach Berlin verfrachtet werden.

Um diesem Übelstande etwas abzuhelfen, war von der Handelskammer zu Amsberg eine Erhöhung des Zolles auf italienische Schieferplatten angeregt worden. Dieser Antrag wurde leider mit folgender Begründung abgelehnt: ,Nach dem Ergebnis der Ermittlungen sind die deutschen Schieferwerke nicht imstande, die in der heimischen Industrie, namentlich in der Elektrotechnik und Billardfabrikation benötigten Schieferplatten in der erforderlichen Güte und Menge zu liefern." Diese Ermittlumgen sind anscheinend bei den Berliner Firmen, die fast nur italienisches Material rerarbeiten, eingeholt. Die Schieferbau-Alitiengesellschaft Nuttlar war jahrelang in der Lage, den Bedarf der allgemeinen Elektrizitätsgesellschaft zu decken, und ist nur deshalb als Lieferantin ausgefallen, da die limitierten Preise mit den Selbstkosten nicht mehr in Einklang zu bringen waren. Man würde sich im westfälischen Schiefergrubenbezirk überzeugen können, daß bei lohnender Marktlage in einiger Zeit sich die Produktion von Schieferplatten verdoppeln ließe. Seit Jahren vorgerichtete Gruben warten auf eine günstige Geschäftslage. Wenn aber Italien Billardplatten für 12 Mark pro Quadratmeter anbietet, für die die westfälischen Werke bei geringem Verdienst 17 Mark ansetzen müssen, so ist eine Betriebs - 
rrweiterung ausgeschlossen. Ebenso verhält es sich bei Platten für Elelitrotechnik. Die Selbstkosten für westfälische roh bearbeitete Platten bei einer stärke von 20 Millimeter stellen sich auf 6,28 Mark pro Quadratmeter. Der Preis für italienische Platten gleicher Stärke beträgt frei Köhn inklusive Zoll je nach Cröße 3,07, 3,17, 3,38, 3.85 Nark pro Quadratmeter. Die Tatsache, daß in letzter Zeit mehrere schieferplattentrerke des Sinerlandes zum Erliegen gekommen sind, nicht aus llangel an Rohmaterial, sondern infolge der drückenden Lionkurrenz des Auslandes, scheint unbekannt geblieben zu sein und ist jedenfalls nicht gewürdigt worden.

Auch das Reichsschatzamt ${ }^{1}$ stellte Erhebungen ản über Italiens Tonkurrenz auf dem Schieferplattenmarkte. Das Ergebnis dieser Erhebangen läßt sich aber in heiner Weise mit den wirklichen Verhältnissen in Einklang bringen. Das Reichsschatzamt stellte fest: ,Die angestellten Erhebungen haben ergeben, daß der italienische Schiefer zwar infolge der geringeren Arbeitslöhne der italienischen Industrie als Rohware billiger ist als der inländische Schiefer, daß sich aber die Herstellung der fertigen Ware daraus - Platten, namentlich für technische Zwecke - teurer stelle, wie bei der Terwendung inländischen Rohmaterials.

Zunächst kommt die erhebliche. den Preis der Rohware oft übersteigende Tertenerung durch Fracht und Zoll in Betracht. Ferner enthält der italienische Schiefer - dessen Vorzug in seiner geringeren Hürte, sogenannten Fettigkeit besteht - oft unerwünschte Beimischungen, z. B. Eisen, die die Bearbeitung erschweren oder die Platten für gewisse Zwecke überhaupt unbrauchbar machen. Die geringere Härte erleichtert zwar die Bearbeitung beim Spalten, Schneiden, Hobeln, Schleifen und namentlich beim Bohren, sie bewirkt aber andererseits, daß der Schiefer leicht unregelmäßig spaltet und schon beim Transport in der Richtung der Schichten platzt. Die Folge davon ist, daß die Herstellung fertiger Platten in bestimmter Stärke daraus schwieriger ist, als aus westfälischem Naterial. Sehr oft gelingt nicht die Anfertigung einer Platte in der beabsichtigten Stärke, die Rohplatte muß vielmehr immer weiter, bis zur Erzielung einer dümeren Platte behandelt werden. Der bei der Weiterverarbeitung entstehende Abfall ist daher sehr groß; er beträgt fast die Hälfte der Rohware, in einzelnen Fällen sogar beträchtlich mehr. Nach den im Betrieb einer Firma gemachten Beobachtungen betrugen die bei der Terarbeitung des ausländischen Schiefers entstehenden Abfälle allein beim Hobeln etwa zwei Fünftel bis drei Fünftel der Rohware. Bezüglich des Alfalles, der keinerlei Verwertung gestattet, dessen Beseitigung vielmehr noch Kosten verursacht. muß der inländische Bezieher nicht nur den Rohwarenpreis, sondern natürlich auch den Zoll und die Fracht bezahlen. Außerdem ist er dem ausländischen Lieferer gegenüber hinsichtlich mangelhafter Beschaffenheit des Materials ziemlich machtlos. Alle diese Cmstände beeinflussen die Her-

1 Aus Akten der H.K. zu Arnsberg. 
stellungskosten fiir die fertige Ware derart. dab damit ein Wetthewerb gegen das inländische Erzeugnis nur dann möglich ist, wemn dem italienischen schiefer seiner leichteren Bohrbarkeit wegen für bestimme Zweclie der Torzug gegeben wird. Nach den Angaben einer. der gröbten Fimmen der elektrotechnischen Industrie sind Preise der Fabrikate aus inländischen und ausländischen Schicfer ziemlich gleich."

Auf dieses schreiben des Reichsschatzantes ist zunächst zu bemerken, daß sich die Untersuchung der Angaben lediglich auf Informationen bei denjenigen Werken beschränkt hat, die naturgemäl. ein großes Interesse an der Abweisung unserer Anträge haben. Würde man in ähnlicher Weise eine Besichtigung der Werlie rorgenommen haben, die lediglich deutsches Material verarbeiten, so wïrde sehr bald festrostellt worden sein, daß italienische Schiefer bei der Verarbeitung bei weitem niclit so viel Abfall liefern, wie es bei unseren Platten der Fall ist. Die Schieferung ist bei italienischer Ware entschieden gleichmïBigex als bei westfälischer Ware. Zur Herstellung einer Platte ron ca. 1 Quadratmeter Inhalt müssen die Stücke in der Crube auf mindestens 50 Villimeter ausgeschlagen werden. Ein derartiger Materialverlust wird bei italienischem Schiefer nicht nachzuweisen sein. Zur Widerlegung dex Behauptung, daß ein Wettbewerb grgon Italien unter den hentigen Verhältnissen schon möghch sei, ist zu bemerken, daß die größte der Berliner Firmen der Elektrizitätsbranche früher zu den Almehmern der Schieferbau-Alitiengesellschaft Nuttlar zählte. Die Fima ist aber abgesprungen, da es für Nuttlar vollständig ausgeschlossen war, in die Preise der Berliner Fonliurenz einzutreten. Beispielsweise wird in den Briefen der ausländischen Lieferanten ausdrücklich hervorgehoben, dab der Schiefer frei ron allem sichwefelkies usw. sei und erstklassiges Material, während das Reichsschatzant hinsichtlich des italienischen Schiefers das Gegenteil behauptet. Den Abfall, den die Terarbeiter des ausländischen Materials haben, haben die westfälischen Werke auch. Die westfälische Schieferindustrie Veschede rechnet in ihrem Betrieb beispielsweise mit 70-75 Prozent schrot ron dem gewomnenen Rohschiefer. Der einzige Unterschied ist meines Erachtens der, daß der italienische Rohschiefer infolge der geringeren Arbeitslöhne usw. billiger angeboten werden kann wie unser heimischer Schiefer.

\section{Konkurrenz anderer Bedachungsmaterialien.}

Einen nicht gering zu schätzenden Konkurrenten findet der Dachschieferindustrielle in dem künstlichen Bedachungsmaterial, dem Ziegel und dem seit einigen Jahren auf den Markt greworfenen Kunstschiefer. Lange Zeit galt das Schieferdach neben den viel hostspieligeren Metalldächern als das vornehmste aller Dächer. Die Leichtigkeit, die Dichtheit, Haltbarkeit und Feuersicherheit eines mit gutem Schiefer gedeckten Daches, die Fähigkeit des Schiefers, sich jeder Dachform anzupassen, sicherte diesem ron Anbeginn einen hervorragenden Platz unter allen Bedachnngsmaterialien. Jetzt wird ihm dieser Platz mehr und mehr streitig gemacht. In erster Linie geschieht es ron dem Ziegel-

Plümpe, Schieierindustrie. 
dach. Toch bis in die letzten Jahrzehnte konnten die Dachziegel wegen ihrer schwere, ihres mangelhaften Verschlusses und ihrer schwerfälliglieit insbesondere bei Eindeckung schiefwinkliger oder gehogener Flächen mit dem Dachschiefer nicht in Nettbewerb treten. Erst in neuerer Zeit ist das Ziegeldach bei ebenen Dachflächen als thenbürtiger Gegner aufgetreten. Seit die Dachziegel in Form und Farbe wesentliche Terbesserungen erfahren haben, ist die Verwendung in auffallend starker Zunahme begriffen. Auch der Preis und die leichte Herstellungsart sprechen an vielen Stellen für den Ziegel. Dazu kommt, dab die heutige Geschmacksrichtung dem Ziegeldach geneigt ist. Die frischrote Färbung eines Ziegeldaches rerursacht mit den jetzt allgemein beliebten weißen Putzflächen der Außenwände freistehender Häuser ein farbenfreudiges und oft anmutiges Zusammenwirken. Man vergißt freilich dabei, daß die schönste Ziegehöte nach wenigen Jahren zu verschwinden pflegt und an deren Stelle ein bescheidenes, liaum noch als Farbe wirkendes Braun tritt. Außerdem ist noch zu beachten, daß die Ziegel sehr porös sind, leicht Wasser aufnehmen und infolgedessen bei plötzlichem Temperaturwechsel, z. B. im Winter, leicht abbröckeln und springen. Es sind daher sehr bald Reparaturen notwendig, die das Dach rertenern, während ein Schieferdach jahrelang ohne jede Reparatur auskommt.

Es ist angebracht, an dieser Stelle einen Tergleich zwischen Schiefer und Ziegel anzustellen.

Zunächst übertrifft der Schiefer den Dachziegel hinsichtlich seiner Leichtigkeit bei weitem. Die Belastung eines Quadratmeter Daches durch guten Schiefer braucht nicht über 22 Kilogramm zu betragen, während die Belastung durch Ziegel zwischen 35 und 60 Kilogramm zn schwanken pflegt. Es wird also ein Dachgerüst viel weniger belastet und braucht weniger liräftig hergestellt zu werden, wenn ein Schieferdach angebracht werden soll, als bei einem Ziegeldach. Noch günstiger stellt sich das Terhältnis dadurch, daß ein Schieferdach eine viel geringere Dachneigung rerträgt, als ein Ziegeldach. Bei einem mit Schiefer gedeckten Satteldach braucht die Firsthöhe nur ein Fünftel der Gebäudetiefe zu betragen, bei einem Ziegeldach dagegen mindestens ein Drittel. Hierdurch können die etwas höheren Kosten für Schiefereindeckung gegenüber der Ziegeleindeckung vielfach reichlich ausgeglichen werden.

Die Dichtheit des Schieferdaches ist viel vollkommener als die eines Ziegeldaches, und zwar sowohl gegen Regen und Schnee als besonders auch gegen Staub und PuB. Diese letzten Erscheinungen fallen besonders in Städten ins Gewicht.

Auch die Haltbarkeit muB besonders hervorgehoben werden. Freilich ist hier Voraussetzung, daß guter Schiefer, wie er in Westfalen und in anderen Teilen Deutschlands vorhanden ist, verwandt wird und der Schieferdecker sorgfältige Arbeit leistet. Von welcher Dauer eine gute Schiefereindeckung sein kam, beweist die Tatsache, daß sich in der Gegend von Nuttlar und in andern Teilen des Sauerlandes Bauernhäuser und Kirchen befinden, die nachweisbar ror meh- 
reren . Jahrhunderten mit sichiefer gedeckt worden sind und arst in den letzten Jahren ernenert wurden.

Ein woiterer Torzug des Schiefers ist stint Anpastungsfähigkrit. Auber Mrotallplatten vermag kein bedachungsmaterial den geliummonten und gelogenen liähen eines Daches sich gleich gut anzupassen und seine Unrißlinie in so scharfer Form zur Erscheinung zu bringen, als der Schiefer. Die Findeckung der reichbewegten, oft mehrfach mit Schweifkuppeln ausgestatteten Kinchtimme wiude auf große Schwierigkeit gestoßen sein, wem sich der Dachschiefer nicht als ein Baust off dargeboten hätte, der jeder Dachform, jeder Dachneigung und jedter kühnen Verbiegung des Daches sich willig angeschlossen hätte. Besonders kam es dabei auf die Wichtigkeit der Mulden und Kohlen an. die der sichiefer trefflich herzustellen remochte.

Die Torzüge, die ein schieferdach gegeniiber dem Ziegeldach besitzt. sind. wie wir gesehen haben, tatsächlich so groß, dis der sichiefer wohl verdient, mehr bei der Bedachung benutzt zu werden. Nan kann sich daher nur wondern, daß selbst an Orten der Produlition statt schiefer Ziegel in Anwentung liommen. Ich habe an solchen Orten, wo schiefer gewonnen wird. und in deren nächster Umgebung Häuser gesehen, die mit Kiegel gedeclit waren, die ron auswärts bezogen werden muBten. während man den Schiefer aus nächster Nähe hätte beziehen können. Schuld daran ist einerseits die große Vorliebe des Publikums für bunte Dächer, die völlige Unkemntnis der Berölkerung in bezug auf die Torzüge, die ein Schieferdach bietet, anderseits aber die rorzügliche Reklame der Ziegeleien, mit der das kaufende Publikum überschwemmt und betört wird, wohingegen von seiten der westfälischen Schiefergrubenbesitzer nichts oder doch nur sehr wenig getan wird.

Sache der Grubenbesitzer ist es, durch Aufklïrung der leitenden Baukreise und der Bevölkerung mittels Reklameschriften dahin zu wirken, daß dem schiefer mohr Beachtung geschenlit wird. Die Torzüge des Schiefers miißten darin klar und deutlich hervorgehoben und genaue Berechnungen der Kosten pro Quadratmeter angegeben werden. In Kampfe gegen den Ziegel mïßten aber anch die Dachdeckermeister den Schiefergrubenbesitzer tatkräftig unterstuitzen. Auf diese Weise würle sicher mit manchem Vorurteil gebrochen werden und das Schieferdach an Ansehen gewinnen.

Als gefährlicher Konkurrent ist auch seit einigen Jahren ein anderes Bedachungsmaterial den Schiefergruben in dem Eternitschiefer. Asbestzementschiefer oder Kunstschiefer entstanden, der besonders im östlichen Teile Deutschlands rerwendet wird. Dieses Material wird von verschiedenen Unternehmungen hergestellt und rersucht. mit marktschreierischer Reklame das Publikum für sich einzunehmen. Das Material besteht aus einem Gemisch ron Asbestfasem und Zement, läßt sich färben und kann in ähnlicher Weise wie Schiefer zur Dachdeckung benutzt werden. Die Platten haben eine gewisse Ähnlichkeit mit Schiefer. wenn auch selbst das nicht fachmännisch geschulte Auge die beiden Materialien ohne weiteres unterscheiden liann. 
Del Aufbau der Asbestzementplatten soll analog der Naturschieferfelsbildung geschehen, indem anf der Pappen- oder Papiermaschine Lage für Lage gebildet wird. Diese Kunstprodukte werden unter Bezeichnungen wie Eternitschiefer, Asbestzementschiefer, Thümmelitschiefer. Asbestlimstschiefer, Asbestschiefer rerbreitet und angeboten. In der Reklame preisen die Hersteller der Asbestzementplatten diese als ein Naterial an, das die guten Eigenschaften der Schiefer habe, seine Mängel aber vermeide und billiger sei als Schiefer.

\section{Interesselosigkait der Behörden.}

Ein weiteres wichtiges Moment zur Beurteilung der wirtschaftlich ungünstigen Lage bietet die Interesselosigkeit der staatlichen und kommunalen Behörden dem Schiefer gegenüber, der sich seit undenklichen Zeiten als Bedachungsmaterial bewährt hat. Oft sind es Sparsamkeitsrücksichten, die die Behörden veranlassen, Ziegel usw. als Bedachungsmaterial zu verwenden, obgleich eine solche Bedachung, wenn gut ausgeführt, keineswegs billiger ist als ein Schieferdach.

Beispielsweise hat im Jahre 1909 das badische Finanzministerium, das Ministerium der auswärtigen Angelegenheiten die unterstellten Baubehörden angewiesen, mit Rücksicht auf die badische Ziegelindustrie nich' mehr wie bisher Schiefer, der von auswärts bezogen werden mußte, sondern Ziegel bei Staatsbauten verwenden zu lassen. Auch beim Neubau des Oberbergamts in Dortmund, einer Stelle, bei der doch die Schiefergruben wärmste Unterstützung hätten erwarten dürfen, fanden Ziegel Terwendung. Fast sämtliche Bahnwärterhäuschen an der Ruhrtalbahn sind mit Falzziegeln gedeckt, obschon sich diese Deckungsart in der rauhen Gegend des Sauerlandes wenig bewährt und Schiefer aus nächster Nähe hätte beschafft werden können.

Tergegenwärtigt man sich, wie viele Bauten von Staats- und Kommunalbehörden jährlich ausgeführt werden, so kommt man leicht zu dem Schluß, daß, wenn der größte Teil mit Schieferdach versehen würde, der deutschen Schieferindustrie geholfen werden könnte. Ist rloch nach dem Urteile von Fachleuten das Schieferdach, wenn auch nicht billiger, dafür aber dauerhafter und, was von Wichtigkeit ist, im Verbrauch rentabler und kann außerdem im Aussehen mit jedem andern Bedachungsmaterial konkurrieren. Auch Privatlente würden, wenn sie sehen, daß von den Behörden Dachschiefer bevorzugt wird, allmählich dazu übergehen, ihre Dächer mit Schiefer decken zu lassen.

Leider mul festgestellt werden, daß sich die Torliebe der Behörden nicht a lein auf buntfarbiges Material, Falzziegel, Zementplatten usw. zur Bedachung erstreckt, sondern auch in vielen Fällen, wo die Terwendung ron Sichiefer nicht umgangen werden konnte, rie Behörden dem ausländischen Schiefer den Vorzug geben, selbst wemn Angebote ron besserem deutschem Material zu angemessenen Preisen rorliegen. Leider haben dabei manchmal Beamte die entscheidende Stimme, die volkswirtschaftliche Rücksichten nicht in Erwägung ziehen und sich von der Reklame blenden lassen. 
Bei dew grobherzoglichen Banant in Darmstart wurde für die Bedachung des Proviantmagazins cine schioferlieferung ansoeschrieben, für die silbacher Schiefer angeboten wurde. Auf 11 unsch des bauantes wurlen eine Anzahl Atteste eingereicht, durch welche die Daur. haftigkeit des schiefers hinreichend bewiesen wurde. Trotzhlem erhielt das westfülische Schieferwerk die Nachricht, daß die Zeugnisse nicht genügende sicherheit für die Wetterbeständigkeit des Schiefers böten. Da ein amtliches Attest die gute Beschaffenheit res Sichiefers nach mehr als hundert Jahren bestätigte und auch das Angebot zu angemessenem Preise erfolgte, so ist wohl anzunehmen, daß andere Gründe für das ablehnende Verhalten der Baubehörde vorherrschten und bestimmend waren. Es wurde lnxemburger Schicfer vorgezogen. obgleich dieses Material teurer als das westfälische angeboton war. Überhaupt sind seit dem Jirla lo des Kriegsministeriums, der verfügt, da $B$ luxemburger schiefer als Bedachungsmaterial nicht ausgeschlossen werden soll, im Reichsland und in Süddeutschland sehr große Militärlieferungen an Luxemburg gefallen.

Wiederholt sind die in Frage kommenden Bchörden gebeten worden, bei der Ausführung von öffentlichen Gebäuden dem einheimischen Schiefer ror dem ausländischen den Vorzug zu geben. Es können rerschiedene Beispiele dafür angegeben werden, dab die betreffenden Baubehörden, und zwar gerade solche, die dem Ministerium für öfentliche Arbciten unterstellt sind, im gegenteiligen Simne verfahren, indem sie luxemburger schiefer verwandten.

Doch nicht luxemburger Schiefer allein ist es, dor dem dentschen, besonders dem westfälischen Schiefer den Absatz erschwert, auch sonstige ausländische Schiefer werden in großen Mengen eingefïhrt und, wie mir ron verschiedener Seite mitgeteilt wurde, selbst bei amtlichen Banten rerwendet. Neuerdings schien die Hoffnung begründet, daß bei staatlichen Bauten der deutsche Schiefer in erster Linie berïcksichtigt werden sollte, als nämlich im Jahre 1912 gelegent lich der Beratung der Wehrvorlage im Reichstage das Kriegsministerium auf einen rom Abgeordneten Pauly geäuBerten entsprechenden Wunsch die Zusage gab, daß in Zukunft der deutsche Schiefer bei den bevorstehenden militärischen Bauten in erster Linie Berücksichtigung finden sollte. Diese Erklärung wurde von der westfälischen Schiefer industrie mit großer Genugtuung aufgenommen, und man knüpfte daran die Erwartung, daß das Beispiel des Kriegsministeriums bei den Bauten in anderen Ressorts nachgeahmt werden würde. Die Stimmung ist aber bald einer großen Enttäuschung gewichen, als bekannt wurde, claß gerade von seiten des Kriegsministeriums, trotz Abgabe der Zusage, im entgegengesetzten Sinne verfahren wird.

Die Nachricht von der abermaligen Bevorzugung des luxemburger Schiefers durch die militärische Baubehörde hat in der Schieferindustrie eine tiefe Erbitterung hervorgerufen, wie verschiedene ÄuBerungen aus den Kreisen der Schieferindustrie erkennen lassen. Z. B. ist für den Neubau der Kaserne des Regiments der Jäger zu Fuß, Nr. 8 zu Trier ausdrücklich luxemburger Schiefer vorgeschrieben 
worden. Ein derartiges Vorgehen erscheint als eine bedanerliche Berinträchtigung der Interessen unserer deutschen schieferindustrie.

Es gewinnt den Anschein, daß unsere Interessen aus allgemein politischen Frwägungen und wegen des Interesses, das die Dentsche GroBindustrie in Lnxemburg hat, den Wïnschen der luxemburgischen Regierung geopfert werden.

Bei Aufbringming der Vittel für Staatszwecke, bei der Belastung lurch staatliche Maßnahmen, zum Schutze anderer Erwerbszweige wirl die westfälische Suchieferindustrie stets herangezogen, bei der Erteilung von Staatsaufträgen aber leider nicht in wünschenswertem Lnfange bericksichtigt.

\section{Hohe soziale Lasten.}

Schwer zu leiden haben viele Schiefergruben unter den enorm hohen Jasten für soziale Fürsorge im Interesse der Arbeiter. Diese hohen Beträge beeinflussen in erster Linie natürlich die Leistungsfähigkeit eines Unternehmens derart, daß zunächst diese hohe Summe für soziale Lasten aufgebracht werden muB, ehe an einen Gewinn des Unternehmers gedacht werden kann. Anderseits aber sind die hohen Beiträge zur Knappschaftskasse fuir die Arbeiter ein Grund, andere Arbeit als im Schieferbergban zu suchen, wodurch eine Ausdehnung des Betriebes und die Inangriffnahme größerer AufschluBarbeiten verhindert wird. Daß der ungünstige Stand des Knappschaftsvereins einen schlechten Einflub auf die Gruben ausübt, liegt klar auf der Hand.

Im letzten Geschäftsjahre muBte die Schieferbau-Aktiengesellschaft .. Nuttlar" an die Knappschaftsliasse 21 345,30 Mark zahlen $=$ rund 5,7 Prozent des Aktienkapitals. Außertem waren aufzubringen 6203,12 Mark für die Cnfall-. Invaliden- und Angestelltenversicherung. Im ganzen waren 27548,42 oder 202,56 Mark pro Kopf im Interesse der trbeiter pro Jahr aufzubringen. Diesé Summe macht ungefähr 7,5 Prozent vom Alitienliapital aus. Es müssen mithin erst 7,5 Prozent für soziale Lasten verdient werden, bevor an eine Gewinnrerteilung an die Aktionäre gedlacht werden kann. Die Aufstellung gibt ancli ein Bild davon, wie die Beträge seit 1883 inmer mehr angeschwollen sind:

\begin{tabular}{|c|c|c|c|c|c|c|c|c|}
\hline 1888 & 29,30 & Marti & 1893 & 69,22 & Mark & 1903 & 89,62 & Mark \\
\hline 1584 & 25,81 & .. & 1894 & 70,46 & .. & 1904 & 96,07 & , , \\
\hline $1855^{\circ}$ & 32,61 & ., & 1895 & 70,51 & .. & 1905 & 101,13 & \\
\hline 1866 & 38.51 & .. & 1896 & 70,04 & ,, & 1906 & 99,07 & \\
\hline 1587 & 41.71 & ., & 1897 & 64,91 & .. & 1907 & 109,56 & \\
\hline 1858 & 43,99 & .. & 1898 & 68,27 & .. & 1908 & 148,32 & \\
\hline 1589 & 45,35 & , & 1899 & 74,32 & ., & 1909 & 177,10 & \\
\hline 1890 & 48,25 & .. & 1900 & 74,22 & ., & 1910 & 170,10 & \\
\hline 18.91 & 60,56 & .. & 1901 & 71,99 & ., & 1911 & 172,44 & \\
\hline 1592 & 60,78 & , & 1902 & 91,10 &. & 1912 & 169,08 & \\
\hline & & & & & & 1913 & 202,56 & \\
\hline
\end{tabular}

Und wie gering sind die Leistungen der Knappschaftskasse! 


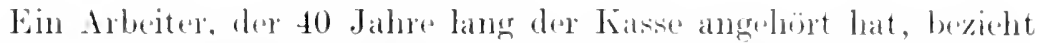
nur 18 . Mark den Monat Pension. Es kann nicht davon die Rede sein, daß der stand der Knappsehaftsrereine in allgemeinen ungünstig sei. Jieses ist nur bei dem Briloner Knappschaftsrereine der Fall. Vielleicht liegt die heutige geringe Leistungsäligheit claran, da lo

1. in früheren Jahren zu niedrige Beiträge erhoben worden sind, die einen Pensionsbezug nicht rechtfertigen,

2. sich die Zahl der Arbeiter im Laufe der Jahre immer mohr verringert hat, dagegen

3. die Kahl der Witwen und Waisen stark gestiegen ist.

Die Hauptschuld an der ungünstigen Lage des Knappschaft:vereins tragen die Blejerzgruben zin Ramsbeck. Ramsbeck mit seiner Umgebung stellt das gröbte Kontingent der Tuberliulosefälle infolge seiner gesundheitsschädlichen Industrie. Arbeiter, die vom 14. Lebensjahre ab in der Industrie (Erzanfbereitung) und rom 17. Jahre ab in der Erzgrube beschäftigt waren, und dies ist die Melnzahl, sind in Alter von $28-42$ Jahren gestorben, nachdem mehrere ron ihmen schon lange. Jahre invalid geworden waren. Die Kahl der sterbefälle 1911 betrug 43, daron starben 20 , also fast 47 Prozent, an Tuberkulose. Durch die in Jahre 1905 erfolgte Einstellung des Hüt tenbetriebes des Ramsbecker Erzbergbanes wurde die Arbeiterzahl von 1200 auf 500 (ingeschränkt. Die Einwohn@rahl der Gemeinde sank ron 2349 in Jahre 1905 auf 1788 im Jahre 1912, ging also in 7 Jahren um 24 Prozent zurïck. Die Zahl der Geburten fiel ron $93 \mathrm{im}$ Jahre 1905 auf $44 \mathrm{im}$ Jahre 1911, die Heiraten ron $23 \mathrm{im}$ Jahre 1905 anf $10 \mathrm{im}$ Jahre 1911.

Diesen Cmständen ist es zuzuschreiben, dab, wie aus dem Auszug aus den Rechnungen der Arbeiter-Pensionskasse zu ersehen, am Jahresschlusse 1913 auf 1000 alitive Vitglieder bei 291 Invaliden s02 Witwen und 426 Waisen entfielen. Dab derartige Verhältnisse die finanzielle Lage des Knappschaftsvereins ungünstig beeinflussen, liegt klar auf der Hand.

Außerdem ist den älteren bergantlich verhehenen Schiefergruben durch neue micht mehr dem Bergregal unterstehende Werke eine bedeutende Konkurenz erwachsen. Die Werke oder Mitgheder, die der Bergbehürde nicht unterstellt sind, brauchen nur einer Krankenkasse anzugehören. Die Besitzer dieser Werke stehen sich folglich um die Beträge, die zur Pensionskasse gezahlt werden müssen, besser, können infolgedessen anch ihre Preise für Schiefer ganz anders festsetzen als diejenigen Werke, die fer Bergbehörde unterstellt sind. Dagregen haben sie den einen Tachteil, daß ihnen das Enteignungsrecht nicht zusteht.

\section{Uneinigkeit und Preisunterbietung in den heimischen Schieferindustrie- kreisen.}

Bedauerlich ist, daß zu den vielen widrigen Lmständen, die eimer günstigen Entwicklung der Schieferindustrie entgegenwirken, auch noch imnerhalb der Industriekreise, bei den schiefergrubenbe- 
sitzern. Uneinigkeit und Preisunterbietmngen himzutreten, die sie vollends zum Erliegen bringen können. Man sollte annehmen, ein Industriezweig. der auf einen kleinen Teil unseres Taterlandes beschänlit ist. würde, wenn er sich in seiner Existenz von außen her bedroht sieht, sich um so fester zusammenschließen, um durch eine Terkaufsereinigung oder ein sindikat seinen gesamten Absatz zu annehmbaren Preisen zu regeln und auf diese Weise wenigstens einen kleinen Torteil zu erringen. Wünschenswert wäre dies namentlich in der Schieferplattenindustrie, die mit besonders schwierigen Verhältnissen zu kämpfen hat. In der Dachschieferindustrie sind Preisunterbietungen an der Tagesordnung. Diejenigen Werke, die unter gïnstigen Bedingungen produzieren, sei es, daß sie mit Hilfe moderner techmischer Hilfsmittel die Gestehmingsosten auf ein Minimum reduzieren oder, wie es bei einem seit eimigen Jahren bestehenden Werke der Fall ist, nicht die hohen sozialen Lasten zu tragen haben. weil sie nicht mnter Aufsicht der Bergbehörde stehen, stellen die Preise so niedrig, daß die andem Nerke gezwungen sind, ihrerseits mit den Preisen herunterzugehen, wenn sie nicht ihren Betrieb einzustellen oder auf Torrat zu arbeiten gewillt sind. Es ist daher auch erklärlich, daß die meisten Grubenbesitzer schon jahrelang mit geringem oder lieinem Gewim, oft sogar mit Unterbilanz arbeiten. Seit Jahren wiederholte Versuche, die Grubenbesitzer zu einem Syndikat zu rereinigen, um auf diese Teise ihre wirtschaftliche Lage zu bessern, scheiterten bisher an ihrer Uneinigleit. Es sind weniger prinzipielle Fragen, als vielmehr kleinliche Bedenken und Beanspruchung ron Torzugstellungen, die eine Tereinigung bisher scheitem ließen. Der letzte Versuch, nachdem fast alle Firmen sich bereit erklärt hatten. schlug z. B. deshalb fehl, weil die .. Westfälische Schieferindustrie" zu Meschede, die bei der willkürlich, ohne Nebengedanken erfolgten Aufstellung der beteiligten Firmen an dritter Stelle anfgeführt wurde. an erster Stelle oder umittelbar hinter der Schieferbau-Aktiengesellschaft Nuttlar stehen wollte. AuBerdem verlangte die Fima als meistproduzierendes Werk gegenüber den älteren Werken einen Torzug ron 5 Prozent in den Terkaufspreisen, eine Sonderstellung, über die sich bei einigem Entgegenliommen noch hätte reden lassen. Überhaupt rersuchte dieses Werk den andern Grubenbesitzem die Bedingungen, unter denen es bereit sei. dem Syndikat beizutreten, zu diktieren, und als ihrem Terlangen bei den Terhandlungen nicht sofort entsprochen wurde, brach sie diese ab, so daß sie Teremigung als gescheitert angesehen werden mußte.

Unter diesen Umständen ist es schwierig, eine Tereinigung der Gruben herbeizuführen. Heute ist die Sachlage in der westfälischen Schieferindustrie folgende: sämtliche Werke, mit Ansnahme der erst seit einigen Jahren bestehenden Firma. haben ilure Preise anf das äuBerste reduziert, so daß durch den Terkauf ihrer Produkte gerade die Herstellungsliosten usw. gedeckt werden. Nur in seltenen Fällen und bei günstiger gelegenen Werken wird ein minimaler Gewimn erzielt. Die geschilderten Verhältnisse lassen lilar genug erkemen. daß 
die Schieferindustrie Westfalens, dieser für das Saurland notwendige Industriezweig, unter den denkbar ungïnstigstem Berlingungen besteht und sich geradezn in einer Totlage befindet. Die Einschränkung und Einstellung des Betriebes mehrerer Werke in nenerer Zeit ist ausschließlich anf die widrigen Verhältnisse zurïclizuführen, unter denen sie zu arbeiten haben.

\section{Reformvorschläge.}

\section{Regelung der Knappschaftskassenverhältnisse.}

Die hohen Beiträge, die rom Briloner Knappschaftsverein erhoben werden, haben bei den dem Verein angehörenden Dachschiefergruben, deren Belegschaft sich durchweg einer besseren Gesundheit erfreut als die demselben Terein angehörende Belegschaft der Ramsbecker Gruben. zu der Erörterung der Frage geführt, ob es zweckmäßig für sie sei, aus dem Terein auszutreten und gemäß § 168a des Allgemeinen Berggesetzes eine Allgemeine Krankenkasse zu gründen. Die beabsichtigte Grïndung fand aber leider nicht die Genehmigung der vorgesetzten Behörde. Unter diesen Umständen erscheint als das einzige Mittel, die traurigen Verhältnisse der Knappschaftsvereine zu bessern, die Zusammenlegung sämtlicher oder wenigstens mehrerer Knappschaftsrereine. Dadurch wïrde eine bessere Ausgleichung der ungünstigen Verhältnisse herbeigeführt werden. Seit einiger Zeit ist die zwangsweise Tereinigung des Briloner Vereins mit benachbarten 5 Vereinen beabsichtigt. Findet ein Zusammenschluß statt, so werden freilich die Mitglieder des Briloner Tereins auf einen Teil ihrer Anrechte verzichten müssen und die Pension wird herabgesetzt. Eine wirkliche Gesundung kann aber nur durch Zusammenziehung sämtlicher Knappschaftsvereine erfolgen. Es ist zu bedauern, daß die neue Reichsrersicherungsordnung die Tereinigung nicht herbeigeführt hat.

\section{Höherer Schutzzoll.}

Der in Jahre 1885 eingeführte Zoll für Dachschiefer hatte auf die deutsche Industrie sehr fördernd gewirkt. Er hat in hohem Maße dazu beigetragen, zur Terwendung deutschen Materials zu erziehen. Deutscher Schiefer kam mehr und mehr in Gebrauch, und unsere heimische Industrie fand den Mut für Verbesserung und Ausdehnung ihrer Werke. Während bis dahin manche Gruben nur geringe Mengen liefern konnten, wurde nunmehr die Dampfkraft in gröBerem Maße eingeführt und eine Anzahl Gruben mit unterirdischem Betriebe und Stollenförderung eingerichtet. Der Schiefer konnte besonders für deutsche Schuppenform in einfacher Deckung in großen Mengen geliefert werden: auch Pechtecke und Achtecke wurden, was für die Praxis wesentlich war, wem auch nicht in größeren Vengen, aber doch hänfiger als früher geliefert. Die westfälischen Gruben eroberten sich nach und nach einen guten Ruf neben den andern deutschen Gruben und dem Material ausländischer Schiefergruben. All dies 
kam nicht in letzter Linie den zahheichen Arbeitem zugute, deren Einliommen und Lebenshaltung sich besserten.

Als alles in bester Entwicklung war, anch begomnen wurde, dem Mangrel an geeigneten Terkehrswegen abzuhelfen, der überall dazu beigetragen hatte, die westfälische sichieferindustrie niederzuhalten, kamen die neuen Handelsverträge und morbereitet, ungeahnt traf msere Industrie der schwere Schlag: die Herabsetzung des Dachschieferzolles ron 1.50 Mark auf 0,50 Mark pro 100 Kilogramm. Ein Grund zu dieser Maßnahme lag nicht vor, da schon vor der Zollherabsetzung belgischer und französischer Schiefer billiger als die einheimiscle Vtare in Deutschland rerkanft wurde. Den auf das beste mnterichteten belgischen und französischen Zwischenhändlern wird es aber leicht gewesen sein, die ErmäBigmng des Zolles zu erlangen, liomten sie sich doch darauf berufen, daß England damals eine Begünstigung genoß. England führte nämlich seine Schiefer auf dem Seewege ein, wofür der ermäBigte Zollsatz von 0,50 Mark zur Anwendung kam.

Die Existenz der westfälischen Schiefergruben war nun auf das schwerste geschädigt und bedroht, und es bedurfte der Anspannung aller Kräfte, mo diesem Schlage nicht ganz zu erliegen. Die sauerländische schieferindustrie würde in die alten kleinlichen Verhältnisse zurückgeworfen worden sein, wenn nicht die Besserming der allgemeinen Geschäftslage und die Verringerung der Einfuhr aus England der Industrie zu Hilfe gekommen wäre.

Die gute Geschäftslage war leider nicht ron langer Daner und der Rückgang der englischen Einfuhr durch rorübergehende Ursachen bedingt. so namentlich durch arge streitigkeiten auf den ausgedehnten Grubenfeldern des Lord Penrhyn in Newwales. Bald machte sich daher wieder ein stärkeres Angebot englischen Schiefers bemerkbar. Die Minderprodulition in England führte zudem einen neuen äußerst gefährlichen energischen Gegner auf den Kampfplatz der Konkurrenz. Fordamerikanischen Produzenten gelang es nämlich, größere Mengen Dachschiefer nach England einzuführen und deutsche Importeure für den Tertrieb amerikanischer Schiefer in Deutschland zu gewinnen.

Der nelle Zolltarif ron 1902, der noch jetzt in Kraft ist, sieht einen satz ron 1.25 Wark pro 100 Kilogramm vor, gleichgültig ob er seewärts oder anf dem Landwege eingeführt wird. Leider ist dieser satz viel zu gering, mm schutz zu gewähren. Die Regierung hatte wohl den Willen zu helfen, scheint jedoch ungenügend und nicht sachgemäB mterrichtet gewesen zu sein. Sämtliche Toraussetzungen, mit denen begründet wurde, daß eine Erhöhung des Zolles über 1,25 Mark hinaus unangebracht sei, beruhten auf mrichtiger Annahme und augenscheinlichen Mißrerständnissen.

Zunächst war es falsch anzunehmen, daß die erhöhte Schiefereinfuhr seit 1892 micht ledighich anf die rertragsmäBige Zollherabsetzung, sondern auch auf die starke Zunahme der Bautätigkeit zurückzuführen sei, welche der inländischen Dachschiefergewinnung 
zugute geliommen wäre. Die Einfuhr wuehs mbeirt durch die Schwankungen der Konjunktur soit 1592 stetigr und ereichte in den Jahren 1901/2, in denen die heimische schieforindustric äuberst darniederlag, einen sehr hohen stand. In der Beurteilung der Jage des Schiefergeschätes hatte die Angabe der Handelskammer zu loblum imegeführt, wonach in deren Bezink die Produktion ron 525000 Mark in Jahre 1893 auf 1683000 Mark in Jahre 1899, also um reichlich das Dreifache, gewachsen sei. Diese Angabe war jeeloch fiir das Jahr 1893 nicht richtig. Es wurden damals mindestens für 1200000 Mark Dachschiefer produziert. Ton 1896-1898 trat mit dor Hochlionjunktur auf allen Gebieten eine bescheidene Besserung anch des Schiefergeschäftes und damit eine höhere Anspanmung der Betriebe ein. Aber schon im Jahre 1899, als noch die (roBindustrie in höchster Blüte stand, trat (in solcher Rïckschlag ein, daB in Handelskammerbezirk Koblenz für rumd 500000 Marki Dachschiefervorräte unverkanft liegen blieben, während dic ausländische Einfuhr noch nehr anschwoll.

Auch die in der Begründung angegebenen Ziffern, die den Preis des Schiefers betreffen, waren irtümliche. Sie beruhten augenseheinlich auf einem Schreibfehler, indem hier der Quadratmeter Schiefer mit dem lanfenden Meter verwechselt wurde. Der laufende Meter Schiefer, ein gebräuchliches Maß für Rohschiefer, ist ein Mcter aufrecht nebeneinander gesetzter roher Dachschiefer verschiedener Größe und declit je nach der Sortierung 2-14 Quadratmeter Dachfläche, war also der groben Verschedenheiten seines Wertes wegen hier zur Aufstellung cimes Vergleiches nicht geeignet. Um richtig zu urteilen. wäre es eine selbstrerständliche Notwendigkeit gewesen, zu vergleichen, wie die Preise ron Schiefer, pro Quadratmeter Dachfläche gerechnet, sich zueinander verhielten.

Die zu cinem Quadratmeter Dachfläche, in rinfacher dentscher Art gedeckt, notwendigen schiefer liosteten im Jahre 1893 je nach Qualität 0,90-1,40 Mark, welcher Preis lis zum Höhejunkte der Konjunktur auf 1,10-1.80 Mark stieg und 1901 wieder auf dem Tiefstand von $0,90-1,40$ Mark angelangt war. Wie zu ersehen, hatte die Hochkonjunktur den Schieferpreis nur un 0,40 Nark pro Quadratmeter gehoben, und diese Preiserhöhung ist auch nur zum geringsten Teile den Grubenbesitzern zugute gelommen, sie wude vielmehr durch hölere Löhne, die gestiegenen Kosten aller Betriebsmaterialien und durch die erhöhten Kosten der Fürsorge für die Arbeiter zim größten Teile aufgewogen.

Der Zolltarif enthäl auch für rohe Schieferblöcke, Schieferplatten und fertige Waren aus schiefer derartig niedrige Sätze, daß deren Erhöhung, um einen besseren Schutz der deutsehen, speziell der westfälischen Schieferindustrie zu erwirken, eine Existenzfrage für die Grubenbesitzer ist. Die dem Zolltarifentwurf beigefügte Begründung führt als Schiefer einführende Länder Großbritannien, Belgien, Frankreich und Österreich-Ungarn an. Für die Einfuhr ron Platten und Schieferblücken kommen aber die Schweiz, Italien und Amerilia nicht weniger in Frage. Wenn auch dem minderwertigen 
Material aus der Schweiz weniger Bedeutung beizumessen ist, so ist die Konliurenz Italiens seit einigen Jahren um so fühlbarer geworden. Die in großer Anzahl rerbreiteten Preislisten Italiens enthalten folgende Sätze: Schieferplatten, roh, gespalten und gesägt, $20-30$ Willimeter stark. in Größe ron nicht unter 1 Quadratmeter Inhalt, 53 Mark pro 1000 Kilogramm, frei Bord Bremen oder Hamburg; beiderseitig gehobelte und gesägte Platten in den gleichen Dimensionen 66 Mark pro 1000 Kilogramm. Hiernach stellt sich der Preis der gebräuchlichsten 20 Millimeter starken Platten ohne Zoll auf 2,92 bzw. 3,63 Mark pro Quadratmeter gleich 55 Kilogramm, frei obige Hafenplätze oder um rund 7 Mark pro Quadratmeter niedriger als derjenige für westfälisches Material ab Grube. Daß bei solchen Preisen jeder Wettbewerb der heimischen Gruben ausgeschlossen ist, braucht nicht näher erwähnt zu werden.

In folgendem sind die Tarifsätze für Schiefer zusammengestellt und auch die Sätze angegeben, die nach Meinung der westfälischen Schieferindustriellen nötig sind, um die deutsche Dachschiefer-, besonders die westfälische Schieferplattenindustrie genügend zu schützen:

\begin{tabular}{|c|c|c|c|}
\hline Nr. & & $\begin{array}{l}\text { Zollsatz nach } \\
\text { dem Tarif } \\
\text { v. } 1902 \text { pro } \\
\text { Doppelzentn. } \\
\text { Mark }\end{array}$ & $\begin{array}{l}\text { Festzusetzen- } \\
\text { der Zoll pro } \\
\text { Doppelzentn. } \\
\text { Mark }\end{array}$ \\
\hline 233 & $\begin{array}{l}\text { Schiefer: rohe Schieferblöcke } \\
\text { Rohe Schieferplatten, roher Tafelschiefer } \\
\text { Dachschiefer (Schieferplatten von mehr als } \\
20 \text { Millimeter Stärke sind als Schieferblöcke } \\
\text { zu behandeln) }\end{array}$ & 1,25 & $\begin{array}{l}5,- \\
8,-\end{array}$ \\
\hline 684 & $\begin{array}{l}\text { Schieferblöcke und Schieferplatten, an einer } \\
\text { oder mehreren schmalen Seiten (Kanten) ge- } \\
\text { sägt (geschnitten), weder gehobelt noch ge- } \\
\text { schliffen oder poliert . . . . . . . . }\end{array}$ & $3,-$ & $12,-$ \\
\hline 688 & $\begin{array}{l}\text { Geschliffene, gehobelte, profilierte ocler sonst } \\
\text { weiter bearbeitete Schieferplatten, bearbeit. } \\
\text { Tafelschiefer, Schiefertafeln auch in Pahmen } \\
\text { aller Art, anderweit nicht genannte Waren } \\
\text { aus Schiefer ohne Verbindung mit anderen } \\
\text { Stoffen . . . . . . . . . . . . . . . . }\end{array}$ & $10,-$ & $15,-$ \\
\hline
\end{tabular}

Bei dem bisherigen niedrigen Zoll für Schieferblöcke, aus denen sich bei ihrer mehr oder weniger leichten Spaltbarkeit ohne erheblichen Aufwand Schieferplatten, Tafelschiefer und Dachschiefer gewinnen lassen, wird die heimische Schieferindustrie eine günstigere wirtschaftliche Lage niemals erreichen. Werden aber sowohl Blöcke wie auch rohe Schieferplatten usw. einem höheren Zoll unterworfen. so wird es sich nicht mehr verlohnen, den Schiefer in Blöcken einzuführen und die Spaltung im Inlande vorzunehmen. Diese Zollerhöhung würde für die ausländische Iionkurrenz nur eine geringe Terteuerung 
ausmachen, der deutscluen, besonders der westfälischen Industre, jodoch ron grobem Nutzen sein.

Durch den erhöhten Zoll anf Tafelschiefer würde win l'eil der dentschen Schiefergruben in die Lage rersetzt, die jetzt murentable l'rodulition an Tafelschiefer wesentlich zu erhöhen. lis wiurdrn nene 'Tafelfabriken entstehen können, die ausschlicßlich dentsches Material verarbeiteten, die aber, wenn sie schon heute vorhanden wären, nicht instande wären, trotz des Zolles auf ausländische Ware, den Wettbeworb mit den Fabrilsen aufzunehmen, die lediglich ausländisches Material auf den Markt bringen. Der Zoll, der jetzt die ausländischen Werke trifft, hat zu einex Terteuerung des ausländischen Produktes nicht geführt und wird ron den mit hervorragend gïnstigen Produktionsverhältnissen begliickten Gruben selbst gretragen.

Die westfälischen (iruben und auch Thüringen liefern ein Material fur Schiefertafeh, das dem des Auslandes nicht nachsteht und bei lohnenden Preisen in größeren llengen produziert werden könnte. Heute wird dex Schicfer, der zu Tafelschiefer verwendet werden könnte, zur Herstellung ron Dachschiefor benutzt. Es lag bisher nicht im Interesse der westfälischen Werlie, Tafelschiefer in gröBeren Mengen herzustellen. Nicht weniger würden die Platten produzierenden Werlie arleichtert aufatmen liömen, da bei einer Zollerhöhung die Auslandspreise nicht mehr hindernd im Wege ständen. Für Billardfabrikation und Elektrotechnili känne dann deutsches, besonders westfälisches Material in Frage, das in ebenso großen Dimensionen - für Billard - und in metallfreiem Zustand - für Elelitrotechnik - geliefert werden liann.

Es ist deshalb dringend wünschenswert, ron allen Seiten darauf hinzuarbeiten, daß die Industriellen selbst in ihrer eigenen Sache gelört werden. Dies ist um so wichtiger, als der Schieferbergbau Westfalens in einsamen, entlegenen und daher meist in sehr ärmlichen Distrikten sich befindet und, wemn auch die darin investierten Summen nicht mit denen anderer großartiger Industrien konkurrieren können, dennoch die Berölkerung weiter Distrikte in den Kreisen Arnsberg, Brilon, Meschede, Wittgenstein auf diesen Erwerbszweig angewiesen ist. Auch muß man immer bei der Taxierung der Schieferbergbaurerhältnisse beachten, daß die Gewinnung in Westfalen unter sehr schwierigen Verhältnissen geschieht und die Industrie selbst sich kaum in einiger Entwicklung befindet, da es ihr erst seit cinigen Jahren gelungen ist, Bahnanschlüsse zu erhalten und Anerkenmung und Verwendung zu finden, während das Ausland billige und bis ins Herz unseres Landes eindringende Wasserstraßen benutzen kann.

Das Gewicht des westfälischen Schiefers ist im allgemeinen etwas größer als das des ausländischen, dafür ist jener aber um so haltbarer. Das Ausland benutzt seine dünnen Platten, um diese nach Deutschland abzustoßen, während es selbst zumeist die starken Platten rerwendet.

Daher wäre es geboten, wenigstens durch Fernhaltung des fremden schiefers den Verbrauch des deutschen Schiefer's zu heben. Durch 
ausreichenden Schutz gegen den zu Wasser als Ballast und zu Lande (ingehenden ausländischen Schiefer würde es der Schieferindustrie in Westfalen möglich sein, sich auszubreiten, da bauwürdiger Schiefer in umfangreicher Menge vorhanden, nur noch nicht genügend aufgeschlossen ist. Die inländische Gewinnung kann den einheimischen Bedarf vollkommen decken, so daß Einfuhr von ausländischem Material vermieden werden kann.

Wie schon bemerkt, ist England mit etwa zwei Dritteln seiner Schieferausfuhr auf Deutschland angewiesen; auch sind die Preise für englischen schiefer durchweg hochgehalten, und ich glaube, daß nicht die Konsumenten im Inland, sondern die englischen Grubenbesitzer den gewünschten höheren Zoll tragen werden. Eine Schädigung der sichiffahrt halte ich für ausgeschłossen. Sollte dies sich geltend machen, so müßte vom volkswirtschaftlichen Standpunkte aus das Interesse für die Arbeiter der deutschen Schieferindustrie demjenigen einiger reicher Reeder vorausgehen. Nuttlar liefert heute schon, wenn auch nur in geringen Quantitäten, Dachschiefer und Schieferplatten bis nach Königsberg, ein Beweis, daß trotz der hohen Eisenbahnfrachten unser Material gegen England konkurrenzfähig ist. Die durch den beantragten Zoll entstehende Verteuerung des englischen Schiefers würde dazu veranlassen, in den Küstenprovinzen darüber nachzudenken, ob man sich nicht an das deutsche Material halten könne.

\section{Bildung einer Verkaufsvereinigung.}

Ein weiteres Mittel zur Verbesserung der unhaltbar gewordenen Preise liegt ohne weiteres auf dem Gebiete des Zusammenschlusses der Schieferindustriellen. Schon in Jahre 1904 wurde eine Anregung gegeben, daß die Platten hersteilenden Gruben des Sauerlandes sich $\mathrm{zu}$ einer gemeinsamen gleichmäßigen Preisfestsetzung vereinigen sollten. Eine derartige Vereinigung, wenn auch nur auf loser Grundlage, liam dann in der Tat für 1904 anch zustande und hatte den gewünschten Erfolg, wurde aber für das Jahr 1905 nicht wieder erneuert. Immerhin hielt eine mäßige Preisaufbesserung aus dem Vorjahre noch an, an deren Stelle seither mehr und mehr eine nach unten gerichtete Bewegung Platz gegriffen hat. Unter diesen Umständen wäre es, da diesem Tersuch ein Erfolg nicht abgesprochen werden kann, für die Grubenbesitzer von höchster Wichtigkeit, mit allen Mitteln darnach zu streben, daß eine Preiskonvention zustande käme, wodurch für Plattenerzeugnisse angemessene Preise streng durchgeführt und erzielt würden.

Für Plattenartikel liegen die Terhältnisse besonders schlecht, so daß hier zunächst ein Zusammenschluß erzielt werden müßte.

Am zweclimäßigsten dürfte es sein, eine gemeinsame Verkaufsstelle zu grimden, die in der Hand eines Tertragsindustriellen und am Orte eines Tertragswerkes läge. Die Unterhaltung einer neutralen Terkaufsstelle würde den Mehrerlös zum größten Teile absorbieren. 
Die geneinsante Verkanfsstelle hätte nicht nur den Verlianf dey Erzeugnise zu ïbernehmen, sondern anch den beelarf zu rerteilen und die profulition zu bestimmen. Für diesen $/ w e c k$ wible jedtes Terbandswerk den Durchschnitt seiner Verkäufe in den letzten drej Jahren angeben müssen und in disitm Verhältnis ungrialn prozentual an der Gesantherstellungsmenge betejligt werden. Anberden müBte natülich auch auf die Leistungsfähigkeit in berug auf reswinnung und Verarbeitung der einzelnen Werlie Rücksicht genommen werden. Man wïrde sich für die Plattenlieferung etwa folgente Berteiligung der Werke rorstellen:

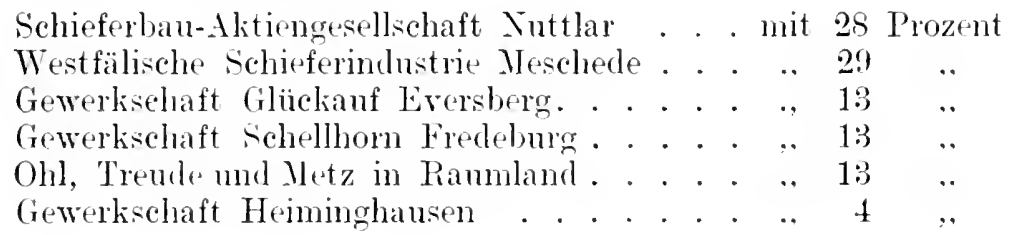

Die vereinigten Werke wählen zum Leiter der Verkanfsgenossenschaft einen Geschäftsführer, der sich zur imparteischen Behanellung aller vorkommenden Geschäfte verpflichtet und vierteljährlich Rechenschaft 'ror' der Gesellschafterversammlung ablegt. Als Geschäftsjahr gilt das Kalenderjahr. Die Berechnung der Warenlioferungen an die Besteller erfolgt durch das livfernde Wert. Die Rechnung ist dem Geschäftsfühw zum Vermerk, zur Abstempelung mit dem Tereinsstempel und Weitergabe an den Besteller zu übergeben. Das Delkredere der Lieferung ibbernimmt das liefernde Werk und hat sowohl das Inkasso als auch die Erledigung der entstehenden Relilamationen zu besorgen. Die Mitglieder verpflichten sich, lieinerlei Ware mter Umgehung des Verbandes anzubieten oder zu liefern. Gestattet ist nur die direkte Lieferung kleinerer Quantitäten, die ron den Werlien abgeholt werden (Landabsatz im Gegenteil zu Bahnabsatz). Aber auch hierfür gilt die Bestimmung, daß die Rechnungen an den Geschäftsführer zu befördern und die Lieferungen auf das Iontingent in Anrechnung zu bringen sind.

Die Enkosten der Geschäftsführung werden durch eine Linlage entsprechend der Jahreslieferung aufgebracht, die zu Anfang eines jeden Geschäftsjahres ron der Gesellschafterversammlung festgesetzt und ron dem Geschäftsführer eingezogen werden. Es liönnte auch ein bestimmter Satz für Cnkosten angegeben werden bzw. eine Grenze, in der sich die Höhe der Lnliosten bewegt. Das liefernde Werk bekäme dadurch eine größere $\mathrm{C}^{\circ}$ ersicht über seinen Erlös und die Geschäftsführung hätte einen Anhalt, in welchem Rahmen sie die Propaganda usw. betreiben kann. Alle etwaigen Streitiglieiten wären unter Umgehung der ordentlichen Gerichte durch ein Schiedsgericht zu schlichten, in das jede der beiden Parteien ihren Vertreter wählt, während der Obmam durch ein Amtsgericht bestimmt wird. Terletzungen müßten bestraft werden auf Grund eines Gesellschafts- 
beschlusses durch Verhängung einer Strafe bis zu 50 Prozent der betreffenden Lieferung.

Falls ein Terbandswerk stillgelegt wird, sollen die freiwerdenden Mengen auf die äbrigen Werke prozentual verteilt werden, ohne daß dem betreffenden Werk ein Anspruch aus der Minderlieferung gegenüber dem Terband zusteht. Etwaige sonstige Mehr- oder Minderlieferungen der Terbandsmitglieder bei der Abrechnung am Schluß des Geschäftsjahres sollen anf das nächste Jahr übertragen werden.

AuBer dem Liefermngrecht haben die Werke auch eine Lieferungsfrist. Bleibt ein Werk länger als einen Nonat in der Lieferung im Piickstande, so soll sich sein Anspruch für das betreffende Geschäftsjahr zufolge des Rückstandes in der Weise rermindern, daß der Anspruch gekürzt nnd der Auftrag den übrigen Werken pro rata ihrer Anteile zugeteilt wird. Ein Rückstand, hervorgerufen durch höhere Gewalt, könnte nachgeliefert werden dürfen, und zwar spätestens innerhalb dreier Monate nach Beendigung der Störung.

Bei einer Konkurrenz außenstehender Werke soll es der Geschäftsleitung anheimgegeben werden, in die Konkurenzpreise einzutreten und die Lieferung einem Terbandswerk zu übertragen gegen den festgesetzten Verbandspreis. Der Nindererlös liönnte von sämtlichen Werken im Terhältnis ihrer Beteiligung getragen werden.

Zur Sicherheit für die rertraglichen Bestimmungen hinterlegen die Mitglieder einen Solawechsel in Höhe von je 500 Mark zu Händen des Geschäftsführers, dem sie ausdrücklich das Recht zur Unterzeichnung und Einziehung des Wechsels gewähren, wenn die Mitgliederversammlung eine Strafe auferlegt und das Schiedsgericht sie bestätigt hat. Die Sicherheit ist nach jedem Falle der Inanspruchnahme wieder auf die Höhe ron 500 Mark zu ergänzen.

Zum Zweck der allgemeinen notwendigen Aufbesserung der Verkaufspreise und Bedingungen für die Waren der Plattenerzengnisse stellen die Mitglieder gemeinschaftlich eine Preisliste auf und verpflichten sich, billigere Preise und günstigere Bedingungen, als sie in der Preisliste eingesetzt sind, nach keiner Seite hin zu stellen oder zu berechnen, auch keine geheimen Sondervergütungen auf solche Lieferungen zu machen.

Nur bei Festlegen mäBiger Preise ist eine solche Konvention möglich und nützlich. Lediglich eine Erhöhung innerhalb gewisser Grenzen wäre zweckmäßig. Sonst wäre es bei der heutigen Ủberproduktion denkbar, daß bei zu hoch geschraubten Preisen die Maschinen nur zum Teil beschäftigt werden würden. Für diejenigen Terke, die genügend Naterial zur Verfügung haben, wäre dies von großer Bedeutung. Auch ist zu berücksichtigen, daß bei zu hohen Preisen einer weiteren Einführung ron Schiefer in der Industrie direkt entgegengewirkt und die Verwentung in manchen Fällen ganz unterbunden wird. Außerdem würden hohe Preise das fremde Material nicht verdrängen können. 


\section{4. Änderung des Tarifsatzes für Schieferplatten bei Versendung als Stückgiuter.}

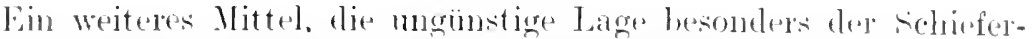

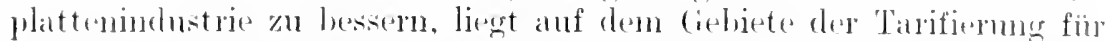

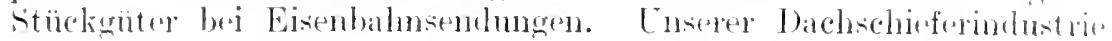

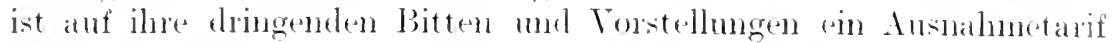

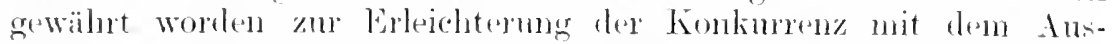

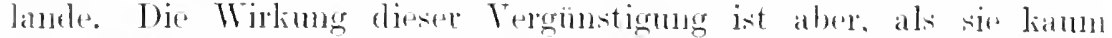
angefangen hatte, sich bemerlibar zo machen, dadurch lejeler wiedel

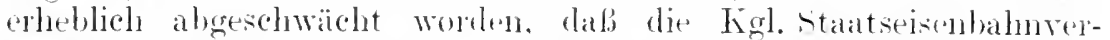
waltung den Ansmahnetarif, dor bisles für mo nicht eimmal bei simntlichen dentechen Eisenhahnverwaltungen durchzusetzen wall, allen ansländischen Vertragsländern elonfalls grwährte. sofern sie nur

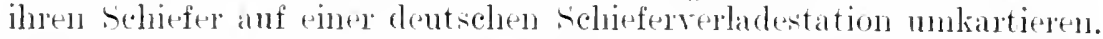
Dadurch ist nicht nur dem belgisehen und französischen schiefer. der Wegr nach Dentschland noch nehr geebmet als bishere, sonderm anch dem zollfreien luxemburer schiefer das erwilmte manters Geschäftsgebahnen, sich als inländischen Moselschiefer auszugeben, erleichtert.

Für die Ausfuln aus Deutschland hat der Tarif gar lieine berdeutung. Das ainzige Land, das schefer dontschen Lrsprungs in nemenswerten Mengen bezieht, ist Osterreich-Lngasn, führt aber eine noch gröpere Wenge in Dentschland ein.

schieferplatten tarifieren gegenwärtig bei Aufgabe als Frachl-

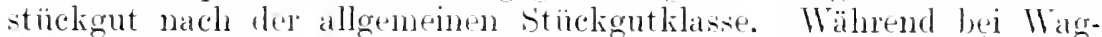
gonladungen spezialtarif III in Anwendung liommt, werden stüclgiiter zu den hohen sätzen der allgemenen stückgntliksse resfrachtet. Eine Ausnahme besteht hente schon bei schiefertafeln, die abberhapt im spezialtarif berechnet werder.

Der Artikel ...uBleisten" repräsentiert ungefähr die Hälfte der ganzen Plattenproduktion. Der Verkanfspreis stellt sich heute auf durchschnittlich 4.80 Wark pro Quadratmeter = 55 Kilegramm. Nach dem grïligen Tarif ...Allgeneine stücligutklasse. beträgt beispielsweise die Fracht für 55 Kilogranm ron Xuttlar

$\begin{array}{clrc}\text { nach } & \text { Kassel } & -, 77 & \text { Mark } \\ \text {, } & \text { Köhn } & 1,07 & , . \\ \text {. } & \text { Wesel } & 1,04 & ., \\ \text {,. Wagrleburg } & 1.65 & . . \\ \text {., } & \text { Berlin } & 2,31 & , .\end{array}$

Das Terhälnnis zwischen dem Werte der Ware und dem Frachtsatze ist hiernach denkbar ungünstig.

Als Stückgüter werden ron den Schiefergruben rerandt: Tischplatten, Pissoinplatten, Fensterbänke, FuBleisten, Treppensteine, Platten für elektrotechnische Zwecke usw.

Plümpe, Schieferindustrie. 
1) Preis fü fertig bearbeitete scheferplatten stellt sich mo Quadratmeter Fußleisten . . . . . . auf 4,50 bis 4,80 Mark

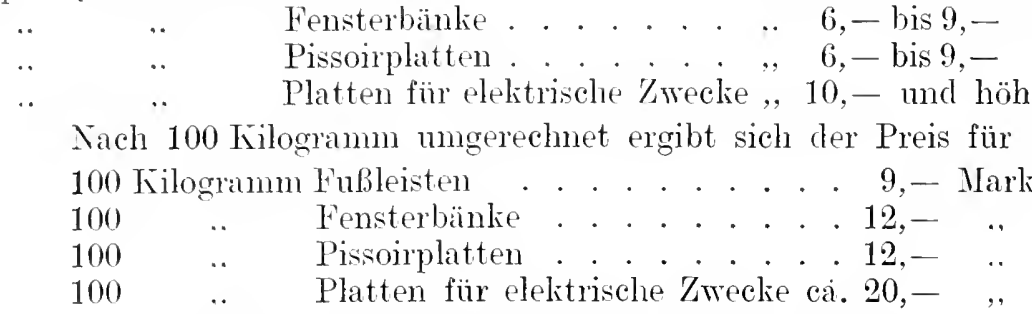

Der für Fußleisten erzielte Terkaufspreis deckt sich kaum mit den Selbstliosten. Verschiedene Gruben liegen schon still, andere arbeiten mit ganz geringem Gewinn und reduzierter Belegschaft. Letztes geht daraus hervor, daß fast alle Betriebe, mit Ausnahme eines einzigen Betriebes, in der dritten mond vierten Klasse Gewerbesteuer veranlagt sind. Wenn ein Werk nicht noch größere Schieferplatten anfertigen und Absatz dafür erzielen kamn, ist ron einem Betriebsüberschuß überhaupt kei e Rede mehr. Die stetig steigenden Selbstliosten ermöglichen es nur den gutsituierten Werken, den Betrieb aufrechtzuerhalten. Ein Werk unseres Bezirkes verteilte im Jahre 1910 an Dividende 5 Prozent, wovon 3) Prozent auf clen Betrieb und 2 Prozent auf Zinseneinmahme entfielen.

Schon durch die erwähnte Tatsache, daß verschiedene Gruben den Betrieb eingestellt haben, andere zurzeit mit geringem Gewinn oder gar mit Verlust arbeiten, ist wohl der Beweis erbracht, daß ein dringendes wirtschaftliches Bedürfnis rorhegt, den Schiefergruben durch FrachtermäBigung zu Hilfe zu kommen, nicht nur, um die Schieferindustrie Westfalens wieder zu heben, sondern sie auch gegen den immer mehr vordringenden Wettbewerb des Auslandes zu schïtzen. Man darf nicht glauben, daß die Versetzung der bearbeiteten Schieferplatten aus der allgemeinen Stückgntlilasse in den Spezialtarif für bestimmte Stïckgüter irgendwelche Berufungen zugunsten ron Artikeh aus anderen Gesteinsarten zufolge haben würde, zumal Waggonladungen von 5-10 Tonnen nach dem Spezialtarif II und III verfrachtet werten. Bei größeren Platten können nur Marmor, Granit usw. in Frage kommen. Diese werden naturgemäß nur zu besseren Banten verwandt und kommen deshab als Konkurrenz zu Schieferplatten nicht in Betracht. Bei FuBleisten kam es sich nur um die Konkurrenz mit Tomplatten handeln; diese bleiben aber auch, wenn die Frachtsätze für Schiefer ermäBigt würden, bedeutend billiger.

Die jetzige Verfrachtung ron Schieferplatten in Stückgut nach rer allgemeinen Stückgutklasse und die Verfrachtung von 5 und 10 Tonnen derselben Trare im Spezialtarif ist ein Unding und kommt hei anderen Gütern nicht ror. Messing-, Nickel- und Eisenwaren werden nach Spezialtarif verfrachtet, obwoln dieselben einen riel höheren Handelswert haben als Schieferplatten und mindestens ebensoviel Raum eimnehmen. 


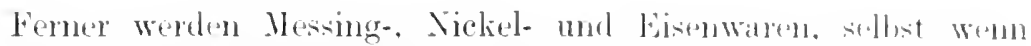

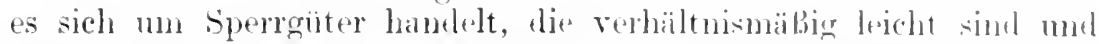

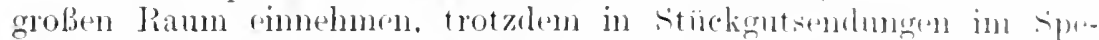
zialtarif verfrachtet. Im Vurhältnis zn dieser Vorfrachtmer nehnes schieferplatten riel weniger Raum ein, haben einen riol geringeren Handelswert und un so groberen Anspruch auf hilligere Verfrachtom. Es ist dies un so mehr berechtigt, als die schieferplatten. welche in stäkgutsendungen befördert werden, vorwegend fïr schaltapparate. Transformatoren und sonstige elelitrische Zweclie verwendet werden. Fïr diese Maschinen besteht schon unter Position 2 des bipezialtarifs B; und unter Position 26 ein Ausnahmetarif. dessen frowhirung. wenis anch eine schwache, so doch immerhin fühlbare Lnterstiitzung in dem schweren hampfe um die Existenz dieser Industrie bilden wiirde.

Den ron der Kgl. Eismbahndirektion vorgebrachten Grinden, daß der Versand sich in den letzten Jahren gehoben habe mond daher ron einem Niedergange in der Schieferindustrie nicht gestrochen werden kömnte, kam entgegongehalten werden. dab, wenn anch der Fersand in den letzten Jahren quantitatir gestiegen ist, darans nicht eine Besserung der Grochaftslage der Schieferplattenwerke gefolgert werden diurfe. Die Lage einer Industrie liam lieinoswegs danach beurteilt werden, ol sich der Versand der Erzengnisser gegenüber den letzten Jahren gehoben hat, sondern nur danach, ob anch entsprechende Preise erzielt worden sind. Nur dieses Joment kann lediglich als Anhalt zur Beurteilung der Geschäftslage dienen. In der schieferindustrie Westfalens sind die Preise für Platten, die in .Jahre 1s:4; pro Quadratmeter im Durchschnitt noch 18.04 Mark betrucen. im Jahre 1907 auf 10,28 Nark zurückgegangen, während 1909 eine kleine Aufbesserung auf 10,49 Mark zu loustatieren war. Siejtem ist es nicht besser geworden. Ans dem Vehrrersand ist also oin Aufsehwong nicht zu konstatieren und ebensowenig ist der erzielte Gewimn auf das Plattengeschäft zuriuckzufülıren.

Der Gewinn rührt viehmehr aus dem Absatz ron Dachschiefer her, dessen Terkaufspreis etwas gestiegen ist. Es ham also werter der Mehrversand noch der ron einem Werke erzielte fiewinn für die Beurteilung der Frage maßgebend sein. Auch der Grund, daß durch die FrachtermäBigung nur ein Gewinn ron wenigen Mark zu praielen und darum liein Anlaß wäre, dem Antrage stattzugeben, ist nicht stichhaltig. Der geringe Lnterschied zwischen der jetzigen und der beantragten Frachtberechmung fällt rielmehr sehr ins Gewicht, da die westfälischen Gruben mit jedem Pfennig zu rechnen haben, um leistungsfähiger zu werden. Die Differenz zwischen der beantragten Versenciung nach dem spezialtarif und der bisherigen nach der allgemeinen Stückgutlilasse ist nach Ansicht der Kigl. Eisenbahndirektion sehr gering. [un so mehr hat also die Eisenbahnrerwaltung Teranlassung, dem Antrage stattzugeben, dem die Differenz ist für die Werke durchaus nicht gering zu veranschlagen, wenigstens wiirden die Werke unseres Bezirkes dadurch, daß Schieferplatten für di Folge nach spezialtarif verladen werden, wesentlich konkurenzfähiger 
gegenüber tlen aus tem Anslande eingefuihten Platten sein. Beispiekweise können hiesige Werke nach Holland, Hamburg, Bremen иsw. nu mit groben Opfern Geschäfte abschließen, weil sie noch verlältnismäBig hohe Frachten haben. AuBerdem ist es der Einheitlichleit halber zu befürworten, stückgiiter-Schieferplatten nach Spezialtarif zu verfrachten. Weil Waggonladungen von 5 und 10 Tonnen bereits unter die sipezialtarife klassifiziert werden.

Wemn die Eisenbahnverwaltung angibt, der Tersand an Schieferplatten habe sich nach den Erhebungen der in Betracht kommenden Stationen Erersberg. Nuttlar, Fredeburg, Gleidorf nicht ungünstig gestaltet. so kann dem nur entgegengehalten werden, daß die Eisenbahm meines Erachtens nicht genau über die tatsächlichen Verhältnisse orientiert zu sein scheint. Ich erwähne dem gegenüber, daß die Schieferbaugewerkschaft .,Oberkirchen" Station Gleidorf ihren Betrieb wegen mrentabler Terkaufspreise gänzlich eingestellt hat und daß aus dem Auslande laut Statistik jährlich für 5 Millionen Mark schiefer eingeführt werden. Wenn sich der Absatz in den letzten Jahren um einige Tausend Kilogramm pro Jahr gehoben hat, so ist dieses jedenfalls nur mit großen Preisopfern dex Schieferwerke erzielt worden.

Ein Mittel zur turchgreifenden Besserung wäre allerdings auch darin für die westfälischen Gruben nicht zu sehen gewesen. Da eine solche aber umbedingt erstrebt werden ma, so wäre es wünschenswert, ja durchans notwendig. dals genannter Antrag als Notstandstarif speziell für die westfälischen Schieferplattenwerle zur Einführung gelange, weil diese, abgelegen von den großen Verbranchsstäten, mit den großen Frachten zu rechnen haben, die ihnen die Konkurrenz mit gïnstiger gelegenen Werken erschweren. Der Antrag geht also dahin, der westfälischen Schieferindustrie für die Stationen Nuttlar. Eversberg, Fredeburg usw. für Stückgüter-Schieferplatten den spezialtarif II zu bewilligen.

Bei der nicht gïnstigen wirtschaftlichen Lage der westfälischen schieferinclustrie wäre es notwendig, oben gemachte Torschläge zu verwirklichen, zum Besten der im Schieferbergbau tätigen Unternehmer, zum Besten aber auch der in ihm beschäftigten Arbeiter. Pflicht des Staates ist es aber, daß für die ron ihm zu errichtenden Banten, die nach Torschrift nur mit dentschem Schiefer gedeckt werden sollen, anch tatsächlich nur deutsches Material Verwendung findet, das nach fachmännischem Urteil dem besten ausländischen volliommen gleichwertig an die Seite gestellt werden kann. Pflicht eines jeden einzelnen ist es, statt ausländisches Material zu haufen, erst zu prïfen, ob er nicht deutschen Schiefer haben kam. Welche summen gehen jährlich dem Taterlande durch Berorzugung des ausländischen Schiefers verloren!

Deutschland, darunter anch Westfalen, birgt so reichhaltiges und gutes Material, daß bei günstigen wirtschaftlichen Verhältnissen nicht nur dem Inlande, sondern auch dem Auslande damit gedient werden könnte. 


\section{Anhang.}

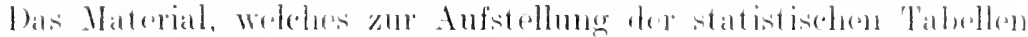

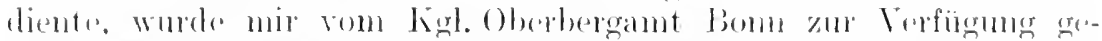

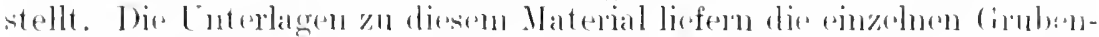
hesitzer in vierteljährlichen Nachweismeren. 1)a rin einheitlich dureh-

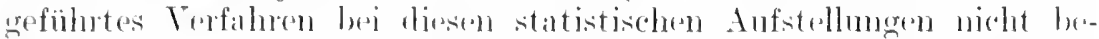

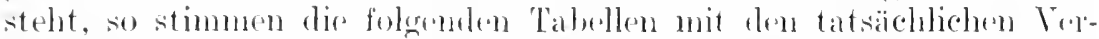
hältnissen nicht genan ïtrepein. Einge Grubenbesitzer rechnent nach Gewicht. andere nach laufentern Vetern. Tn einzehen Jahren worde

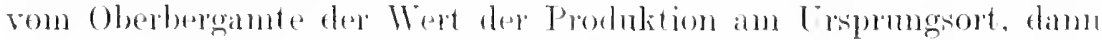

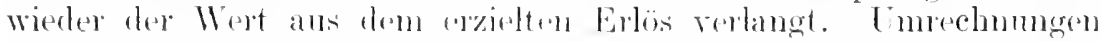

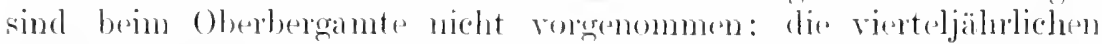

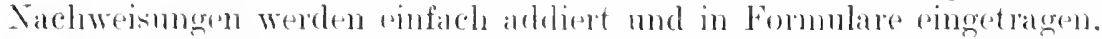
dir seit 40 Jahren gleichlantend gethlieben sind. 'Trotz dieser Mängol

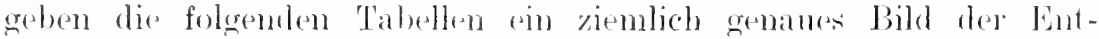

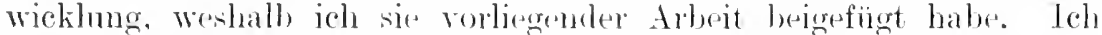
labe anch, soweit es mönglich war, vesucht, das mir zur Terfügnng gestellte Material mit den tatsächlichen Terhältnissen in Einklangr zul bringen.

'l'af 1 il 1.

Gesamtprodulition mol - Goldwert der Dachschiefer und schieferplatten Wostfalens.

\begin{tabular}{|c|c|c|c|c|c|c|c|c|c|c|}
\hline \multirow{3}{*}{ Jahr } & \multicolumn{3}{|c|}{ Zahl der Werke } & \multicolumn{2}{|c|}{ Dachschiefer } & \multicolumn{2}{|c|}{ Sichieferplatten } & \multirow{3}{*}{$\begin{array}{c}\text { Geldwert } \\
\text { der (ies.- } \\
\text { Förderung } \\
\text { Mark }\end{array}$} & \multicolumn{2}{|c|}{ Preis } \\
\hline & ohne & mit & & Menge & Wert & Menge & Wert & & & \\
\hline & Gew & ung & Brüche & $\mathrm{m}$ & Mark & 1 & Mark & & $1 \mathrm{~m}$ & $1 \mathrm{c}(\mathrm{m}$ \\
\hline 1880 & $16 \tilde{s}$ & 21 & 186 & 64268 & 248676 & $1+337$ & 60670 & 309346 & 3,87 & 4.23 \\
\hline 1881 & 168 & 18 & 186 & 841001 & $26880: 3$ & 128.52 & 53702 & $32250 \tilde{5}$ & 3,20 & 4.18 \\
\hline 1882 & 168 & 18 & 186 & 8.5220 & $27+172$ & 114.50 & 46872 & 321044 & 3,22 & 4,09 \\
\hline $188: 3$ & 168 & 19 & 187 & 995335 & 280816 & 11639 & 52632 & 333448 & 2,82 & $4, \pi 2$ \\
\hline 1884 & 168 & 19 & 187 & 120361 & 319329 & 10780 & $52+82$ & 371811 & 2,65 & 4,87 \\
\hline 188.5 & 169 & 19 & 188 & 128701 & 340062 & 12662 & 30139 & 370201 & 2,64 & 2,38 \\
\hline 1886 & 168 & 20 & 188 & 1232.54 & 338738 & 13749 & 28613 & 367351 & 2,75 & 2,18 \\
\hline 1887 & 169 & 19 & 188 & 118646 & $3+630.5$ & 12152 & $30: 315$ & 376620 & 2,92 & 2.49 \\
\hline 1888 & 170 & 18 & 188 & 123430 & $3746 \pi$ & 10192 & 21796 & 396453 & 3,04 & 2.14 \\
\hline 1889 & 168 & 20 & 188 & $13+65.5$ & 406 & 10160 & & 40 & $: 3,02$ & 2,16 \\
\hline 1890 & 166 & 22 & 188 & 152764 & $447+11$ & 10501 & 23984 & 471395 & 2,93 & 2,28 \\
\hline 1891 & 168 & 20 & 188 & 171216 & 491716 & 11919 & 26000 & 517716 & 2,87 & 2,18 \\
\hline 1892 & 167 & 19 & 188 & 169767 & 488 & 11144 & 31529 & 819978 & 2.88 & $2.8: 3$ \\
\hline 1893 & 167 & 21 & 188 & 155712 & 432015 & 11306 & 3319.5 & 46.5210 & 2,77 & 2,94 \\
\hline 1894 & 167 & 21 & 188 & 130570 & 377871 & 16689 & 40) 270 & $+181+1$ & 2,89 & 2.41 \\
\hline 1895 & 169 & 19 & 188 & 111587 & 340100 & 18188 & 47549 & 387649 & $3,0 \pi$ & 2,61 \\
\hline 1896 & 170 & 18 & 188 & 129254 & 399750 & 18407 & 7.54 .54 & 47.5204 & 3,109 & 4.10 \\
\hline 1897 & 167 & 21 & 188 & 115494 & 393582 & 19275 & 78718 & 472300 & 3,41 & 4.08 \\
\hline 1898 & 171 & 17 & 18 & 128614 & 445760 & $19 \pm 42$ & $8+115$ & 529875 & 3,47 & 4.37 \\
\hline 1899 & 170 & 18 & 188 & 127564 & 442840 & 23900 & 11.743 & .58 .583 & 3.47 & $4,8 t$ \\
\hline 1900 & 170 & 18 & 188 & $110+67$ & 409208 & $27+10$ & 137.5 .59 & .74767 & 3,70 & 2,90 \\
\hline
\end{tabular}




\begin{tabular}{|c|c|c|c|c|c|c|c|c|c|c|}
\hline \multirow[b]{2}{*}{ Jahr } & \multicolumn{3}{|c|}{ Zahl der Werke } & \multicolumn{2}{|c|}{ Dachschiefer' } & \multicolumn{2}{|c|}{ Schieferplatten } & \multirow{2}{*}{$\begin{array}{c}\text { Geldwert } \\
\text { der Ges.- } \\
\text { Förderung } \\
\text { Mark }\end{array}$} & \multicolumn{2}{|c|}{ Preis } \\
\hline & $\begin{array}{l}\text { ohne } \\
\text { Gewin }\end{array}$ & $\begin{array}{l}\text { mit } \\
\text { mung }\end{array}$ & $\begin{array}{l}\text { Sa.der } \\
\text { Briiche }\end{array}$ & $\begin{array}{c}\text { Menge } \\
\text { in }\end{array}$ & $\begin{array}{l}\text { Wert } \\
\text { Mark }\end{array}$ & $\begin{array}{l}\text { Menge } \\
\text { qm }\end{array}$ & $\begin{array}{l}\text { Wert } \\
\text { Mark }\end{array}$ & & $\mid \begin{array}{l}\text { pro } \\
1 \mathrm{~m}\end{array}$ & $\begin{array}{c}\text { pro } \\
\text { l qm }\end{array}$ \\
\hline 1901 & 17 & 17 & 18 & 903 & 3136 & 247 & 125 & 438 & 3,47 & 5,06 \\
\hline 1902 & 169 & 19 & 188 & 81306 & 312345 & 27524 & 135363 & 447708 & 3,84 & 4,92 \\
\hline 1903 & 171 & 17 & 188 & 754.56 & 355090 & & & & 4,71 & 4,95 \\
\hline 1904 & 171 & 17 & 188 & 83158 & 338211 & 31219 & 155706 & 493917 & 4,07 & 4,99 \\
\hline 190.5 & 170 & 18 & 188 & 78344 & 347576 & 29316 & 143712 & 491288 & 4,44 & 4,90 \\
\hline 1906 & 171 & 17 & 188 & 70. & 299921 & 31328 & 256096 & 17 & 4,27 & 8,17 \\
\hline 1907 & 170 & 18 & 188 & 70864 & 377990 & 18480 & $157150^{\circ}$ & 535140 & 5,33 & 8,50 \\
\hline 1908 & 170 & 18 & 188 & $76 \pm 94$ & & 243 & 226191 & 591347 & 4,77 & 9,29 \\
\hline 1909 & 169 & 19 & 188 & 7244 & 37 & 18 : & 142 & 329 & 5,12 & 7,66 \\
\hline 1910 & 169 & 19 & 188 & 63635 & 322999 & 25257 & 205612 & 528611 & 5,07 & 8,14 \\
\hline 1911 & 169 & 19 & 188 & 63296 & & 24530 & 198136 & & 5,25 & 8,08 \\
\hline 1912 & $16 \mathrm{~s}$ & 20 & 188 & 80689 & 456614 & 30273 & 232525 & 689139 & 5,66 & 7,68 \\
\hline
\end{tabular}

Tafel 2 .

In Prozenten a usgedriuckt betrug die Beteiligung der einzelnen Kreise a) an Dachschiefer:

\begin{tabular}{|c|c|c|c|c|c|}
\hline Jahr & $\begin{array}{l}\text { Wittgenstein } \\
\text { Prozent }\end{array}$ & $\begin{array}{l}\text { Meschede } \\
\text { Prozent }\end{array}$ & $\begin{array}{l}\text { Brilon } \\
\text { Prozent }\end{array}$ & $\begin{array}{l}\text { Siegen } \\
\text { Prozent }\end{array}$ & \\
\hline 1880 & 34,83 & 31,55 & 13,04 & 20,58 & 100 \\
\hline 1881 & 46,75 & 28,87 & 10,95 & 13,43 & 100 \\
\hline 1882 & 47,26 & 28,09 & 11,01 & 13,64 & 100 \\
\hline 1883 & 49,59 & 27,49 & 10,42 & 12,50 & 100 \\
\hline 1884 & 61,02 & 21,62 & 6,94 & 10,42 & 100 \\
\hline 1885 & $6 \tilde{5}, 67$ & 19,55 & 5,43 & 9,35 & 100 \\
\hline 1886 & 62,91 & 23,88 & 5,64 & 7,57 & 100 \\
\hline 1887 & 61,52 & 14,28 & 18,55 & 5,65 & 100 \\
\hline 1888 & 60,96 & 13,77 & 17,83 & 7,44 & 100 \\
\hline 1889 & 69,76 & 7,18 & 17,25 & 5,81 & 100 \\
\hline 1890 & 70,90 & 6,97 & $17,-$ & 5,13 & 100 \\
\hline 1891 & 72,42 & 7,30 & 14,81 & 5,47 & 100 \\
\hline 1892 & 72,93 & 7,43 & 15,11 & 4,53 & 100 \\
\hline 1893 & 66,69 & 8,96 & 21,34 & 3,01 & 100 \\
\hline 1894 & 71,25 & 20,03 & 5,29 & 3,43 & 100 \\
\hline 1895 & 64,75 & 22,58 & 8,42 & 4,95 & 100 \\
\hline 1896 & 67,32 & 21,28 & 7,53 & 3,87 & 100 \\
\hline 1897 & 60,16 & 27,14 & 8,91 & 3,79 & 100 \\
\hline 1898 & 61,58 & 25,96 & 9,16 & 3,30 & 100 \\
\hline 1899 & 61,29 & 26,52 & 9,13 & 3,06 & 100 \\
\hline 1900 & 56,63 & 29,97 & 10,78 & 2,62 & 100 \\
\hline 1901 & 51,66 & 37,44 & 10,90 & - & 100 \\
\hline 1902 & 50,17 & 35,88 & 11,74 & 2,21 & 100 \\
\hline 1903 & 48,80 & 38,92 & 12,28 & - & 100 \\
\hline 1904 & 53,70 & 35,52 & 10,78 & - & 100 \\
\hline $190 \tilde{5}$ & 46,59 & 43,35 & 10,06 & - & 100 \\
\hline 1906 & 42,96 & 44,54 & 12,50 & - & 100 \\
\hline 1907 & 35,49 & 53,05 & 11,46 & - & 100 \\
\hline 1908 & 44,15 & 44,93 & 11,62 & - & 100 \\
\hline 1909 & 35,40 & 50,91 & 10,06 & 3,63 & 100 \\
\hline 1910 & 30,02 & 61,04 & $8,-$ &,- 94 & 100 \\
\hline 1911 & 24,92 & 61,89 & 12,68 & 0,51 & 100 \\
\hline 1912 & 34,34 & 51,70 & 13,96 & - & 100 \\
\hline
\end{tabular}


Tafel :?.

In Prozenton ausgedruckt betrug die Peoteiligung dor einzelnen Krojob) an sichieferplatten:

\begin{tabular}{|c|c|c|c|c|c|}
\hline Jathr & $\begin{array}{c}\text { Wittgenstein } \\
\text { Prozent }\end{array}$ & $\begin{array}{l}\text { Mesehede } \\
\text { Prozent }\end{array}$ & $\begin{array}{l}\text { Brilon } \\
\text { Prozent }\end{array}$ & $\begin{array}{l}\text { Siegen } \\
\text { Prozent }\end{array}$ & \\
\hline 1880 & 5,39 & 82,85 & 4,21 & 7,52 & 100 \\
\hline 1881 & 6.07 & 87,933 & 3.38 & 2,62 & 100 \\
\hline 1882 & 4,75 & $8: 3,17$ & 3,83 & $8,2.5$ & 100 \\
\hline 1883 & $12, \pi 3$ & 84,10 & 2,02 & 1,35 & 100 \\
\hline 1884 & $10, \pi$ & 84,97 & $: 3,56$ & 0,70 & 100 \\
\hline 188.5 & 11,40 & 8.5.5! & 2,33 & 0,68 & 100 \\
\hline 1886 & $\because 1,92$ & 74,38 & $4, \geq 1$ & $(0,4)$ & $l(x)$ \\
\hline 1887 & 12,14 & 24,37 & 62,911 & $(0,58$ & 100 \\
\hline 1888 & 14,95 & 31,11 & 53,10 & 0.04 & 100 \\
\hline 1889 & $\therefore$ & 41.77 & 58,233 & - & 100 \\
\hline 1890 & - & 41,42 & 58,58 & - & 100 \\
\hline 1891 & - & 37.15 & 62.85 & - & 100 \\
\hline 1892 & $2, \pi 2$ & $3: 2,79$ & 64,69 & - & 100 \\
\hline 1893 & - & $30,1.5$ & 69.85 & - & 100 \\
\hline 1894 & - & 99.87 & 0,13 & - & $1(n)$ \\
\hline 189.5 & - & 99,43 & 0,57 & & 100 \\
\hline 1896 & - & 99.98 & $0,(1) 2$ & $\ldots$ & 100 \\
\hline 1897 & - & 99,79 & $0, \geq 1$ & - & 100 \\
\hline 1898 & - & 96,72 & 3,28 & - & 100 \\
\hline 1899 & - & 91,97 & 8,03 & - & 100 \\
\hline 1900 & - & 94,29 & 5,71 & - & 100 \\
\hline 1901 & - & 89,85 & 10,15 & - & 100 \\
\hline 1902 & - & 92,21 & 7,79 & - & 100 \\
\hline 1903 & - & 89,53 & 10,47 & - & 100 \\
\hline 1904 & - & 87.25 & 12,75 & - & 100 \\
\hline 190.5 & - & 84,42 & 15,58 & - & 100 \\
\hline 1906 & & $8:-$ & $12,-$ & - & 100 \\
\hline 1907 & - & 78,81 & 21,19 & - & 100 \\
\hline 1908 & - & 89,50 & 10,50 & - & 100 \\
\hline 1909 & - & 89,64 & 10,36 & - & 100 \\
\hline 1910 & $\ldots$ & $90, \pi 8$ & 9.42 & - & 100 \\
\hline 1911 & & 94,68 & 5,32 & -. & 100 \\
\hline 1912 & - & 91,29 & 8,71 & - & 100 \\
\hline
\end{tabular}

Talel 4.

Produktion und Geldwert der Jachschiefer und Schieferplatten des Kreises Brilon.

\begin{tabular}{|c|c|c|c|c|c|c|c|c|c|c|}
\hline \multirow[b]{2}{*}{ Jahr } & \multicolumn{3}{|c|}{ Zahl der Werke } & \multicolumn{2}{|c|}{ Dachschiefer } & \multicolumn{2}{|c|}{ Schieferplatten } & \multirow{2}{*}{$\begin{array}{c}\text { Geldwert } \\
\text { der Ges.- } \\
\text { Fordlerung } \\
\text { Wark }\end{array}$} & \multicolumn{2}{|c|}{ Preis } \\
\hline & $\begin{array}{l}\text { ohne } \\
\text { Gewin }\end{array}$ & $\begin{array}{l}\text { mit } \\
\text { nung }\end{array}$ & $\begin{array}{l}\text { Sa.der } \\
\text { Briiche }\end{array}$ & $\begin{array}{c}\text { Menge } \\
\mathrm{m}\end{array}$ & $\begin{array}{l}\text { Wert } \\
\text { Mark }\end{array}$ & $\begin{array}{c}\text { Menge } \\
\text { qm }\end{array}$ & $\begin{array}{l}\text { Wert } \\
\text { Mark }\end{array}$ & & $\begin{array}{l}\text { pro } \\
1 \mathrm{~m}\end{array}$ & $\begin{array}{l}\text { pro } \\
1 \mathrm{qm}\end{array}$ \\
\hline 1880 & 23 & 4 & 27 & 8383 & 4.5: & 604 & 2416 & 47796 & 5,41 & $1,-$ \\
\hline 1881 & 24 & 3 & 27 & 9199 & & 435 & & 48 & 5,21 & $4,-$ \\
\hline 1882 & 23 & 4 & 27 & 9382 & 48402 & 43 & 1756 & 50158 & 5,16 & $4,-$ \\
\hline 1883 & 23 & 4 & 27 & 10374 & 37434 & 235 & 295 & 37729 & 3,61 & 1,26 \\
\hline 1884 & 23 & 4 & 27 & 8351 & 31161 & 384 & 461 & 31622 & 3,73 & 1,20 \\
\hline 188.5 & 24 & 3 & 27 & 7004 & 35961 & 29 & 667 & 36628 & 5.13 & 2,26 \\
\hline 1886 & 24 & 3 & $2 \bar{i}$ & 7064 & 39286 & 579 & 566 & 39852 & 5,56 & 0,98 \\
\hline
\end{tabular}




\begin{tabular}{|c|c|c|c|c|c|c|c|c|c|c|}
\hline \multirow[b]{2}{*}{ dahr } & \multicolumn{3}{|c|}{ Zahl der Werke } & \multicolumn{2}{|c|}{ Dachschiefer } & \multicolumn{2}{|c|}{ Schieferplatten } & \multirow{2}{*}{$\begin{array}{c}\text { Geldwert } \\
\text { der Ges.- } \\
\text { Förderung } \\
\text { Mark }\end{array}$} & \multicolumn{2}{|c|}{ Preis } \\
\hline & $\begin{array}{l}\text { ohne } \\
\text { Gewint }\end{array}$ & $\begin{array}{r}\text { mit } \\
\text { aung. }\end{array}$ & $\begin{array}{l}\text { Sa.der } \\
\text { Briiche }\end{array}$ & $\begin{array}{c}\text { Menge } \\
\mathrm{m}\end{array}$ & $\begin{array}{l}\text { Wert } \\
\text { Mink }\end{array}$ & $\begin{array}{c}\text { Menge } \\
\text { qm }\end{array}$ & $\begin{array}{l}\text { Wert } \\
\text { Mark }\end{array}$ & & $\begin{array}{l}\text { pro } \\
1 \mathrm{~m}\end{array}$ & $\begin{array}{c}\text { proo } \\
1 \text { qm }\end{array}$ \\
\hline 1887 & 24 & 3 & 27 & 22013 & $96: 351$ & 7645 & 23503 & 119854 & 4,38 & 3,07 \\
\hline 1858 & 24 & 3 & 27 & 22016 & 98190 & 5493 & 16251 & $11+441$ & 4,46 & 2,96 \\
\hline $188 ! 1$ & 23 & 4 & 27 & 23222 & 110644 & 5916 & 17613 & 128257 & 4,76 & 2,98 \\
\hline 1890 & 22 & $j$ & 27 & 25974 & 120696 & 6151 & 18488 & 139184 & 4,64 & 3,01 \\
\hline 1891 & 2.2 & $\pi$ & 27 & 2.5 359 & 125710 & 7491 & 21531 & 147241 & 4,96 & 2,87 \\
\hline 189.2 & 2.2 & 5 & 27 & 25509 & $12+1+2$ & $7: 09$ & 21475 & 145617 & 4,87 & 2,98 \\
\hline 1893 & 22 & $\tilde{r}$ & 27 & 33230 & $11+825$ & 7897 & 23629 . & 138454 & 3,46 & 2,99 \\
\hline 1894 & 24 & 3 & 27 & 690.5 & & 21 & 21 & 862 & 7,65 & $1,-$ \\
\hline 189.5 & 24 & 3 & 27 & 9391 & 98 & 103 & 47 & 145 & 5,97 &,- 46 \\
\hline $18 ! 16$ & 2.5 & 2 & 27 & (9) $720: 3$ & & 4 & 4 & 492 & 6,74 & $1,-$ \\
\hline 15017 & 23 & 4 & 27 & $10: 301$ & 69643 & 40 & 10 & 69653 & 6,76 &,- 25 \\
\hline $18: 18$ & 24 & 3 & 27 & 11781 & 80139 & 631 & 5281 & 85 420 & 6,80 & 8.37 \\
\hline 1899 & 24 & 3 & 2 & $\mathrm{I} 1 \mathrm{C}$ & & 19 & & 18 & 6,94 & 6,61 \\
\hline 1900 & 24 & 3 & 27 & 1190.5 & 80 & 2708 & 16000 & 96116 & 6,73 & 5,91 \\
\hline 1901 & 24 & 3 & 27 & 9842 & 59770 & 2512 & 16682 & 76452 & 6,07 & 6,64 \\
\hline 1902 & 24 & 3 & -1 & 46 & 58 & 2 & 13007 & 11 & 6,17 & 6,06 \\
\hline 1903 & 24 & 3 & 27 & 926.5 & 56 & 30 & 17160 & 73656 & 6,10 & 5,58 \\
\hline 1904 & 24 & 3 & 27 & 8.961 & & & 21 & 75319 & 6,03 & 5,34 \\
\hline 1905 & 24 & 3 & 27 & 78 & & & 21684 & 66719 & 6,71 & 4,75 \\
\hline 1906 & 24 & 3 & 27 & 8785 & 50497 & 3759 & 20677 & 71174 & 5,75 & 5,50 \\
\hline 1907 & 23 & $t$ & 27 & 8120 & .61 & 3915 & 21147 & 77836 & 6.98 & 5,40 \\
\hline 1908 & 23 & $t$ & 27 & 8889 & & & 23045 & 81924 & 6,62 & 9,02 \\
\hline 19009 & 24 & 3 & 27 & 2789 & 493 & 1920 & 19200 & 68.581 & 6,77 & $10,-$ \\
\hline $1910^{i l}$ & 24 & 3 & 27 & 5088 & $28+$ & 2378 & $37+42$ & $659+1$ & 5.60 & 15,75 \\
\hline 1911 & 24 & 3 & 27 & 8030 & & & $1+017$ & 10346 & 5,77 & 10,73 \\
\hline 1912 & 24 & 3 & 27 & 11264 & 63644 & 2636 & 13570 & 77214 & 5.60 & 5,31 \\
\hline
\end{tabular}

Tafel 5.

Produlition und Geldwert der Dachschiefer und Schieferplatten des Kreises Meschede.

\begin{tabular}{|c|c|c|c|c|c|c|c|c|c|c|}
\hline \multirow[b]{2}{*}{ Jahr } & \multicolumn{3}{|c|}{ Zahl der Werke } & \multicolumn{2}{|c|}{ Dachschiefer } & \multicolumn{2}{|c|}{ Schieferplatten } & \multirow{2}{*}{$\left|\begin{array}{c}\text { Geldwert } \\
\text { der Ges.- } \\
\text { Förderung } \\
\text { NLark }\end{array}\right|$} & \multicolumn{2}{|c|}{ Preis } \\
\hline & $\begin{array}{l}\text { ohne } \\
\text { Ciewin }\end{array}$ & mit & $\begin{array}{l}\text { Ra. der } \\
\text { Brüuche }\end{array}$ & $\begin{array}{c}\text { Menge } \\
\mathrm{m}\end{array}$ & $\begin{array}{l}\text { Wert } \\
\text { Mark }\end{array}$ & $\begin{array}{c}\text { Menge } \\
q_{11 m}\end{array}$ & $\begin{array}{l}\text { Wert } \\
\text { Mark }\end{array}$ & & $\begin{array}{l}\text { pro } \\
1 \mathrm{~m}\end{array}$ & $\begin{array}{l}\text { pro } \\
1 \mathrm{qm}\end{array}$ \\
\hline 1880 & 12 & 8 & 133 & 2027.5 & 136 & 11882 & 52908 & 110 & 2,82 & 4,45 \\
\hline 188 & 126 & $\tau$ & 133 & (?) & & 11 & & & 2.77 & 4,45 \\
\hline 1882 & 127 & 6 & 133 & 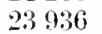 & 0 & 9 & 6 & 92 & 2,75 & 4,21 \\
\hline 1883 & 127 & 6 & 133 & & & & & 691 & 2,89 & 5,17 \\
\hline 1884 & 127 & 6 & 1: & & & & & & 2,85 & $5,5 \tilde{3}$ \\
\hline 188.5 & 126 & 7 & 13 & 2 & 7 & 10 & 2 & 94 & 2,99 & 2,49 \\
\hline 188 & & 7 & & & & & & & 2,80 & 2,40 \\
\hline 1887 & 128 & 5 & 1: & 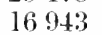 & & & & & 2.24 & 1.53 \\
\hline 1888 & 127 & 6 & 133 & if & & 3171 & 3 & & 2,42 & 1,12 \\
\hline 188 & 126 & 7 & & & & & & & 4,12 & 1.02 \\
\hline 189 & 127 & 6 & 1: & 10 & 4 & & & & 4,14 & 1,26 \\
\hline $18 !$ & 127 & 6 & 1: & & & & & & 4,25 & 1,01 \\
\hline 18 . & 12 & 6 & 1: & & & & & & 4.60 & 2,23 \\
\hline 18913 & 124 & !) & 133 & 13954 & 57037 & 3409 & 9 566 & 66603 & 4,09 & 2,81 \\
\hline $18 !$ & $12: 2$ & 11 & 133 & & 109161 & & & & 4,17 & 2,41 \\
\hline 1895 & 123 & 10 & 133 & 25201 & 108899 & 18085 & 47502 & $156+01$ &,+ 32 & 2.63 \\
\hline
\end{tabular}




\begin{tabular}{|c|c|c|c|c|c|c|c|c|c|c|}
\hline \multirow[b]{2}{*}{ Jahr } & \multicolumn{3}{|c|}{ Zahl der Werke } & \multicolumn{2}{|c|}{ Dachschisfer } & \multicolumn{2}{|c|}{ Schieferplatten } & \multirow{2}{*}{$\begin{array}{l}\text { Grolwert } \\
\text { dor Gros- } \\
\text { Forrlerung } \\
\text { Mark }\end{array}$} & \multicolumn{2}{|c|}{ Prein } \\
\hline & $\begin{array}{l}\text { ohne } \\
\text { Gewin }\end{array}$ & $\begin{array}{c}\text { mit } \\
\text { iungr }\end{array}$ & $\begin{array}{l}\text { Sil. der } \\
\text { Briuche }\end{array}$ & $\begin{array}{c}\text { Mence } \\
\text { m }\end{array}$ & $\begin{array}{l}\text { Wert } \\
\text { Mark }\end{array}$ & $\begin{array}{c}\text { Nenge } \\
\text { qum }\end{array}$ & $\begin{array}{l}\text { Wert } \\
\text { Mark }\end{array}$ & & $\begin{array}{l}\text { pro } \\
1 \mathrm{~m}\end{array}$ & $l^{p r o}$ \\
\hline 189 & 12 & 10) & 183 & & $1-7$ & 13 & 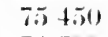 & 0000 & $4, \pi 2$ & 4.10 \\
\hline 189 & 1.2 & 11 & $13:$ & $31:$ & 11 & $19:$ & & & 4,57 & 4,09 \\
\hline 1898 & 123 & 10) & & $3: 383$ & 1.54 & 18611 & & $3332-28$ & 4,63 & 4,24 \\
\hline 189 & 122 & 11 & & & & 21 & & & 4.78 & $4,69 !$ \\
\hline 1900 & & 11 & & t & & 24 & 9 & 69 & 4,911 & 4.92 \\
\hline 1901 & 122 & 11 & & ; & & 22 & & & 4,116 & 4,88 \\
\hline 1902 & $12 \div 2$ & 11 & l: & & & & & & 4,76 & 4,82 \\
\hline & & & & & & & & & $4,5 !)$ & 4.57 \\
\hline 1904 & 122 & 11 & 1: & 3 & & 27 & & & 4,42 & 4.94 \\
\hline 1905 & 121 & 12 & $1:$ & & & & & 1!) & 5,01 & 4,93 \\
\hline & & 11 & & & & 27 & & 99 & 4,78 & 8,54 \\
\hline 1907 & 122 & I1 & & 375 & $2.28: 351$ & 14 & & 3.54 & 6.07 & 9,34 \\
\hline 1908 & 122 & 11 & $\mathrm{l}:$ & 338 & & & & & 5,81 & 9,33 \\
\hline & 122 & 11 & & & & & & 560 & 5.93 & $7,3 !$ \\
\hline 19 & 122 & 11 & $1:$ & $358+1$ & 200032 & 22879 & 168170 & 385202 & 5,67 & 7,35 \\
\hline 1911 & 123 & 10 & 13 & 3917.5 & & & & & 5,69 & 7,93 \\
\hline 1912 & 122 & 11 & 1333 & +1716 & 278313 & 27637 & 218955 & 497268 & 6,67 & 7,92 \\
\hline
\end{tabular}

Tafel 6.

Produktion und (ieldwert der J)achschiefer und schieferplatten des Kreises Siegen.

\begin{tabular}{|c|c|c|c|c|c|c|c|c|c|c|}
\hline \multirow[b]{2}{*}{ Jahr } & \multicolumn{3}{|c|}{ Zahl der Werke } & \multicolumn{2}{|c|}{ Dachschiefer } & \multicolumn{2}{|c|}{ Schieferplatten } & \multirow{2}{*}{$\begin{array}{c}\text { Geldwert } \\
\text { der Ges.- } \\
\text { Förderung } \\
\mid \text { Mark }\end{array}$} & \multicolumn{2}{|c|}{ Preis } \\
\hline & $\begin{array}{l}\text { ohne } \\
\text { Gewin }\end{array}$ & $\begin{array}{c}\text { mit } \\
\text { nung }\end{array}$ & $\begin{array}{l}\text { Sa. der } \\
\text { Briiche }\end{array}$ & $\begin{array}{c}\text { Menge } \\
\text { m }\end{array}$ & $\begin{array}{l}\text { Wert } \\
\text { Mark }\end{array}$ & $\begin{array}{c}\text { Menge } \\
\mathrm{qm}\end{array}$ & $\begin{array}{l}\text { Wert } \\
\text { Mark }\end{array}$ & & $\begin{array}{l}\text { pro } \\
1 \mathrm{~m}\end{array}$ & $\begin{array}{r}\text { pro } \\
1 \mathrm{qm} \\
\end{array}$ \\
\hline 1880 & 1 & 3 & 4 & 13227 & 79036 & 1078 & 4658 & $8: 3694$ & 5,98 & 4,32 \\
\hline 1881 & 1 & 3 & 4 & 1 & 70 & $3: 36$ & 921 & 71726 & 6,28 & 2,95 \\
\hline 1882 & 1 & 3 & 4 & 11630 & 680 & 944 & +435 & $72+54$ & $5,9,5$ & 4,70 \\
\hline 1883 & 1 & 3 & 4 & $12+36$ & $631+6$ & $15 i$ & 443 & $1358 !$ & 5,08 & 2,82 \\
\hline 1884 & l & 3 & 4 & 12524 & $b 4$ & 75 & 272 & 64556 & 5,13 & 3,63 \\
\hline 1885 & 1 & 3 & 4 & 12069 & $65:$ & 86 & 324 & 6.5 541 & 5,40 & 3,77 \\
\hline 1886 & 1 & 3 & 4 & 9137 & 508 & 67 & 192 & 51 & 5,57 & 2,86 \\
\hline 1887 & 1 & 3 & 4 & & 38 & 71 & 221 & 39196 & 5,82 & 3,11 \\
\hline 1888 & 2 & 2 & 4 & 91 & + & 4 & 12 & 80 & 5,43 & $3,-$ \\
\hline 1889 & 2 & 2 & 4 & 7826 & 44 & - & - & 44901 & 5,74 & - \\
\hline 1890 & 1 & 3 & 4 & 7843 & 40 & - & - & 406.57 & 5,18 & - \\
\hline 1891 & 1 & 3 & 4 & $9: 360$ & $47 !$ & - & - & 921 & 5,12 & - \\
\hline 1892 & 2 & 2 & 4 & 7760 & 36 & - & - & 36873 & 4,75 & - \\
\hline 1893 & 2 & 2 & 4 & 4681 & 19217 & - & - & 19217 & 4,11 & - \\
\hline 1894 & 3 & 1 & 4 & 4484 & 1654.5 & - & - & 16545 & 3,69 & - \\
\hline 1895 & 3 & 1 & 4 & 4743 & 17 & - & - & 17 & $3,4.5$ & - \\
\hline 1896 & 3 & l & 4 & +99.5 & 1796.5 & - & - & 17965 & 3,60 & - \\
\hline 1897 & 3 & 1 & 4 & 4376 & 17504 & - & - & 17.504 & $4,--$ & - \\
\hline 1898 & 3 & 1 & 4 & & 181 & - & - & 18096 & 4,26 & - \\
\hline 1899 & 3 & 1 & 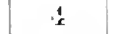 & 3902 & 17153 & - & - & 171.53 & 4,40 & - \\
\hline 1900 & 3 & 1 & 4 & 2903 & 12570 & - & - & 12570 & 4,33 & - \\
\hline 1901 & $t$ & - & 4 & - & - & - & - & - & - & - \\
\hline 1902 & 2 & 2 & 4 & 1803 & 7316 & - & - & 7316 & 4,06 & - \\
\hline 1903 & 4 & - & 4 & - & - & - & - & - & 一 & - \\
\hline 1904 & 4 & - & 4 & - & - & - & - & $1-$ & - & 一 \\
\hline
\end{tabular}




\begin{tabular}{|c|c|c|c|c|c|c|c|c|c|c|}
\hline \multirow[b]{2}{*}{ Jahr } & \multicolumn{3}{|c|}{ Zahl der Werke } & \multicolumn{2}{|c|}{ Dachschiefer } & \multicolumn{2}{|c|}{ Schieferplatten } & \multirow{2}{*}{$\mid \begin{array}{c}\text { Geldwert } \\
\text { der Ges.- } \\
\text { Förderung } \\
\text { Mark }\end{array}$} & \multicolumn{2}{|c|}{ Preis } \\
\hline & $\begin{array}{l}\text { ohme } \\
\text { Gen }\end{array}$ & $\begin{array}{l}\text { mit } \\
n n n @ r\end{array}$ & $\begin{array}{l}\text { Sia. der } \\
\text { Brüche }\end{array}$ & $\begin{array}{c}\text { Menge } \\
\mathrm{m}\end{array}$ & $\begin{array}{l}\text { Wert } \\
\text { Mark }\end{array}$ & $\begin{array}{c}\text { Menge } \\
\text { qm }\end{array}$ & $\begin{array}{l}\text { Wert } \\
\text { Mark }\end{array}$ & & $\mid \begin{array}{l}\text { pro } \\
1 \mathrm{~m}\end{array}$ & $\begin{array}{c}\text { pro } \\
\text { lqm }\end{array}$ \\
\hline 190.5 & 4 & $\ldots$ & 4 & - & - & - & - & - & - & - \\
\hline 1906 & 4 & - & 4 & - & - & - & - & $\ldots$ & - & - \\
\hline 1907 & $t$ & - & 4 & - & - & - & - & - & - & - \\
\hline 1908 & 4 & - & 4 & - & - & - & - & - & -1 & - \\
\hline 1909 & 3 & 1 & 4 & 2630 & 15650 & - & - & 15650 & 5,99 & - \\
\hline 1910 & 3 & 1 & 4 & 600 & 3580 & - & - & 3580 & 5,97 & - \\
\hline 1911 & 3 & 1 & 4 & 320 & 2150 & - & - & 2150 & 6,72 & - \\
\hline $191: 2$ & 4 & - & 4 & - & - & - & - & - & - & - \\
\hline
\end{tabular}

Tafel 7 .

Produktion und Geldwert der Dachschiefer und Schieferplatten des Kreises Wittgenstein.

\begin{tabular}{|c|c|c|c|c|c|c|c|c|c|c|}
\hline \multirow[b]{2}{*}{ Jahr } & \multicolumn{3}{|c|}{ Zabl der Werke } & \multicolumn{2}{|c|}{ Dachschiefer } & \multicolumn{2}{|c|}{ Schieferplatten } & \multirow{2}{*}{$\left|\begin{array}{c}\text { Geldwert } \\
\text { der Ges. } \\
\text { Förderung } \\
\text { Mark }\end{array}\right|$} & \multicolumn{2}{|c|}{ Preis } \\
\hline & $\begin{array}{l}\text { ohne } \\
\text { Crewin }\end{array}$ & $\begin{array}{l}\text { mit } \\
\text { mung }\end{array}$ & $\begin{array}{l}\text { Sa. der } \\
\text { Brüche }\end{array}$ & $\begin{array}{c}\text { Menge } \\
\mathrm{m}\end{array}$ & $\begin{array}{l}\text { Wert } \\
\text { Mark }\end{array}$ & $\begin{array}{c}\text { Menge } \\
\mathrm{qm}\end{array}$ & $\begin{array}{l}\text { Wert } \\
\text { Mark }\end{array}$ & & $\begin{array}{l}\text { pro } \\
1 \mathrm{~m}\end{array}$ & $\begin{array}{l}\text { pro } \\
\text { l qm }\end{array}$ \\
\hline 1880 & 2 & 6 & 8 & 22383 & 67124 & 773 & 688 & 67812 & $3,-$ &,- 89 \\
\hline 1881 & 3 & 5 & 8 & 39266 & 82904 & 780 & 780 & 83648 & 2,11 & $1,-$ \\
\hline 1882 & 3 & $\tilde{j}$ & 8 & 40272 & 91996 & $5+4$ & 544 & 92540 & 2,28 & $1,-$ \\
\hline $188: 3$ & 3 & 6 & 9 & 4) 361 & 101118 & 1459 & 1321 & 102439 & 2,05 & $\simeq 91$ \\
\hline 1884 & 3 & 6 & 9 & 73476 & 149872 & 1161 & 824 & 150696 & 2,04 &,$- 7 \mathrm{I}$ \\
\hline 188.5 & 4 & 6 & 10 & 84446 & 163572 & 1444 & 2166 & 165738 & 1,94 & 1,50 \\
\hline 1886 & 3 & $\tau$ & 10 & 77575 & 165756 & 2877 & $33 \tilde{3} 3$ & 169109 & 2,14 & 1,17 \\
\hline 1887 & 2 & 8 & 10 & 72992 & 173101 & 1475 & 2075 & 175176 & 2,37 & 1,41 \\
\hline 1888 & 3 & 7 & 10 & 75260 & 185513 & 1.524 & 1986 & 187499 & 2,46 & 1,30 \\
\hline 1889 & 3 & 7 & 10 & 93936 & 211459 & - & - & 211459 & 2,25 & - \\
\hline 1890 & 2 & 8 & 10 & 108305 & 241972 & - & - & 241972 & 2,24 & - \\
\hline 1891 & 4 & 6 & 10 & 123996 & 264926 & - & - & 264926 & 2,14 & - \\
\hline 1892 & 4 & 6 & 10 & 123868 & 269 & 281 & 1900 & 271252 & 2,18 & 6,76 \\
\hline 1893 & 5 & 5 & 10 & 103847 & 240936 & - & - & 240936 & 2,32 & - \\
\hline 1894 & 4 & 6 & 10 & 93025 & 199324 & - & - & 199324 & 2,14 & - \\
\hline 189.5 & $j$ & 5 & 10 & 72252 & 158054 & - & - & 158054 & 2,19 & - \\
\hline 1896 & 5 & $\pi$ & 19 & 87011 & 191772 & - & - & 191772 & 2,20 & - \\
\hline 1897 & j & 5 & 10 & 69.582 & & - & - & 844 & 2,38 & - \\
\hline 1898 & 7 & 3 & 10 & 7920.5 & 193 & - & - & 193101 & 2,44 & - \\
\hline 1899 & 7 & 3 & 10 & 78183 & 182978 & - & - & 182978 & 2,34 & - \\
\hline 1900 & 7 & 3 & 10 & 62555 & 153 & - & - & 153821 & 2,62 & - \\
\hline 1901 & 7 & 3 & 10 & 46662 & 116516 & - & - & 116516 & 2,50 & - \\
\hline 1902 & 7 & 3 & 10 & 40788 & 107233 & - & - & 107233 & 2,63 & - \\
\hline $190 \%$ & 7 & 3 & 10 & 368 & 163 & - & - & 163794 & 4,45 & - \\
\hline 1904 & 7 & 3 & 10 & 44661 & 1535366 & - & - & 153536 & 3,44 & - \\
\hline 190.5 & 7 & 3 & 10 & $36+96$ & 132550 & - & - & 132550 & 3,63 & - \\
\hline 19066 & 7 & 3 & 111 & 30201 & $09-14$ & - & - & 99544 & 3,30 & - \\
\hline 1907 & 7 & 3 & 10 & 25151 & 92950 & - & - & 92950 & 3,69 & - \\
\hline 1908 & 7 & 3 & 10 & 3375 & 109765 & - & - & 109765 & 3,25 & - \\
\hline 1909 & 6 & 4 & 10 & 2.5647 & 91038 & - & - & 91038 & 3,55 & - \\
\hline 1910 & 6 & 4 & 10) & 19106 & 708 & - & - & 70888 & 3,71 & - \\
\hline 1911 & $\tilde{\jmath}$ & .5 & 10 & & & - & - & 60922 & 3,86 & - \\
\hline 1912 & 4 & 6 & 19 & 27709 & 114657 & - & - & $11+657$ & 4,14 & 一 \\
\hline
\end{tabular}


Tafel 8 .

Die in den Gruben beschäftigten Arbeiter in den Jahren $1850-1912$.

\begin{tabular}{|c|c|c|c|c|c|c|c|c|}
\hline \multirow{2}{*}{ Jahr } & \multicolumn{3}{|c|}{ Unter Tage } & \multicolumn{3}{|c|}{ Über Tage } & \multirow{2}{*}{$\begin{array}{l}\text { Nar. der } \\
\text { Arbeiter }\end{array}$} & \multirow{2}{*}{$\begin{array}{l}\text { Inge- } \\
\text { horige }\end{array}$} \\
\hline & ïbel $21 \mathrm{~J}$. & $16-21 \mathrm{~J}$ & Zus. & über $16 \mathrm{~J}$. & $14-16 \mathrm{~J}$ & Zus. & & \\
\hline 1880 & 181 & - & 181 & 285 & 13 & 298 & 479 & $122 \cdot 2$ \\
\hline 1881 & 196 & .j & 201 & 242 & 29 & 271 & 472 & 12533 \\
\hline $188:$ & 197 & 12 & 209 & 219 & 17 & 236 & 445 & 1206 \\
\hline 1883 & $2+2$ & - & 242 & 226 & 26 & 252 & 494 & 1457 \\
\hline 1884 & 306 & - & 306 & 239 & 36 & 275 & 581 & 1783 \\
\hline 188.5 & 316 & - & 316 & 2.5 & 24 & 249 & 565 & $17+9$ \\
\hline 1886 & 358 & - & 358 & 279 & 34 & 313 & 671 & 2066 \\
\hline 1887 & 331 & - & 331 & 282 & 31 & 313 & 641 & 2043 \\
\hline 1888 & 334 & 28 & 362 & 274 & 48 & 322 & 684 & 194.2 \\
\hline 1889 & 399 & - & 399 & 204 & 63 & 267 & 666 & 1982 \\
\hline 1890 & 408 & - & 408 & 238 & 67 & $30 . \overline{5}$ & 713 & 199.5 \\
\hline 1891 & 429 & - & 429 & 292 & 58 & 350 & 779 & 201.56 \\
\hline 1892 & 446 & - & 446 & 230 & 95 & 325 & 771 & 2.2 .5 \\
\hline 1893 & 422 & 31 & 453 & 261 & 50 & 311 & 764 & $188: 3$ \\
\hline 1894 & 278 & 46 & $4: 4$ & 272 & 47 & 320 & 744 & 1908 \\
\hline $189 \overline{5}$ & 335 & 33 & 368 & 248 & 35 & 283 & 6.51 & 1651 \\
\hline 1896 & 342 & 50 & 392 & 2015 & 50 & 348 & $7+1)$ & 1882 \\
\hline 1897 & 321 & $\overline{0}$ & 372 & 262 & 45 & 307 & 679 & 1674 \\
\hline 1898 & 324 & 61 & 385 & 269 & 49 & 318 & 703 & 1704 \\
\hline 1899 & 353 & 46 & 399 & 279 & 57 & 336 & 735 & 1744 \\
\hline 1900 & 313 & 41 & $3 \bar{i} 4$ & 329 & 49 & 378 & 750 & 1986 \\
\hline 1901 & 233 & 29 & $26:$ & 276 & 26 & 302 & 564 & 1394 \\
\hline 1902 & 247 & 35 & 282 & 270 & 30 & 300 & 582 & 1435 \\
\hline 1903 & 235 & 28 & 263 & 276 & 28 & 304 & 567 & 1494 \\
\hline 1904 & 246 & 36 & 282 & 272 & 30 & 302 & 584 & 1.560 \\
\hline 190.5 & $2 \cdot 27$ & 31 & 258 & 276 & 25 & 301 & 5.59 & 1501 \\
\hline 1906 & 213 & 29 & 242 & 241 & 30 & 271 & 513 & 1353 \\
\hline 1907 & 2.29 & 21 & 250 & 204 & 28 & 232 & 482 & 1227 \\
\hline 1908 & 220 & 17 & 237 & 217 & 25 & 242 & 479 & 1247 \\
\hline 1909 & 242 & 16 & 2.58 & 237 & 34 & 271 & 529 & 1391 \\
\hline 1910 & 225 & 23 & 248 & 200 & 30 & 230 & 478 & 1177 \\
\hline 1911 & 212 & 14 & 227 & 231 & 27 & 258 & 485 & 1244 \\
\hline 1912 & 227 & - & $2 \cdot 27$ & 220 & 31 & 251 & 478 & 1339 \\
\hline
\end{tabular}

Tafel 9.

Die Gesamtzahl der Arbeiter rerteilt sich a uf folgende Kreise:

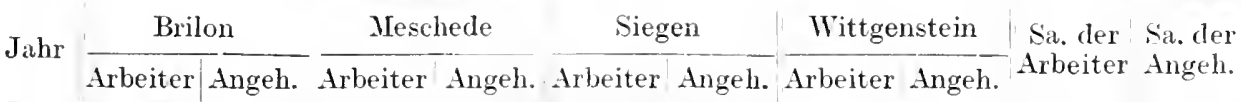

\begin{tabular}{rr|r|r|rrr|rrr|r}
\hline 1880 & 66 & 117 & 204 & 519 & 59 & 155 & 150 & 431 & 479 & 122.2 \\
1881 & 63 & 128 & 194 & 536 & 59 & 84 & 156 & 505 & 472 & 1253 \\
1882 & 57 & 124 & 171 & 499 & 46 & 90 & 171 & 493 & 445 & $12(+6$ \\
1883 & 73 & 132 & 166 & 487 & 53 & 52 & 202 & 786 & 494 & 1487 \\
1884 & 67 & 132 & 163 & 501 & 55 & 147 & 296 & 1003 & 581 & 1783 \\
1885 & 114 & 218 & 80 & 247 & 52 & 143 & 319 & 1041 & 565 & 1719 \\
1886 & 60 & 141 & 196 & 516 & 53 & 143 & 362 & 1266 & 671 & 2066
\end{tabular}




\begin{tabular}{|c|c|c|c|c|c|c|c|c|c|c|}
\hline \multirow{2}{*}{$J a h r$} & \multicolumn{2}{|c|}{ Brilon } & \multicolumn{2}{|c|}{ Meschede } & \multicolumn{2}{|c|}{ Siegen } & \multicolumn{2}{|c|}{ Wittgenstein } & \multirow{2}{*}{$\begin{array}{l}\text { Sa. der } \\
\text { Arbeiter }\end{array}$} & \multirow{2}{*}{$\begin{array}{l}\text { Sa. der } \\
\text { Angeh. }\end{array}$} \\
\hline & Arbeiter & Angeh. & Arbeiter & Angeh. & Arbeiter & Angeh. & Arbeiter & Angeh. & & \\
\hline 1887 & 187 & 434 & 64 & 236 & 42 & 132 & 351 & 1241 & $64 t$ & 2043 \\
\hline 1888 & 220 & 462 & 67 & 237 & 45 & 14.5 & 3.52 & 1101 & 684 & 1945 \\
\hline 1889 & 184 & 478 & 68 & 246 & 45 & 81 & 369 & 1177 & 666 & 1982 \\
\hline 1890 & 196 & 392 & is & 263 & 30 & 10.5 & 409 & 1235 & 713 & 1995 \\
\hline 1891 & 21.5 & 494 & 8.5 & 305 & 31 & 100 & 448 & 1157 & 779 & 2056 \\
\hline $189: 2$ & 214 & 46.3 & 9.5 & 320 & 25 & 87 & 437 & 1353 & $i 1$ & 2225 \\
\hline 1893 & 204 & 414 & 99 & 296 & 2.5 & ss & 436 & 1142 & 764 & 1883 \\
\hline 1894 & 70 & 200 & 24.5 & 664 & 10 & 24 & +19 & 1020 & 744 & 1908 \\
\hline 1895 & 6 & 182 & 250 & 581 & 11 & 33 & 32.5 & 8.55 & 651 & 1651 \\
\hline 1896 & 67 & 108 & 267 & 712 & 13 & 37 & 393 & 102.5 & 740 & 1882 \\
\hline $18 ! 17$ & 70 & 132 & 299 & 730 & 12 & 32 & 298 & 780 & 679 & 1671 \\
\hline 1898 & 81 & 183 & 328 & 7.59 & 11 & 27 & 283 & 735 & 703 & 1704 \\
\hline 1899 & 8.5 & 179 & 363 & 818 & 9 & 24 & 278 & 723 & 735 & 1744 \\
\hline 1900 & 8.5 & 21.5 & 368 & 877 & 8 & 24 & 289 & 870 & 750 & 1986 \\
\hline 1901 & 7 & 144 & 335 & 812 & - & - & 154 & 438 & รั64 & 1394 \\
\hline 1902 & 7.5 & 172 & 325 & 768 & 7 & - & 175 & 495 & 582 & 1435 \\
\hline 1903 & 75 & 174 & 334 & 788 & - & - & 158 & 432 & 567 & 1494 \\
\hline 1904 & 61 & 161 & 346 & 897 & - & 一 & $17 i$ & 502 & $\tilde{584}$ & 1560 \\
\hline 1905 & 68 & 177 & 343 & $8 i 1$ & - & 一 & 148 & 453 & 559 & 1501 \\
\hline 1906 & 66 & 170 & 314 & 791 & - & - & 133 & 392 & 513 & 1353 \\
\hline 1908 & 7 & 12.5 & 311 & 744 & - & - & 103 & $35 \mathrm{~s}$ & 482 & 1227 \\
\hline 1908 & 70 & 2.51 & 305 & 697 & - & - & 104 & 299 & +79 & 1247 \\
\hline 1909 & 6 & 247 & 326 & 832 & 2.5 & - & 110 & 312 & 529 & 1391 \\
\hline 1910 & 60 & 192 & 332 & 781 & 8 & - & 78 & 204 & 478 & 1177 \\
\hline 1911 & 70 & 203 & 317 & 783 & 8 & - & 90 & 2588 & 48.5 & 1244 \\
\hline 1912 & 63 & 188 & $\mathbf{2} 99$ & 789 & - & - & 116 & 362 & 478 & 1339 \\
\hline
\end{tabular}




\section{Literaturverzeichnis.}

Brassert, Bergordnungen der Preußischen Iande. Köln 1858.

Die Besehreibung der Bergreviere Arnsberg, Brilon und Olpe. Herausgegeben vom Kgl. Oberbergamt Bonn 1890.

Die Beschreibung der Bergreviere Siegen I, II, Burbaeh und Miisen. Bearbeitet von Th. Hundt, G. Gerlach, Fr. Roth und W. Schmidt. Bonn 1887.

Akten des $\mathrm{Kgl}$. Oberbergantes Bonn.

Akten des Kigl. Bergrevieramtes Ansberg.

Akten der Handelskammer Arnsberg.

Akten der schieferbau-Aktiengesellschaft Nuttlar.

Akten des von Pape-Antfeldschen Archivs, Antfeld.

v. Dechen, Erläuterungen der geologischen Karte der Rheinprovinz und der Provinz Westfalen. Bonn isst.

W. Jacoby, Berg•, Hütten- und Gewerbewesen des Pegierungsbezirks Arnsberg. Iserlohn $185 \%$.

E. Kayser, Lehrbueh der Geologie. Stuttgart 1912.

A. Knoeh, Der Dachschiefer in der Baupraxis. Berlin 1895.

Sommerfeld, Handbueh der Cewerbekrankheiten, Berlin 1898.

Weinmann, Vom Dachsehieferbergbau Westdeutschlands. Der Steinbrueh. 5. Jahrgang. Heft $8-12$. 


\section{Volkswirtschaftliche und wirtschaftsgeschichtliche Abhandlungen.}

Wilhelm Stieda als Festgruß zur sechzigsten

Wiederkehr seines Geburtstages dargebracht.

Im Verein mit Schülem und Verehrern herausgegeben von

Dr. Wilhelm Eduard Biermann,

a. o. l’rofessor für Nationalökouomie au der Universităt Leipzig.

Mit einem Bildnis von W. Stieda.

Lex. 8. 1912. geh. 9

Inhalt: Siegfried Moltke, Bibliothekar der Handelskammer zu Leipzig, \%wei hapitel aus Leipzigs Handels- und Verkehrsgeschichte. I. Die Bank des Quints (1727). II. Ein Eisenbahnprojekt Leipzig-MIagdeburor (1829). - Dr. B runo Moll, Privatdozent für Nationalükonomie a. d. U. Kiel, Untersuchungen zur Gesehichte des Objektes direkter Stenern. - Dr. Wilhelm Wick, Geschäftsfülırer des Verbandes der öffentlichen gemeinnïtzigen Arbeitsnachweise des Königreichs Sachsen zu Leipzig, Zur Geschichte des öffentliehen gemeinnützigen Arbeitsnachweises in Leipzig. - Dr. Wilhelm Eduard Biermann, a. o. Prof. für Nationalökonomie a. d. U. Leipzig, Der Abbé Galiani als Nationalökonom, Politiker und Philosoph nach seinem Briefwechsel. - Dr. Leon Zeitlin, Berlin, Ludwig Börne als Student der Kameralwissensehaften. - Dr. Karl Bräuer, Assistent des volkswirtschaftlichen Seminars a. d. U. Leipzig, Kritisehe Studien zur Literatur und Quellenkunde der Wirtschaftsgesehiehte. - Dr. Johannes II ärz, stellvertretender Syndikus des Verbandes Sächsiseher Industrieller zu Dresden, Die Bedeutung des Unternehmerstandes für den industriellen Fortsehritt in Sachsen. Ein Beitrag zur Geschichte der sächs. Industrie. - A lex an der Dominicus, Oberbürgermeister zu Berlin-Schöneberg, Das Stellenvermittlungsgesetz und seine Bedeutung für die öffentl. Arbeitsnachweise. - Dr. Johannes Taek, Senatssekretär zn Bremen, Einiges über die Stellung der fremden, insonderheit der niederländischen Schiffahrt in Bremen während des 16., 17. und 18. Jahrhunderts. - Otto MeiBgeier, Vorsitzender des Verbandes deutseher Mietervereine zu Leipzig, Zur Frage der Untervermietung in Leipzig.

\section{$\mathfrak{R} \mathfrak{i} \mathfrak{e} \mathfrak{g} \mathfrak{s} \mathfrak{w} \mathfrak{x} \mathfrak{j} \mathfrak{d} \mathfrak{a} \mathfrak{f} \mathfrak{t} \mathfrak{B} \mathfrak{e} \mathfrak{h} \mathfrak{x} \mathfrak{e}$ von}

\section{Dr. Ferdinand G(h) Gid}

Geb. sojrat, o. o. Wrofelfor an ber slniveriftät Seipzig

Gr.: Oftay. Preiz gebeftet M2. 2.50

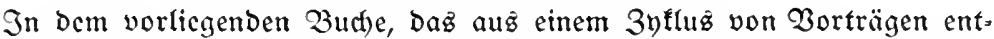

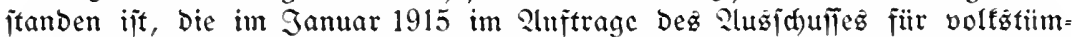

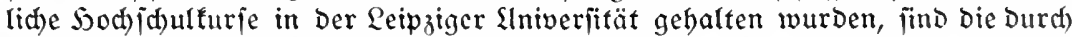

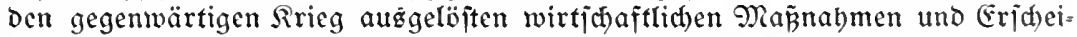
nungen unter cinbeitliđ)en Gefichtäpuntten zulammengcitellt. Der berübute

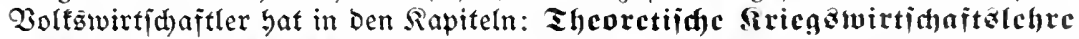

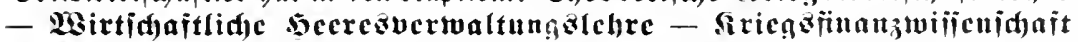

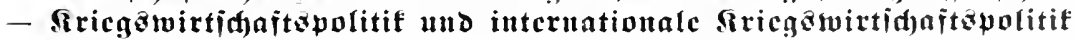
einen reidsen und hod)interellanten Etoரf zujammengetragen, jo oaj biejes aftmelle billige $\mathfrak{B}$ er 
DAS HEUITIGE RLISSLAND. Kulturftudien von ERNST VON DER BRÜGGEN. gr. 8. 〈VI u. 276 Seiten.) geh. M. 6.-

DER ALISSENHANDEL, SERBIENS. Von Dr. IVAN Z. NES'TOROVIC. gr. 8. 〈VIII u. 144 Seiten.)

geh. M. 4.-

DIE VERSORGUNG DEUTSCHI ANDS MIT METALLISCHEN ROHSTOFFEN 〈Erzen und Metallen.> Von Prof. Dr. P. KRLISCH, Abteilungs= dirigent a. d. Königl. Geologilchen Landesanftalt, Dozent für Erzlagerftättenlehre a. d. Kgl. Bergakademie zu Berlin. Mit 97 Abbildungen im Text. gr. 8. 〈XVI und 260 S.) geh. M. 14.-, geb. in Ganzleinen M. 15.DIE ENGLISCHE VERFASSUNG. Von A. LAWRENCE LOWELL, Profelfor der Staatswillen= Thaften a. d. Harvard=Univerlität. Autorifierte deutldhe Ausgabe. Herausgegeben und überletzt von Reg.=Rat Dr. Herr, unter Mithilfe des Reg.=Alleflors Freiherr v. Richthofen. Z Zwei Bände. 〈Erfter Band: XII und 550 S. Zweiter Band: VI und 510 S.) gr. 8. geh. M. 20.-, geb. in Ganzleinen M. 23.BOSNIEN UND DIE HERZEGOVINA unter der Verwaltung Öfterreich=Ungarns. Von Dr. FER= DINAND SCHMID, o. Profeffor a. d. Univ. Leipzig. Mit einer Karte. Lex. 8. 〈VIII und 832 Seiten.) geh. M. 28.-, geb. in Halbfranz M. 31.-

DER BAUERNBESITZ IN DER PROVINZ POSEN IM 19. JAHRHUNDERT. Von Dr. TH. v. JACKOWSKI. gr. 8. 〈VIII u. 154 S.〉 geh. M. 4.50 DIE STAATSTHEORIEN DER FRANZÖSI= SCHEN NATIONALVERSAMMLUNG VON 1789. Von Dr. ROBERT REDSLOB, Profeflor der öffentlichen Rechte a. d. Univ. Roltodk. Lex. 8. 〈VIII und 368 S.> geh. M. 12.-

Verlag von Veit \& Comp. in Leipzig, Marienftr. 18 


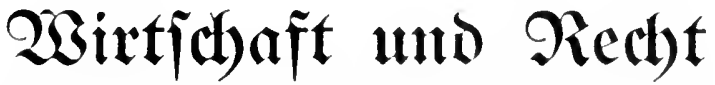

ua (b) Der materialififden (bej(bid)tauffafjung

Eine fozialpbilofophifde sluteriuding von

\section{Dr. Tiubolí Gtammler}

Geb. Bujtizrat, o. J. Drofelior ber Redte alt ber Itniverittät zerlin

Pritte, verbefierte duflage

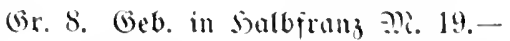

get). 22. 16.-

(Oeb. Initizrat Wrof. Ir. Etampa idtreibt in Der "Deuticten

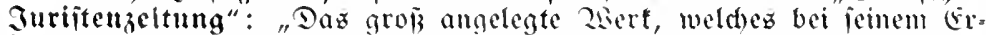
fideinen in Der ganzen willenifhaftidten Welt bas leblafteite Bnter. elie erwedte uno bereits in oritter

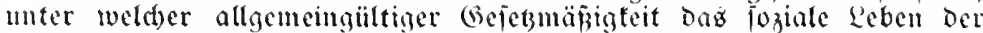

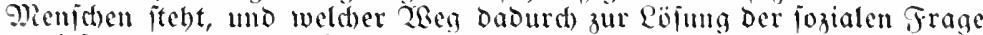

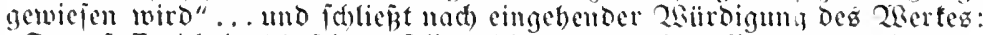
"Eo erfalle ids in Diirfiger Efizze Die vornebmiten (irrumbgedanfen ber Etammlerfden Eozialphiloiophie. S̈ber ibre Zeredtigung wirb in vielem

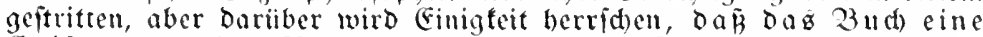
Beifeatat eriten Jiangez ift, Dienurein Sopf von nniverialer

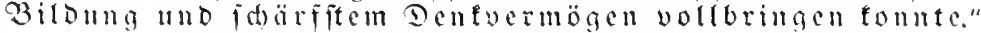

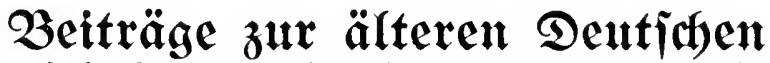 Wirtichaftz=}

(bejammelte Qlufiäze von Driwatbozent Dr. Georg Caro (B) r. 8. (Beb. N2. 3.50

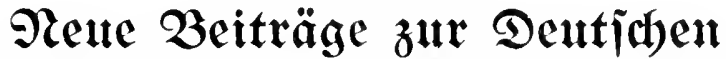 Wirticha ât}

Gefamunelte Plufiäze von Priwatoozent Dr. Georg Garo

(Gr. 8. (Gel). 2x. 4.-

Ë iît von Der Sritif allgemein anertannt worben, wie unizemein frud)tbar Die von fritif(hem (Geijt getragenen Slnterfud)ungen Deä $\mathfrak{B e r}$. falleró waren, Delīen Forid)ungzergebnille weit über Den Pabmen Deä von ibm bebandelten Gebieted binaus allgemeine 3ebeutung haben.

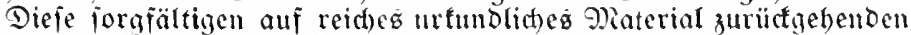

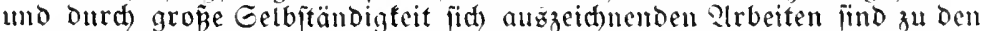
bedeutiamiten Qeijungen zuz äblen, die alli bem (Bebiete der

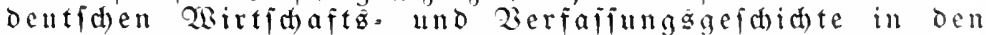
lebten Jabren eridienen fino. Derartige anf grïndiche Quellen= forfdung aufgebaute Epezialarbeiten werden, wem jie wie hier von einem fundigen Forid)er auf bic allgemein widtigen (Brmbprobleme bin gerichtet werden, die allein geficherte 3 ajig fiir eine beutide Berfaffung

Zerlag von Zeit \& Eomp. in Seipzig, Marienitr. 18 


\title{
Oringlictye \\ QSirtydgajtsjragen
}

Inter biejen (iejanttitel werben in Dem unterzeid)neten $B$ erlage cine : Inzabl befte eriffemen, in Denen befonderz fïbrende

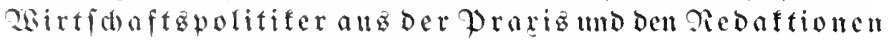
unferer groben 3eitungen zu Gorte fommen follen.

Ë liegen bereitz vor:

Seft 1. Gegen Den Bargelowerfehe von (Ernit Sahn, Rebaftenr ber Frantfurter 3eitung. (Geb). D2. 1.Der Berfaffer weift in Diejem beft eingebento auf Die "Qürfe in unjerer wittf(t)aftlicten Mobilmadbung" bin, mad)t in feiner $3 u=$

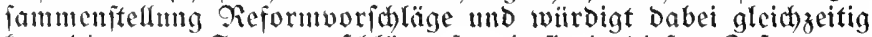
turz Dic neuen Steuervorf(b)läge, fowcit fie in biefem 3ufanmen= hany interefijeren.

Seft 2. Sondoclapolitif und Brieg von 9 rthur Feiler, gedafteur Der Franffurter 3eitumg. (Geb). 9). 1.20

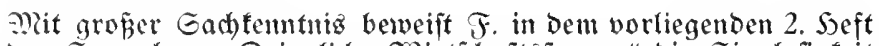
Der Ganmlung "Dringliche WBirtichaftîfragen" Die Ginntofigfeit

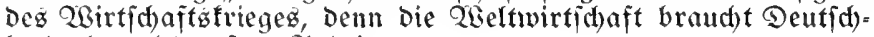
fain, braud)t unfere Qlvbeit.

Seft 3. Dar Girvvertehr Der beutiden Eparfaijen ven Oberbürger= meifter Dr. wou lizaguer=:llm. (3eb). $9 \mathcal{M} .1 .60$ In Diejer jebr zeitgemäßen Grdrift (prid)t fid) Der Borjizende Der Birofommiffion bes̈ Deutjhen Eparfallenverbandeg ausfuibr=

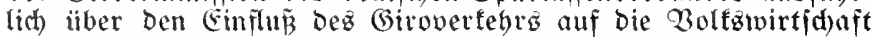
uno iiber bie Gpartallen als Sräger bes bargetolojen Berfehrs anz.

\section{Melturtiduftlide Etudien}

\author{
Borträge uto ăfiätge \\ voll \\ Dr. Sermanu Gefumacher \\ o. io. Drojentor an ber Inviverittät $20 \mathrm{nn}$
}

Grr. 8. (Geb. P2. 12.-, geb. in Ganzleinen 92.13 .50

Die in Der vorliegenden Eamulung enthaltenen Zorträge und $\mathbb{A}$ fuf=

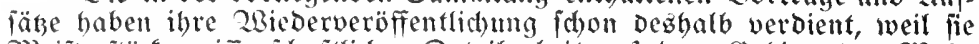
Dleifteritiiffe wiljenj(haftlicher Detailarbeit anf bem bebiete Der Welt= swirtic)aft fino.

Berlag von Beit \& Comp. in Leipzig, Marientrt. 18 


$$
\text { P.LJeis/st }
$$

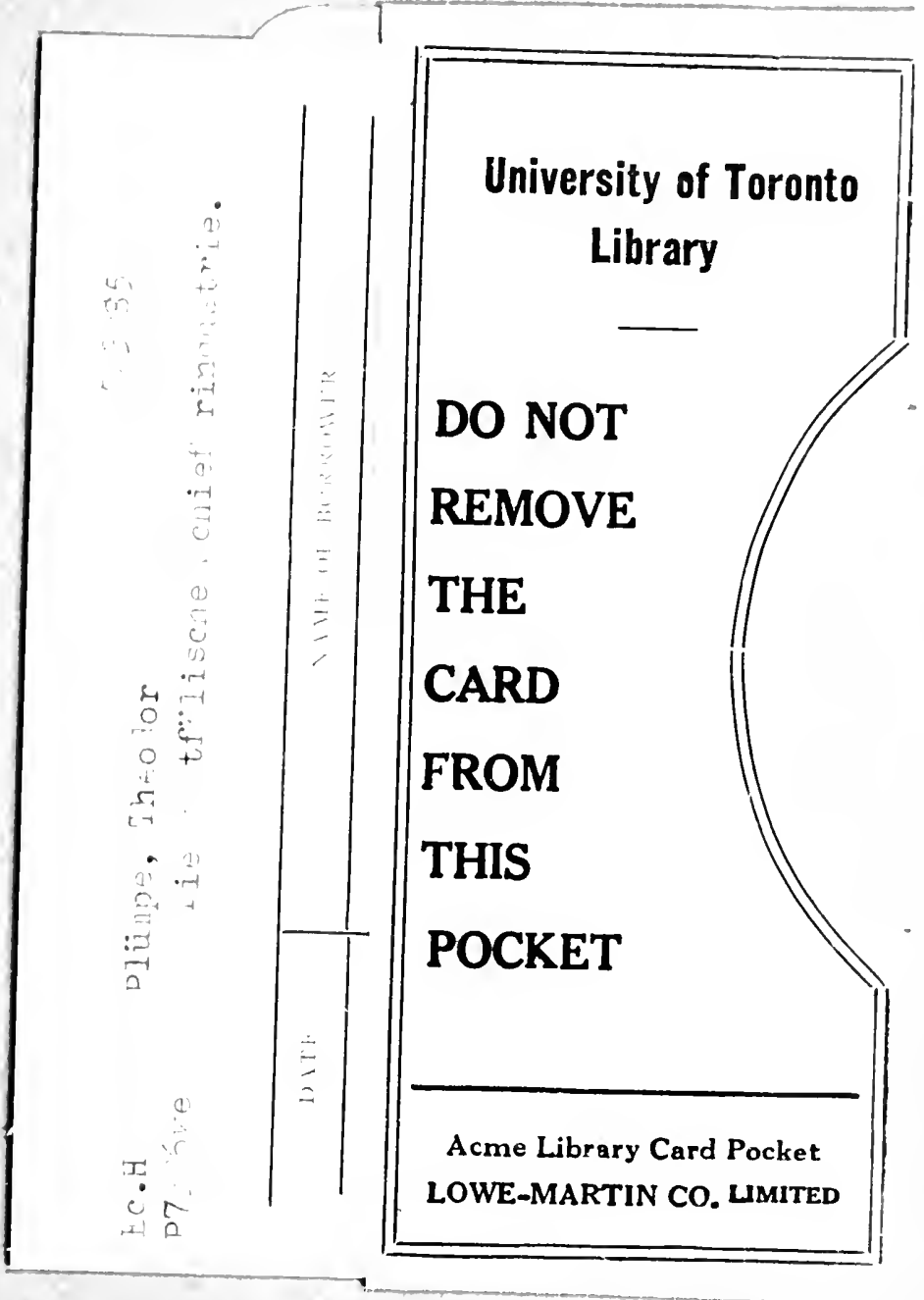


